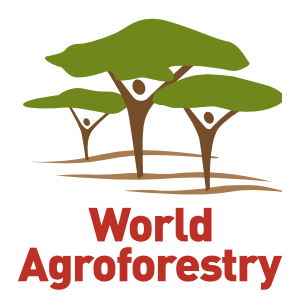

World Agroforestry

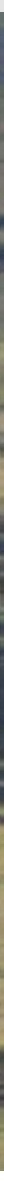

\title{
Relación entre árboles, cobertura y uso de la tierra y servicios hidrológicos en los Andes Tropicales: Una síntesis del conocimiento
}





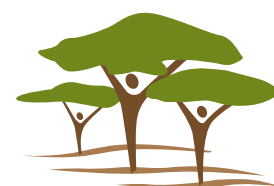

World

Agroforestry

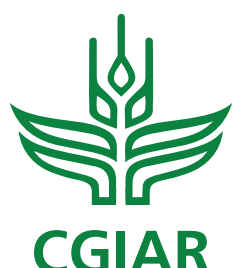

CGIAR
RESEARCH

PROGRAM ON

Forests, Trees and

Agroforestry

\section{Acerca del Centro Internacional de Investigación Agroforestal}

El Centro Internacional de Investigación Agroforestal (ICRAF) es un centro de excelencia en ciencia y desarrollo que aprovecha los beneficios de los árboles para las personas y el medio ambiente.

Aprovechando el mayor repositorio mundial de ciencia e información sobre agroforestería, desarrollamos prácticas de conocimiento, desde las parcelas de los agricultores hasta el nivel global, para garantizar la seguridad alimentaria y la sostenibilidad ambiental.

ICRAF es la única institución que realiza investigaciones agroforestales de importancia mundial en y para todas las zonas tropicales en vías de desarrollo. El conocimiento producido por ICRAF permite a los gobiernos, agencias de desarrollo y agricultores utilizar el poder de los árboles para hacer que la agricultura y los medios de vida sean más sostenibles ambiental, social y económicamente.

Véase www.worldagroforestry.org/about-us

\section{Acerca del Consorcio para el Desarrollo Sostenible de la Ecorregión Andina (CONDESAN)}

El Consorcio para el Desarrollo Sostenible de la Ecorregión Andina (CONDESAN) es una organización de la sociedad civil con sede en Lima Perú, y una oficina país en Quito, Ecuador. El CONDESAN busca promover el manejo sostenible, conservación y restauración de los ecosistemas y paisajes de altura de la región andina. Su misión es ayudar a las poblaciones rurales andinas, a los gobiernos nacionales y locales a tomar las mejores decisiones en cuanto a conservación y desarrollo sostenible.

Motivamos la generación, síntesis y utilización del conocimiento más actual sobre el medio ambiente, las sociedades andinas y sus interacciones. Promovemos el diálogo de políticas a distintos niveles y fortalecemos el capital humano para contar con nuevos líderes del desarrollo sostenible. El CONDESAN enfatiza el trabajo a múltiples escalas, priorizando arreglos de coordinación, cooperación y comunicación entre actores interesados en el desarrollo sostenible en la región Andina.

Véase www.condesan.org 
Relación entre árboles, cobertura y uso de la tierra y servicios hidrológicos en los Andes Tropicales:

Una síntesis del conocimiento

\author{
Jéssica Cerrón \\ Juan del Castillo \\ Vivien Bonnesoeur \\ Manuel Peralvo
}

Sarah-Lan Mathez-Stiefel

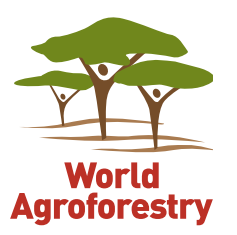


Cita correcta:

Cerrón J, del Castillo J, Bonnesoeur V, Peralvo M, Mathez-Stiefel S L. 2019. Relación entre árboles, cobertura y uso de la tierra y servicios hidrológicos en los Andes Tropicales: Una síntesis del conocimiento. Occasional Paper No. 27. Lima, Perú. Centro Internacional de Investigación Agroforestal (ICRAF), Consorcio para el Desarrollo Sostenible de la Ecorregión Andina (CONDESAN). DOI: http://dx.doi.org/10.5716/OP19056.PDF

Los títulos en la Serie de Artículos Ocasionales tienen por objeto difundir información sobre investigación y prácticas agroforestales y estimular la retroalimentación de la comunidad científica. Otras series de publicaciones del Centro Agroforestal Mundial incluyen: Perspectivas Agroforestales, Manuales Técnicos y Documentos de Trabajo.

Publicado por el Centro Internacional de Investigación Agroforestal (ICRAF)

Avenida Naciones Unidas

PO Box 30677, GPO 00100

Nairobi, Kenya

Tel: $+254(0) 207224000$, via USA +1 6508336645

Fax: $+254(0) 207224001$, via USA +1 6508336646

Email: worldagroforestry@cgiar.org

Internet: www.worldagroforestry.org

(C) Centro Internacional de Investigación Agroforestal (ICRAF) y CONDESAN 2019

ISBN: 978-9966-108-25-8

Diagramación:

Manthra Comunicación·info@manthra.ec·www.manthra.ec

Impreso por:

Master Graphic · mastergraphic.mg@gmail.com

Las opiniones expresadas en esta publicación son de los autores y no necesariamente del Centro Internacional de Investigación Agroforestal (ICRAF) o de CONDESAN. Este documento puede ser citado o reproducido sin costo siempre que la Fuente sea reconocida.

Todas las imágenes son de propiedad de sus Fuentes y no pueden ser utilizadas para ningún propósito sin el permiso escrito de la Fuente. 


\section{Tabla de Contenido}

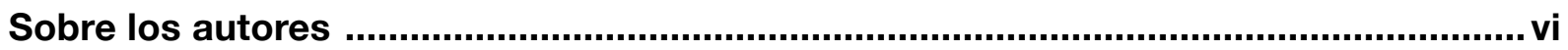

Resumen ejecutivo ….................................................................................................... vii

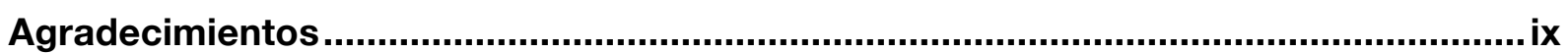

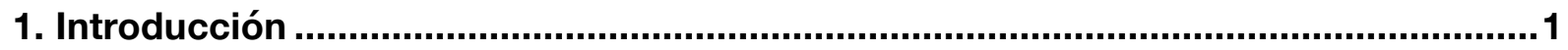

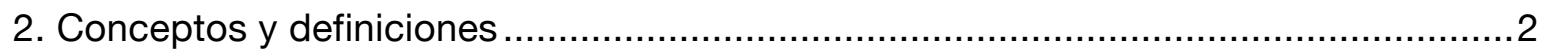

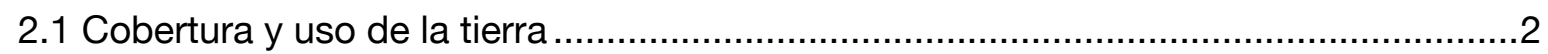

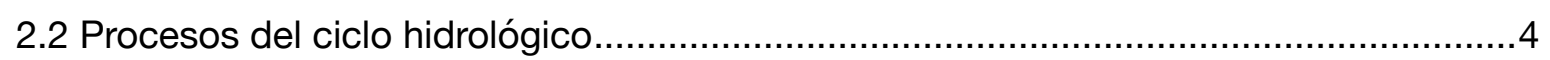

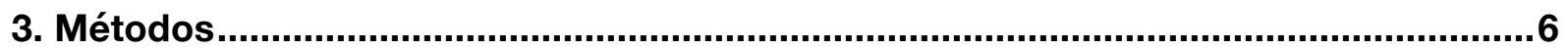

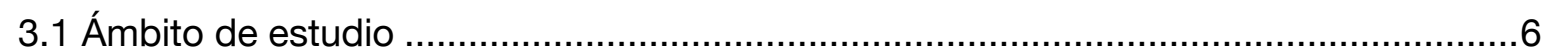

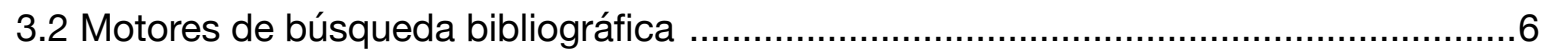

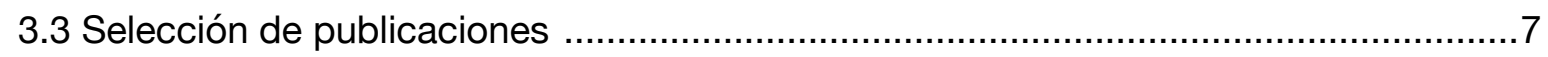

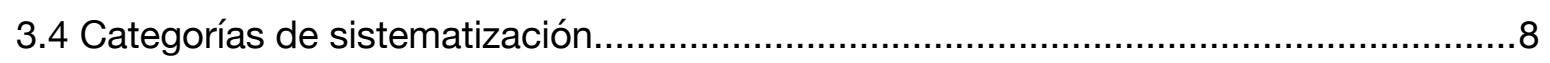

3.5 Categorización de coberturas/usos de la tierra y de los procesos hidrológicos ..........8

3.6 Sistematización y análisis de literatura.....................................................................

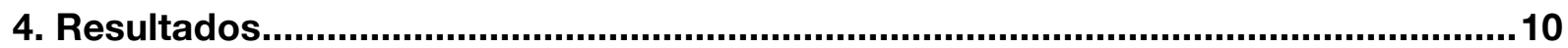

4.1 Cuantificación y selección de literatura ………………………………………....10

4.2 Impacto de los cambios de cobertura y usos de la tierra en los servicios hidrológicos en los Andes .................................................................................13

4.3 Conocimiento local sobre la relación entre especies leñosas y servicios hidrológicos ................................................................................................39

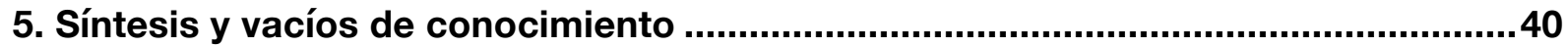

5.1 Bosques nativos comparados con otros usos de la tierra ......................................40

5.2 Páramos comparados con otros usos de la tierra ...............................................42

5.3 Agroforestería comparada con otros usos de la tierra ..........................................42

5.4 Áreas forestadas comparadas con otros usos de la tierra........................................4

5.5 Especies leñosas y su influencia en los procesos hidrológicos ..................................4

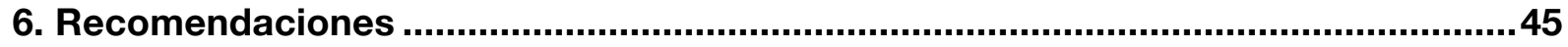

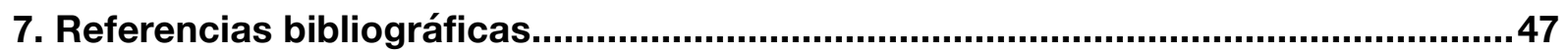

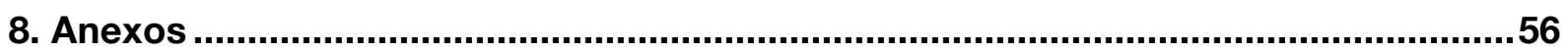




\section{Tablas}

Tabla 1. Definición de categorías de coberturas y usos de la tierra ................................2

Tabla 2. Definiciones de procesos del ciclo hidrológico .................................................5

Tabla 3. Repositorios virtuales de universidades de los Andes consultados....................6

Tabla 4. Términos de búsqueda para estudios empíricos en los Andes tropicales

Tabla 5. Términos de búsqueda para estudios de síntesis en otros ecosistemas de montañas

Tabla 6. Agrupación de coberturas y usos de la tierra .8

Tabla 7. Categorización de servicios hidrológicos y procesos del ciclo hidrológico

Tabla 8. Número de publicaciones sobre estudios experimentales en los Andes por tipo de cobertura/uso de la tierra y proceso hidrológico $(\mathrm{N}=64)$

\section{Figuras}

Figura 1. Procesos del ciclo hidrológico considerados en el estudio.

Figura 2. Categorización y flujo de filtros empleados para el análisis de la literatura

Figura 3. Número de estudios empíricos en los Andes Tropicales por año (a), rango altitudinal (b), país (c) y escala de estudio (d) $(\mathrm{N}=72)$. 


\section{Anexos}

Anexo 1. Fórmulas empleadas en cada motor de búsqueda ........................................56

Anexo 2. Categorías de sistematización empleadas para Andes.................................60

Anexo 3. Categorías de sistematización empleadas para otros ecosistemas de montaña.

Anexo 4. Especies leñosas y su influencia en diferentes procesos del ciclo hidrológico

Anexo 5. Publicaciones evaluadas en las categorías "Andes"

y "Conocimiento Ecológico Tradicional". 


\title{
Sobre los autores
}

\begin{abstract}
Jéssica Cerrón · jessicamcerronm@gmail.com
Jéssica Cerrón es Ingeniera Forestal por la Universidad Nacional Agraria La Molina, Perú. Ha sido consultora para ICRAF, CONDESAN y Bioversity International. Su principal interés profesional es el impacto de las diferentes prácticas de restauración sobre los servicios ecosistémicos y los modos de vida locales.
\end{abstract}

\section{Juan del Castillo·j.delcastilloruiz@gmail.com}

Juan del Castillo es biólogo con especialidad en ecología por la Universidad Nacional Agraria La Molina, Perú. Ha sido consultor de ICRAF, CONDESAN, Bioversity International y CIFOR. Su principal interés profesional es la restauración y gestión participativa de ecosistemas.

\section{Vivien Bonnesoeur · vivien.bonnesoeur@condesan.org}

Vivien Bonnesoeur es especialista en servicios ecosistémicos en CONDESAN y trabaja en el proyecto "Infraestructura Natural para la seguridad hídrica". Con maestría y PhD en el Instituto de Ciencias e Industrias de la Vida y del Medio Ambiente de París, Francia. Su principal interés profesional son los servicios ecosistémicos hidrológicos y el manejo de cuencas.

\section{Manuel Peralvo·manuel.peralvo@condesan.org}

Manuel Peralvo es Ingeniero Geógrafo por la Escuela Politécnica del Ejército de Ecuador y Máster en Geografía y Estudios Ambientales en la Universidad de Texas. Es el coordinador del área de Medios de Vida y Paisajes Sostenibles en CONDESAN y Coordinador de Investigación en el Programa Bosques Andinos. Su principal interés profesional es la caracterización de las relaciones gente - ambiente a diferentes escalas.

\section{Sarah-Lan Mathez-Stiefel·sarah-lan.stiefel@cde.unibe.ch}

Sarah-Lan Mathez es etnobiológa y geógrafa con un PhD en Geografía Humana por la Universidad de Berna en Suiza. En la actualidad es investigadora Senior en el Centro para el Desarrollo y Medio Ambiente (CDE) de la Universidad de Berna. Es Asociada Senior del Centro Internacional de Investigación Agroforestal (ICRAF), en cuyo rol supervisó el presente estudio. Sus principales intereses de investigación son los conocimientos locales, la resiliencia socio-ecológica, la conservación y desarrollo sostenible.

\section{Palabras clave}

Cobertura vegetal; cambios de uso del suelo; servicios hidrológicos; Andes tropicales; conocimiento local; información; investigación. 


\section{Resumen ejecutivo}

En la región Andina existe un creciente interés en el uso de árboles para desarrollar iniciativas de restauración en áreas degradadas a través de la forestación, reforestación y agroforestería. Además del beneficio económico que estas intervenciones pueden generar, particularmente en el caso de plantaciones comerciales con árboles exóticos, uno de los principales argumentos que fundamenta dichas acciones es la recuperación de las funciones de provisión y regulación hídrica de los ecosistemas. No obstante, la relación entre cobertura boscosa y el agua es compleja, y puede tener efectos positivos o negativos en las funciones ecosistémicas de las cuencas hidrográficas dependiendo de diversos factores.

El presente estudio busca compilar y sistematizar el conocimiento científico y local existente sobre la relación entre plantas leñosas, coberturas/usos de la tierra y servicios hidrológicos en los Andes tropicales, con el fin de brindar recomendaciones y orientar prácticas y políticas de restauración. Para ello, se realizó una búsqueda bibliográfica exhaustiva de publicaciones desde 1990 en adelante en los países pertenecientes a los Andes tropicales (Bolivia, Colombia, Ecuador, Perú y Venezuela), así como referencias relevantes a nivel mundial. Dichas publicaciones fueron evaluadas, sistematizadas y sintetizadas en función a cuatro categorías de cobertura y uso de la tierra que incluyeron bosques nativos, páramos, agroforestería y áreas forestadas con especies exóticas, y a su relación con diferentes tipos de servicios hidrológicos. Se priorizaron los ecosistemas forestales y no forestales Andinos, definidos como aquellos sobre los $500 \mathrm{~m}$ de elevación.

Los resultados mostraron que el conocimiento es muy limitado y fragmentado, con importantes vacíos en áreas específicas. Mientras que la mayoría de los estudios se centran en los bosques nativos y en los usos agrícolas de la tierra, existe poca investigación sobre los páramos o sobre la agroforestería, esta última limitada a los sistemas agroforestales con café. Además, los resultados de los diferentes estudios a menudo no son comparables y a veces son contradictorios debido a las diferencias en el diseño y los métodos de investigación.

Nuestra revisión cualitativa destacó la importancia de los bosques nativos montanos en la provisión de agua, en particular a través de la captura de agua de niebla. Además, los bosques nativos montanos juegan un papel importante en la regulación del agua en comparación con las áreas cultivadas y los pastizales, ya que reducen la escorrentía y almacenan más agua. Nuestros resultados también mostraron que los páramos proporcionan una mayor regulación del agua que las áreas forestadas con especies exóticas y otras coberturas de tierra al mantener los flujos base. Las plantaciones con especies exóticas, como pinos y eucaliptos, proveen menos agua que otros usos de la tierra. Asimismo, tienen un flujo base más bajo y un flujo máximo más alto que otros usos y una infiltración y almacenamiento de agua más bajos que los bosques y los páramos. Los estudios revisados indicaron que la provisión de agua de los sistemas agroforestales de café es menor que la de los sistemas cafeteros sin sombra, pero que estos niveles varían según la especie arbórea. Las especies arbóreas, y en particular las prácticas de manejo, influyen en la función reguladora del agua de los sistemas agroforestales de café con sombra en comparación con los monocultivos de café: mientras que la escorrentía es mayor en los sistemas con especies exóticas (por ejemplo, pino, eucaliptos), el nivel de infiltración varía de acuerdo con el manejo y las características de las hojas.

Entre las principales recomendaciones, resaltamos la necesidad de conservar los bosques montanos y los páramos, dada su importancia en la intercepción de la precipitación horizontal, la regulación hídrica, entre otras. En áreas con intervención directa, es clave 
considerar medidas de aprovechamiento forestal sostenible que no afecten procesos hidrológicos, la instalación de densidades medias de árboles en plantaciones y sistemas agroforestales que reduzcan la evaporación pero a la vez incrementen el flujo de caída y la infiltración. En áreas cultivadas, es necesario promover mejores prácticas, lo que puede incluir actividades agroforestales para evitar la contaminación del suelo y el agua por insumos químicos, la rotación del pastoreo para evitar la compactación del suelo y reducir la evaporación y la escorrentía. Asimismo, en ciertos casos se puede considerar las plantaciones con especies exóticas para la recuperación de áreas con altos niveles de degradación dado su efecto positivo sobre la infiltración y la calidad hídrica.

\section{Executive Summary}

In the Andean region, interest is growing in the use of trees to restore degraded areas through afforestation, reforestation or agroforestry. In addition to the economic benefits that these interventions can generate, particularly in the case of commercial plantations with exotic trees, one of the main arguments used to support these actions has been their purportedly positive effects on the recovery of the water provision and regulation functions of ecosystems. However, the relationship between tree cover and water is complex and may have positive or negative effects on the ecosystem functions of watersheds, depending on diverse factors.

This study seeks to compile and systematize existing scientific and local knowledge on the relationship between woody plants, land cover/ use, and hydrological services in the tropical Andes, in order to provide recommendations and inform restoration practices and policies. To this end, we carried out an exhaustive bibliographic search of publications from 1990 onwards in the countries belonging to the tropical Andes (Bolivia, Colombia, Ecuador, Peru and Venezuela) as well as of relevant global references. We evaluated, systematized and synthesized these
Recomendamos también incrementar la investigación sobre el conocimiento que los productores locales tienen sobre las funciones hidrológicas de las especies leñosas y su relación con el uso de la tierra, pues éste puede contribuir a la elaboración de prácticas de manejo más apropiadas. En esta perspectiva, es clave también su involucramiento desde el diseño de las intervenciones. Finalmente, instamos a promover sistemas de monitoreo de largo plazo, a fin de contar con información hidrometeorológica precisa, relevante y útil; así como a producir estudios comparativos sistemáticos que tomen en cuenta la historia del cambio de cobertura y uso de la tierra en un determinado lugar.

publications according to four categories of land cover and use that included forests, paramos (Andean moorlands), agroforestry and forested areas with exotic species, and their relationship with different types of hydrological services. We gave priority to the Andean forest and non-forest ecosystems, defined as those above 500 m.a.s.l.

The results showed that there is very limited and fragmented knowledge, with significant gaps in specific areas. While most studies focus on native forests and on agricultural land uses, there is comparatively less research on paramos (Andean moorlands) or on agroforestry, the latter limited to coffee agroforestry. Furthermore, the results from different studies are often not comparable and are sometimes contradictory because of varying research design and methods.

Our qualitative review highlighted the importance of montane forests in water provision, in particular through the interception of horizontal precipitation. In addition, native forests play an important role in water regulation in comparison with crop and pasture lands, as they reduce runoff and store more water. Our results also showed that paramos provide better water 
regulation than forested areas with exotic species and other land covers by maintaining base flows. Plantations with exotic taxa, such as pines and eucalypts, provide overall less water than other land uses. They have lower base flow and higher peak flow than other uses and lower infiltration and water storage than forests and paramos. The reviewed studies indicated that water provisioning from coffee agroforestry systems is lower than in coffee systems without shade, but that these levels vary according to the tree species. The tree species, and in particular the management practices, influence the water regulatory role of coffee agroforestry systems with shade as compared to systems without shade. While run-off is higher in systems with exotic taxa (e.g. pine, eucalypts), the level of infiltration varies according to management and leaf characteristics.

Among the main recommendations, we highlight the need to conserve cloud forests and paramos, given their importance in the interception of horizontal precipitation, water regulation, among others. In areas with direct intervention, it is key to adopt sustainable forest management practices that do not affect hydrological processes, medium densities of trees in plantations and agroforestry systems that reduce evaporation but at the same time increase the fall flow and infiltration. In cultivated areas, best practices need to be promoted, which may include agroforestry activities to avoid soil and water contamination by chemical inputs, rotation of grazing to avoid soil compaction and reduce evaporation and runoff. Also, in certain cases, plantations with exotic species can be considered for the restoration of highly degraded areas given their positive effect on infiltration and water quality.

We also recommend increasing research on the knowledge that local farmers have about the hydrological functions of woody species and their relationship with land use, as this can contribute to the development of more appropriate management practices. In this regard, it is key to involve local farmers in the design of interventions. Finally, we urge the implementation of long-term monitoring systems, in order to have accurate, relevant and useful hydrometeorological information; as well as the production of systematic comparative studies that take into account the land use and land cover change history in a given place.

\section{Agradecimientos}

Los autores deseamos extender nuestro profundo agradecimiento a los siguientes profesionales que contribuyeron en la elaboración del presente estudio. Destacamos el apoyo de Wouter Buytaert (Imperial College London) como revisor externo, Olivier Deheuvel (Centro Francés de Investigación Agrícola para el Desarrollo Internacional - CIRAD) y Jonathan Cornelius (Centro Internacional de Investigación Agroforestal - ICRAF), quienes también brindaron importantes recomendaciones y comentarios durante la etapa de revisión.

Este estudio fue realizado en el marco del Programa Bosques Andinos (PBA), financiado por la Agencia Suiza para el Desarrollo y la

Cooperación (COSUDE) e implementado por el Consorcio para el Desarrollo Sostenible de la Ecorregión Andina (CONDESAN) y Helvetas Swiss Intercooperation. El estudio fue un esfuerzo colaborativo entre el PBA e ICRAF.

De manera especial recordamos a Carlos Alberto Llerena Pinto (Universidad Nacional Agraria La Molina), quien cordialmente colaboró con comentarios claves que permitieron enfocar el estudio, y ahora ya no se encuentra con nosotros.

\section{En memoria de}

Carlos A. Llerena Pinto

(1950 - 2019) 


\section{Introducción}

Actualmente, en la región Andina hay un creciente interés por el uso de especies leñosas para restaurar áreas degradadas a través de iniciativas de forestación, reforestación y agroforestería. Por ejemplo, en el marco de la Iniciativa 20x20, países de Latinoamérica se han comprometido a restaurar 20 millones de hectáreas degradadas para el 2020. Además del beneficio económico que estas intervenciones pueden generar, particularmente en el caso de plantaciones comerciales con árboles exóticos, uno de los principales argumentos que fundamenta dichas acciones es la recuperación de las funciones de provisión y regulación hídrica de los ecosistemas. No obstante, la relación entre cobertura vegetal y el agua es compleja, y puede tener efectos positivos o negativos en las funciones ecológicas de las cuencas hidrográficas dependiendo de diversos factores como el contexto geográfico, las especies y ecosistemas asociados, los patrones de cobertura vegetal, los usos de la tierra, entre otros. A pesar que las especies leñosas, en particular los árboles, cumplen un rol crucial en la recuperación de funciones hidrológicas, la toma de decisiones basada en percepciones generalizadas, conceptos simplistas o erróneos puede llevar a intervenciones poco efectivas o incluso, dañinas. Estas consideraciones son inclusive más importantes en cuencas andinas, donde los bosques y ecosistemas no arbóreos proveen beneficios hidrológicos clave para las poblaciones locales.

La importancia de los bosques y los árboles para el planeamiento del uso del suelo con objetivos de regulación hídrica, energía y ciclos de carbono está bien establecida (Ellison et al. 2017); sin embargo, el rol de los bosques y los árboles en la hidrología de las cuencas andinas presenta importantes vacíos de información, especialmente en lo relacionado a los impactos combinados del cambio de uso de la tierra y de la cobertura vegetal (Tobón 2009, Bruijnzeel et al. 2011, Ponette-González et al. 2015, MathezStiefel et al. 2017). El punto de entrada de este estudio es que el conocimiento existente acerca de estos vínculos está fragmentado y no disponible para la toma de decisiones.

Por lo expuesto, el objetivo de este estudio es compilar y sistematizar la información científica existente, incluyendo investigaciones académicas y estudios sobre conocimientos locales, sobre la relación entre plantas leñosas, usos de la tierra y servicios hidrológicos en los Andes tropicales, con el fin de brindar recomendaciones y orientar las prácticas y políticas de restauración en la región andina. 


\section{Conceptos y definiciones}

\subsection{Cobertura y uso de la tierra}

La cobertura de la tierra se define como los materiales y entidades bióticas que se observan sobre la superficie terrestre. En contraste, los usos de la tierra se refieren a los arreglos y actividades que las poblaciones humanas realizan con distintos objetivos de manejo (p.ej. producción o conservación).

Las relaciones entre uso y cobertura de la tierra son variadas, pudiendo existir múltiples usos en un mismo tipo de cobertura de la tierra y viceversa (Di Gregorio y Jansen 2000). En la Tabla 1 se presentan las definiciones empleadas en este estudio relacionadas con la cobertura y uso de la tierra.

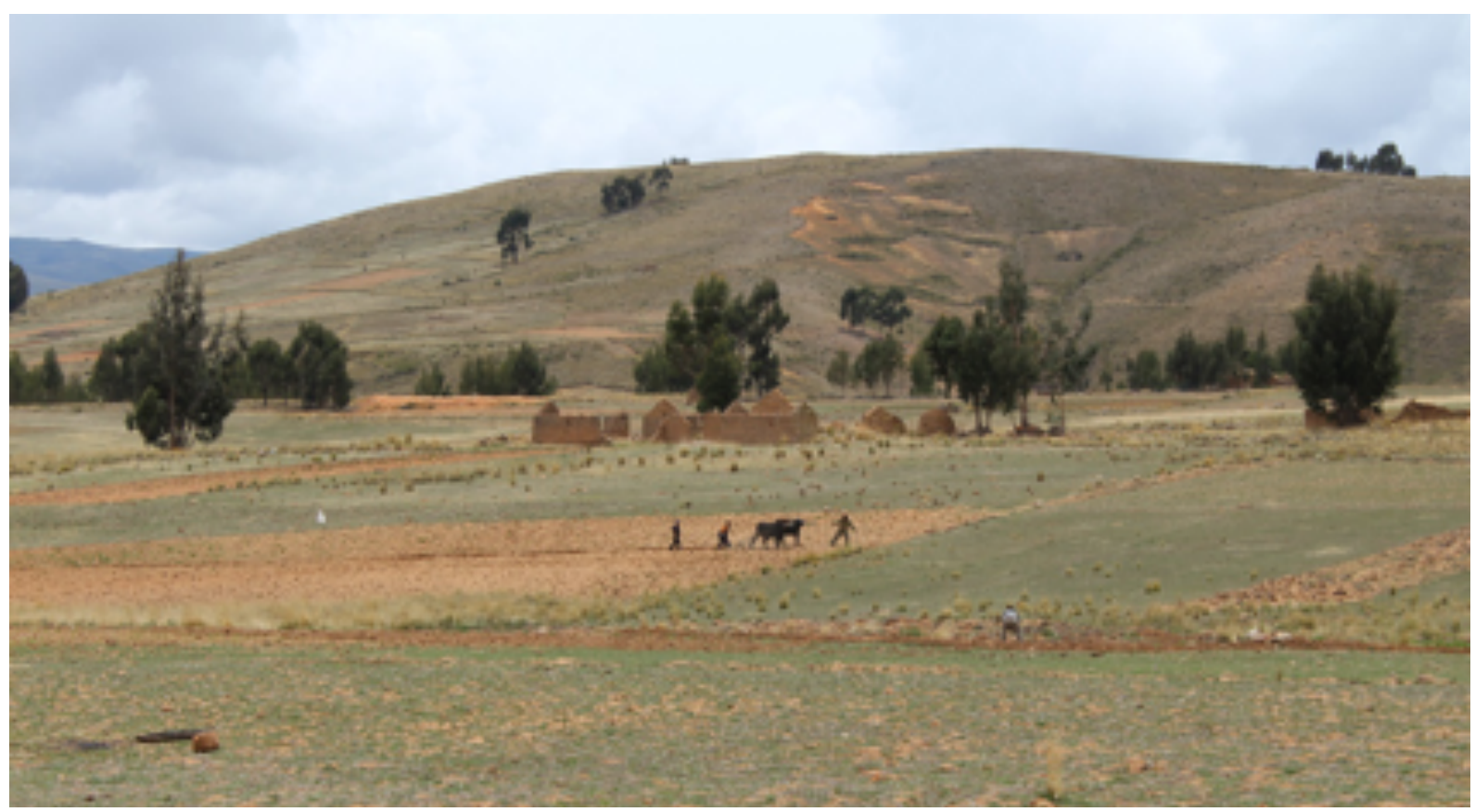

Foto I. Crédito M. Peralvo

Tabla I. Definición de categorías de coberturas y usos de la tierra.

\begin{abstract}
Coberturas de la tierra
Existen múltiples definiciones de bosques, que reflejan distintas visiones normativas, objetivos de manejo (Chazdon et al. 2016) y objetivos políticos (Robbins, 2004). En este estudio, utilizamos la Bosque definición de FAO (2015) que define bosque como tierras que se extienden por más de 0,5 ha dotadas de árboles de una cubierta de dosel superior al 10 por ciento y una altura superior a $5 \mathrm{~m}$, o de árboles capaces de alcanzar esta altura in situ.

Bosque primario
Bosques en distintos estadios sucesionales compuestos de especies nativas, en los cuales no existen indicios evidentes de actividades humanas y donde los procesos ecológicos no han sido alterados de manera significativa (FAO 20I5). 


\begin{tabular}{|l|l|l|l|l}
$\begin{array}{l}\text { Coberturas } \\
\text { de la tierra }\end{array}$ & Definición \\
\hline $\begin{array}{l}\text { Bosque } \\
\text { secundario }\end{array}$ & $\begin{array}{l}\text { Bosques que se regeneran principalmente mediante procesos naturales después de una } \\
\text { perturbación humana y/o natural de la vegetación forestal original en un solo punto en el tiempo } \\
\text { o en un período más extenso de tiempo y que muestran una diferencia relevante en la estructura } \\
\text { de los bosques y/o composición de las especies del dosel con respecto a los bosques primarios } \\
\text { cercanos en sitios similares (Chokkalingam y De Jong 200I). }\end{array}$ \\
\hline Páramo & $\begin{array}{l}\text { Ecosistema húmedo tropical zonal, caracterizado por una vegetación dominada por vegetación } \\
\text { herbácea y arbustiva,y ubicada predominantemente a partir del límite superior del bosque (Rangel } \\
2000) .\end{array}$ \\
\hline Pastizal & $\begin{array}{l}\text { Ecosistemas caracterizados por presentar una vegetación abierta dominada por especies herbáceas } \\
\text { y cuya producción primaria es aprovechada directamente por los herbívoros (Miller 1990). Suelen } \\
\text { estar situados en zonas con productividad relativamente baja que no son adecuados para usos } \\
\text { agrícolas intensivos (Rebollo y Gómez 2003). }\end{array}$ \\
\hline
\end{tabular}

Fuente: Elaboración propia.

\begin{tabular}{|l|l|}
$\begin{array}{l}\text { Usos de la } \\
\text { tierra }\end{array}$ & Definición \\
\hline Agroforestería & $\begin{array}{l}\text { Sistemas y técnicas de uso de la tierra en los que se utilizan deliberadamente plantas leñosas } \\
\text { perennes (árboles, arbustos, palmeras, bambúes, etc.) en la misma unidad de terreno que ocupan } \\
\text { cultivos y/o animales, con algún tipo de ordenación espacial o secuencia temporal. En los sistemas } \\
\text { agroforestales hay interacciones tanto ecológicas como socio-económicas entre los diversos } \\
\text { componentes (Lundgren y Raintree 1983). }\end{array}$ \\
\hline
\end{tabular}

Área cultivada

Áreas donde la vegetación natural ha sido removida o modificada y reemplazada por otros tipos de cubierta vegetal de origen antropogénico. Esta vegetación requiere de actividades humanas para mantenerla a largo plazo. Entre períodos de uso, o antes de comenzar el cultivo, la superficie puede estar temporalmente sin cobertura vegetal. Su aspecto fenológico estacional puede ser modificado regularmente por humanos a partir de la labranza, cosecha e irrigación (Di Gregorio y Jansen 2000). En este estudio, utilizamos esta definición para cultivos agrícolas (p.ej. papa, maíz, café sin sombra, entre otros).
Área deforestada áreas en donde el impacto de la perturbación, sobreexplotación o cambio de las condiciones ambientales afectan al bosque en una medida que no pueda mantener la cubierta de dosel por encima del límite del 10 por ciento (FAO 20I5).
Área forestada no habían sido clasificadas como bosque (FAO 20I5). En este estudio, se refiere a áreas forestadas con especies exóticas.

Áreas establecidas mediante plantación y/o siembra deliberada en tierras que, hasta ese momento,

Bosques
reforestados

Tierra degradada
Áreas restablecidas de bosque a través de la plantación o de la siembra deliberada en tierras que ya son de uso forestal. Implica que no hubo ningún cambio en el uso de la tierra y excluye la regeneración natural del bosque (FAO 20I5). En este estudio, se refiere a áreas reforestadas con especies nativas.

Tierras que han perdido, hasta cierto grado, su productividad y funciones naturales debido a procesos inducidos por la actividad humana (WRI s.f.). 


\subsection{Procesos del ciclo hidrológico}

El agua es un recurso naturalmente cíclico que transita entre la atmósfera y la tierra, lo que permite que sea constantemente recargado (Oki y Kanae 2006, Gilmour 2014). Usualmente su cuantificación se realiza dentro de los límites de la cuenca (Llerena et al. 2007) y mediante el análisis de los procesos que componen dicho ciclo hidrológico. Para este estudio, estos procesos se vinculan a cambios de usos del suelo asociados a cobertura vegetal, los cuales son graficados en la Figura 1 y explicados en mayor detalle en la Tabla 2.

Figura I. Procesos del ciclo hidrológico considerados en el estudio.

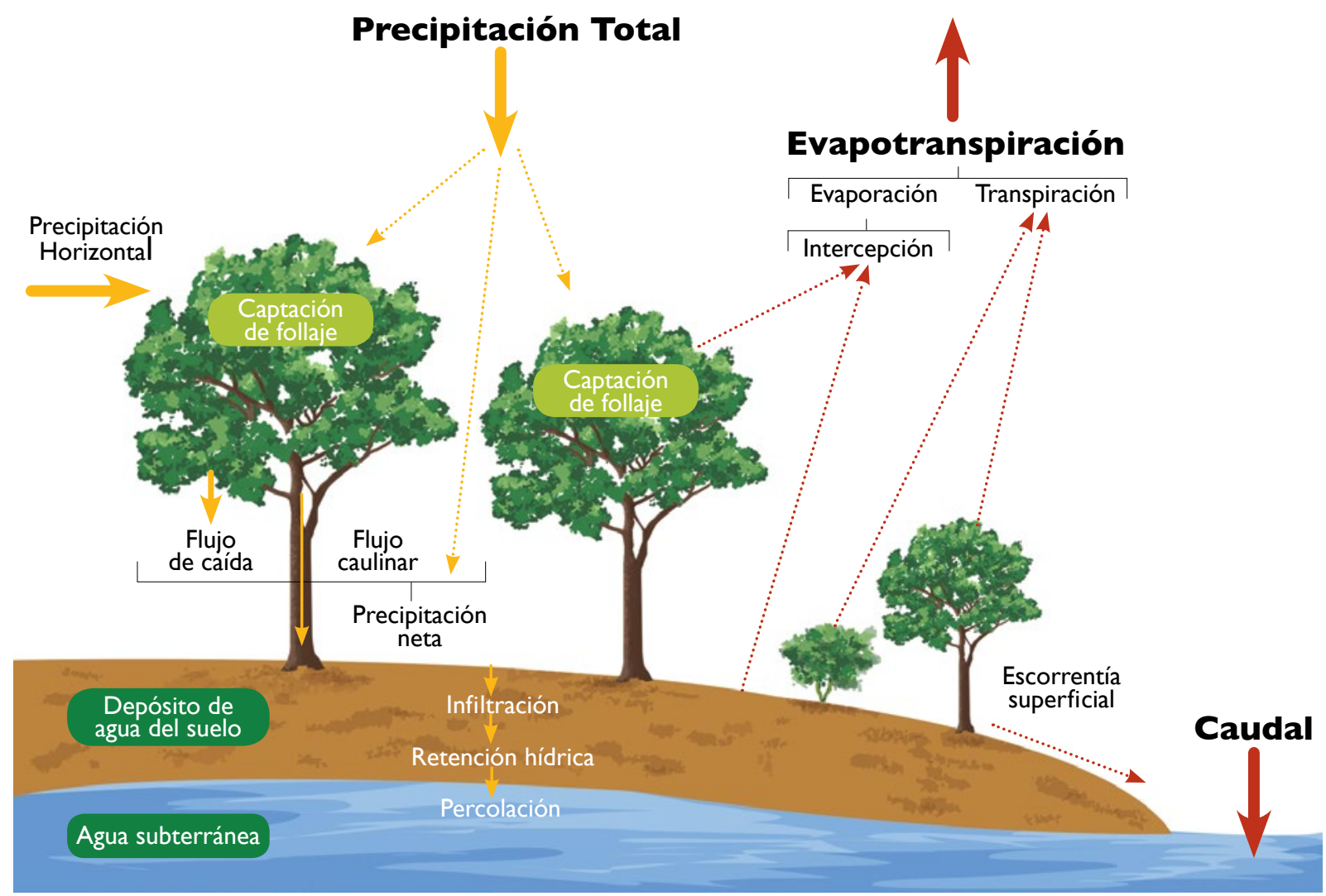

Fuente: Elaboración propia, adaptado de Blanco (2017). 
Tabla 2. Definiciones de procesos del ciclo hidrológico.

\begin{tabular}{|c|c|}
\hline $\begin{array}{l}\text { Procesos } \\
\text { hidrológicos }\end{array}$ & Definición \\
\hline Caudal & $\begin{array}{l}\text { Flujo de agua superficial a través de un cuerpo de agua, como ríos, corrientes, entre } \\
\text { otros, usualmente evaluado a nivel de cuencas (Gilmour 20I4). Dos conceptos } \\
\text { importantes y asociados son el flujo base, definido como el flujo superficial durante } \\
\text { períodos intermedios entre eventos de lluvia o de escorrentía, y que es alimentado } \\
\text { principalmente por descargas de agua subterránea (Misra et al. 20II); y el flujo pico, } \\
\text { definido como el máximo flujo o descarga durante períodos de escorrentía generados } \\
\text { por eventos de lluvia (Buytaert et al. 2007). También llamados caudal de base, caudal } \\
\text { máximo o caudal punta (OMM y UNESCO 20I2). }\end{array}$ \\
\hline Escorrentía superficial & $\begin{array}{l}\text { Es la fracción de la precipitación total que no se infiltra en el suelo y fluye a través de su } \\
\text { superficie, también denominada flujo superficial de exceso de lluvia por saturación (Gilmour } \\
2014 \text {, OMM y UNESCO 20I2). }\end{array}$ \\
\hline Evapotranspiración & $\begin{array}{l}\text { Conformado por la evaporación en superficies del suelo y de plantas, y por la transpiración } \\
\text { de agua por plantas (Ellison et al. 2017, Gilmour 2014, Tobón 2009, OMM y UNESCO 2012). }\end{array}$ \\
\hline Flujo caulinar & $\begin{array}{l}\text { Es aquella parte de la precipitación neta que es interceptada por la vegetación y llega al } \\
\text { suelo luego de escurrir a través de los troncos (Tobón 2009, OMM y UNESCO 20I2). }\end{array}$ \\
\hline Flujo de caída & $\begin{array}{l}\text { Es aquella parte de la precipitación neta compuesta por las gotas de agua que caen o } \\
\text { drenan al suelo desde el follaje y las ramas (Tobón 2009, OMM y UNESCO 2012). }\end{array}$ \\
\hline Infiltración & $\begin{array}{l}\text { Es el paso del agua de lluvia hacia el interior del suelo (Gilmour 20I4), permitiendo la } \\
\text { recarga del agua del suelo y de los acuíferos (Tobón 2009, OMM y UNESCO 20I2). }\end{array}$ \\
\hline Intercepción & $\begin{array}{l}\text { Intercepción de la precipitación total por la cobertura vegetal o por la capa de restos } \\
\text { vegetales (Trabucco et al. 2008). Es considerada una pérdida neta de agua del bosque ya que } \\
\text { termina siendo evaporada (Bruijnzeel } 1990,2004 \text { ) y es usualmente calculada restando la } \\
\text { precipitación neta de la precipitación (Bruijnzeel et al. 2005). }\end{array}$ \\
\hline Percolación & $\begin{array}{l}\text { Es el ingreso del agua hasta el nivel freático bajo la zona de raíces (Tobón 2009), pudiendo } \\
\text { recargar los acuíferos subterráneos (Gilmour 2014). }\end{array}$ \\
\hline Precipitación horizontal & $\begin{array}{l}\text { Es el ingreso adicional de agua conformado por la lluvia o la niebla que es transportada por } \\
\text { el viento y es capturada por la vegetación (Tobón 2009, Bruijnzeel et al. 2005). }\end{array}$ \\
\hline Precipitación neta & $\begin{array}{l}\text { También llamada precipitación efectiva. Es aquella parte de la precipitación que llega a la } \\
\text { superficie del suelo, y está conformada por el flujo caulinar y el flujo de caída (Crockford y } \\
\text { Richardson 2000, Tobón 2009, Bruijnzeel et al. 2005). }\end{array}$ \\
\hline Precipitación total & $\begin{array}{l}\text { Es la precipitación registrada por encima de la cobertura vegetal.También llamada } \\
\text { precipitación bruta o incidente (Bruijnzeel et al. 2005). }\end{array}$ \\
\hline Retención hídrica & $\begin{array}{l}\text { Es la capacidad del suelo de mantener el agua, determinando cuánto es descargado en } \\
\text { corrientes adyacentes y en el agua subterránea (Bruijnzeel et al. 2005, Geroy et al. 20II). }\end{array}$ \\
\hline Calidad hídrica* & $\begin{array}{l}\text { Referido a la carga sedimentaria y de nutrientes del agua, y a características como } \\
\text { la temperatura y otros parámetros, que pueden cambiar como producto de alguna } \\
\text { perturbación (Bruijnzeel et al. 2005, van Dijk y Keenan 2007, HIFM 2008, Hamilton 2009). }\end{array}$ \\
\hline
\end{tabular}

Fuente: Elaboración propia.

(*) Si bien la calidad hídrica no es un proceso sino una variable hidrológica, también ha sido considerada en el estudio, aunque de forma secundaria con respecto a la provisión y regulación hídrica. 


\section{Métodos}

\section{1 Ámbito de estudio}

El estudio se desarrolla a nivel de los Andes tropicales, comprendiendo a Venezuela, Colombia, Ecuador, Perú y Bolivia, excluyéndose a Chile y Argentina. Para este estudio, se define a los Andes tropicales como aquella zona de la Cordillera de los Andes ubicada por encima de los $500 \mathrm{~m}$ de altitud. Se consideraron estudios publicados desde 1990 en adelante.

\subsection{Motores de búsqueda bibliográfica}

A fin de priorizar los motores de búsqueda bibliográfica disponibles, se desarrolló una búsqueda preliminar con las palabras claves "Andes", "agua" y "árboles" en los motores Scopus, CAB Direct, Web of Science, Science Direct, AGRIS, Redalyc y Scielo. Como resultado, las tres primeras tuvieron mayor número de publicaciones, descartándose a Science Direct dado que sus resultados ya estaban incluidos en Scopus, y a AGRIS, pues contaba con una cantidad muy limitada y poco accesible de resultados. Se decidió incluir a Redalyc y Scielo pues arrojaron resultados que, aunque reducidos, no habían sido encontrados en los anteriores motores. Además, se incluyeron Google Scholar y repositorios digitales de algunas universidades de los Andes a fin de ampliar la búsqueda (Tabla 3).

Tabla 3. Repositorios virtuales de universidades de los Andes consultados.

\begin{tabular}{|l|l|l|}
\hline País & Universidad & Repositorio online \\
\hline Bolivia & $\begin{array}{l}\text { Universidad Mayor de San } \\
\text { Andrés }\end{array}$ & http://bibliotecadigital.umsa.bo:8080/rddu/ \\
\hline Colombia & $\begin{array}{l}\text { Universidad Nacional de } \\
\text { Colombia }\end{array}$ & http://www.bdigital.unal.edu.co/cgi/search/advanced \\
\hline Ecuador & Universidad de Cuenca & http://www.ucuenca.edu.ec/recursos-servicios/biblioteca/catalogo \\
\hline Perú & $\begin{array}{l}\text { Universidad Nacional Agraria } \\
\text { La Molina }\end{array}$ & http://repositorio.lamolina.edu.pe/ \\
\hline Venezuela & Universidad de los Andes & http://www.saber.ula.ve/ \\
\hline
\end{tabular}

Con base en la revisión de algunos de los artículos más citados encontrados en la búsqueda preliminar y otros facilitados por especialistas en el tema, se establecieron los términos a emplearse en la búsqueda bibliográfica principal, los cuales son presentados por categoría en la Tabla 4.

A partir de ello se realizaron tres búsquedas. Las dos primeras estaban dirigidas a encontrar estudios empíricos desarrollados en los Andes tropicales en dos agrupaciones, la primera que denominamos "experimentales", para aquellos donde se realizaron experimentos $u$ observaciones con tomas de datos en campo o mediante otras técnicas como sensoramiento remoto; y la segunda que denominamos "conocimiento local", para aquellos que recogían conocimientos locales sobre la relación entre especies leñosas y el ciclo hidrológico. Ambas búsquedas se realizaron con fórmulas en inglés y en español, por separado; y siguiendo las combinaciones "Ubicación, Vegetación y Ciclo hidrológico" y "Ubicación, Vegetación y Conocimiento local". 
Tabla 4.Términos de búsqueda para estudios empíricos en los Andes tropicales.

\begin{tabular}{|l|l|}
\hline Categoría & Términos de búsqueda \\
\hline Ubicación & Andes, andin*,Venezuela, Colombia, Ecuador, Perú, Bolivia, puna, yunga, páramo, jalca \\
\hline Vegetación & $\begin{array}{l}\text { Bosque, árbol, arbor*, arbust*, leños*, agroforest*, cerco, terraza, lindero, barbecho, frut*, } \\
\text { restaur*, deforest*, degrad*, fragment*, reforest*, uso del suelo }\end{array}$ \\
\hline Ciclo hidrológico & $\begin{array}{l}\text { Hidr*, agua, cuenca, precipitación, evapotranspiración, intercepción, flujo caulinar, flujo de } \\
\text { caída, escorrentía, infiltración, percolación, caudal }\end{array}$ \\
\hline Conocimiento local & Conocimiento local, conocimiento indígena, conocimiento tradicional \\
\hline
\end{tabular}

La tercera búsqueda tuvo por objetivo identificar estudios de síntesis y revisiones de literatura relevante desarrollados en otros ecosistemas de montaña del mundo con resultados aplicables o relevantes a los Andes tropicales, para lo cual se incluyeron las categorías de términos según se detalla en la Tabla 5.
Dicha búsqueda se realizó en Scopus y CAB Direct, los dos motores con mayor cantidad de resultados, con la combinación de categorías "Ecosistemas de montaña, Vegetación, Ciclo hidrológico, y Tipo de publicación". Todas las fórmulas empleadas en cada caso se encuentran detalladas en el Anexo 1.

Tabla 5.Términos de búsqueda para estudios de síntesis en otros ecosistemas de montañas.

\begin{tabular}{|l|l|}
\hline Categoría & Términos de búsqueda \\
\hline Ecosistemas de montaña & $\begin{array}{l}\text { Bosque de montaña, bosque montañoso, ecosistema de montaña, ecosistema montañoso, } \\
\text { bosques nublados }\end{array}$ \\
\hline Vegetación & $\begin{array}{l}\text { Bosque, árbol, arbor*, arbust*, leños*, agroforest*, cerco, terraza, lindero, barbecho, frut*, } \\
\text { restaur*, deforest*, degrad*, fragment*, reforest*, uso del suelo }\end{array}$ \\
\hline Ciclo hidrológico & $\begin{array}{l}\text { Hidr*, agua, cuenca, precipitación, evapotranspiración, intercepción, flujo caulinar, flujo de } \\
\text { caída, escorrentía, infiltración, percolación, caudal }\end{array}$ \\
\hline Tipo de publicación & Revisión, síntesis, estado \\
\hline
\end{tabular}

\subsection{Selección de publicaciones}

Primera selección: Del total de publicaciones obtenidas, se realizó la eliminación de aquellas que eran: (1) publicaciones duplicados (a nivel de título y autor) y (2) con resultados sin relación entre especies leñosas y agua (a nivel de título y resumen).

Segunda selección: Los criterios de filtro de exclusión para las búsquedas enfocadas en los Andes tropicales (primera y segunda búsqueda) fueron:
- Inexistencia de resultados sobre el efecto de las especies leñosas en los procesos hidrológicos

- Modelamiento hidrológico (simulaciones sin comparaciones en campo)

- Revisión o síntesis (estado de conocimiento y recomendaciones generales, sin mediciones experimentales) 
- $\quad$ Ámbito de estudio (por debajo de 500 m s.n.m.)

- Métodos de medición cuestionable (mediciones sin especificaciones)

- Documento no disponible

En el caso de las publicaciones enfocadas en otras partes del mundo, se consideraron los estudios realizados en ecosistemas de montaña y revisiones con conceptos y resultados claves en el ámbito de la relación entre plantas leñosas, usos del suelo y procesos hidrológicos.

\subsection{Categorías de sistematización}

Con base en una revisión preliminar de artículos científicos, reportes e informes claves sobre la relación entre las plantas leñosas, usos de la tierra y el agua en los Andes, se desarrolló una propuesta de categorías para emplear en la sistematización y el análisis de la literatura. Esta propuesta fue presentada a especialistas en dinámicas de cambio de cobertura y uso de la tierra e hidrología forestal del ICRAF, del CONDESAN, del Programa Bosques Andinos, del CIFOR y de la Universidad Nacional Agraria La Molina, a fin de recibir recomendaciones y comentarios. A partir de la revisión de los especialistas y de pruebas llevadas a cabo con 10 artículos científicos, se elaboró la versión final de la matriz de sistematización (ver Anexo 2).
Por otro lado, con el fin de obtener conocimiento en ecosistemas de montaña similares en otras regiones del mundo sobre la relación entre las plantas leñosas, coberturas/usos de la tierra y los procesos hidrológicos que pueden ser aplicables a la región de los Andes tropicales, se utilizó una matriz simplificada para extraer los resultados claves (ver Anexo 3).

\subsection{Categorización de coberturas/usos de la tierra y de los procesos hidrológicos}

\section{a) Coberturas y usos de la tierra}

Considerando las definiciones del Capítulo 2, y el interés de este estudio por determinar el impacto de los cambios de cobertura y uso de la tierra en los servicios hidrológicos en los Andes Tropicales, estos se agruparon en cinco grandes categorías, según se aprecia en la Tabla 6 .

Así, se determinaron los capítulos de análisis: "Bosques nativos comparados con otros usos de la tierra", "Páramos comparados con otros usos de la tierra", "Agroforestería comparados con otros usos de la tierra" y "Áreas forestadas comparados con otros usos de la tierra". No obstante, en algunos casos hay traslape entre unos y otros, dado que varios estudios analizaron diferentes usos y coberturas de manera simultánea.

Tabla 6. Agrupación de coberturas y usos de la tierra.

\begin{tabular}{|l|l|l|}
\hline Categorías & $\begin{array}{l}\text { Coberturas y usos } \\
\text { generales de la tierra }\end{array}$ & Cobertura y usos específicos de la tierra \\
\hline Bosques nativos & Bosques naturales & $\begin{array}{l}\text { Bosques primarios o secundarios de diferentes tipos, } \\
\text { regenerados naturalmente }\end{array}$ \\
\hline Bosques reforestados & $\begin{array}{l}\text { Áreas con plantaciones de especies nativas en zonas clasificadas } \\
\text { como bosque }\end{array}$ \\
\hline Páramos & Páramo & Páramo (con arbustivas) \\
\hline Agroforestería & Agroforestería & Áreas con cultivos de café bajo sombra de árboles \\
\hline Áreas forestadas & Área forestada & $\begin{array}{l}\text { Áreas con plantaciones de especies exóticas en zonas no } \\
\text { clasificadas como bosque }\end{array}$ \\
\hline
\end{tabular}




\begin{tabular}{|l|l|l|}
\hline Categorías & $\begin{array}{l}\text { Coberturas y usos } \\
\text { generales de la tierra }\end{array}$ & Cobertura y usos específicos de la tierra \\
\hline & Área cultivada & Áreas con cultivos de café en monocultivo, maíz, papa entre otros \\
\hline \multirow{2}{*}{ Otros usos de la tierra } & Pastizal & Matorral, pajonal, arbustal, pastos \\
\hline & Área deforestada & Áreas de bosque deforestadas, sin cobertura arbórea o forestal \\
\hline & Tierra degradada & Áreas degradadas y/o abandonadas (excepto deforestadas) \\
\hline
\end{tabular}

\section{b) Procesos del ciclo hidrológico}

Para facilitar el análisis de la literatura, los procesos hidrológicos fueron agrupados en tres servicios hidrológicos: la provisión hídrica, la regulación hídrica, y la provisión de agua de calidad (Tabla 7).

Tabla 7. Categorización de servicios hidrológicos y procesos del ciclo hidrológico.

\begin{tabular}{|l|l|}
\hline Servicios hidrológicos & Procesos del ciclo hidrológico \\
\hline Provisión hídrica & Precipitación total \\
\hline Precipitación horizontal \\
\hline Evapotranspiración \\
\hline Precipitación neta, flujo caulinar y de caída \\
\hline Caudal y rendimiento hídrico \\
\hline Regulación hídrica & Escorrentía superficial \\
\hline Provisión de agua de calidad & Infiltración, retención hídrica y percolación \\
\hline
\end{tabular}

(*) Publicaciones en los cuales se evalúan propiedades químicas, sedimentos, concentración de nutrientes, entre otras características vinculadas a la calidad del agua, y que se realizaron tanto a nivel del agua producto del flujo de caída, infiltración, de escorrentía y en el caudal.

\subsection{Sistematización y análisis de literatura}

\section{a) Estudios empíricos en los Andes tropicales}

Experimentales: Se sistematizaron en una matriz los resultados encontrados sobre el impacto de los diferentes coberturas y usos de la tierra utilizando especies leñosas en los procesos hidrológicos en los Andes, los cuales fueron agrupados en cuatro categorías: bosques nativos y páramo (vegetación nativa) y, agroforestería y áreas forestadas (intervención humana), las cuales presentan comparaciones con otros usos de la tierra tales como: pastizal, áreas cultivadas, tierras degradadas entre otras. Asimismo, se sistematizó una lista de especies leñosas que reportaron influencia en los procesos hidrológicos (Ver Anexo 4).

Conocimiento local: Se sistematizó aquellos estudios que mencionaron como parte de sus resultados, información sobre la relación entre las especies leñosas y los servicios hidrológicos en los Andes tropicales. 


\section{b) Síntesis y revisiones en otros ecosistemas de montaña}

Se sistematizaron en una matriz los resultados claves por coberturas y usos de la tierra a fin de establecer diferencias y discusiones entre lo encontrado para nuestro ámbito de estudio y otros ecosistemas de montaña que pueden ser aplicables a los Andes tropicales.

\section{c) Síntesis y vacíos de conocimiento}

En función a la información sistematizada para nuestro ámbito de estudio y otros ecosistemas de montaña, se presenta un capítulo de síntesis de los principales impactos de las coberturas y usos de la tierra con especies leñosas organizados en cuatro secciones, las mismas que son empleadas en la presentación de los resultados detallados. Asimismo, se reportaron los vacíos de conocimiento (experimental y local) en referencia a las coberturas, usos de la tierra y temas abordados.

\section{d) Recomendaciones}

Finalmente, a partir de resultados obtenidos y de la sistematización del conocimiento existente dentro y fuera del área andina, se elaboraron recomendaciones referidas a prácticas de manejo, incluyendo de restauración de áreas degradadas para la región andina.

\section{Resultados}

\subsection{Cuantificación y selección de literatura}

Se identificaron 9223 referencias bibliográficas entre las tres búsquedas (Figura 2), de las cuales 235 pasaron a lectura completa. Cabe indicar que varias referencias encontradas en la primera búsqueda fueron reasignadas a las otras dos categorías (líneas punteadas en la Figura 2) y que entre las publicaciones en otros ecosistemas de montaña se decidió incorporar artículos experimentales además de revisiones, síntesis y estados del arte, a fin de complementar los hallazgos con resultados que podrían ser relevantes o aplicables en los Andes tropicales.

Figura 2. Categorización y flujo de filtros empleados para el análisis de la literatura.

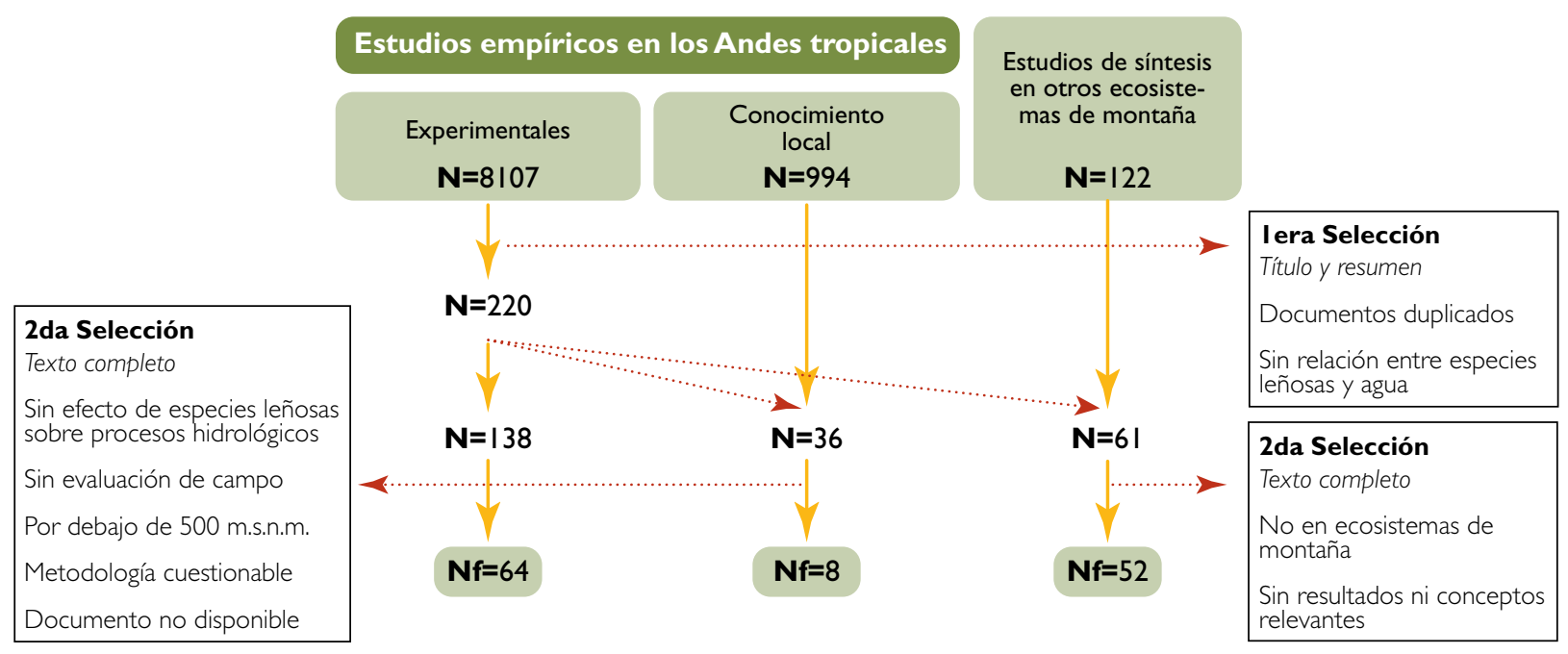

Fuente: Elaboración propia. 
Los 72 estudios empíricos en los Andes tropicales fueron analizados a través de las categorías analíticas del punto 3.4 (Anexo 2), mientras que los 52 estudios de síntesis en otros ecosistemas de montaña lo fueron mediante categorías similares, aunque adaptadas (Anexo 3). En la Figura 3 se grafica la distribución de los 72 estudios para Andes tropicales según diferentes variables. En el literal (a), según el año de publicación, se observa que desde el nuevo milenio hay una tendencia a publicar más estudios, aunque sin ser constante, y con una aparente reducción luego del pico de producción científica del año 2010, aun cuando este fue de apenas ocho publicaciones. En el caso de los rangos altitudinales (literal b), hay una prevalencia de los niveles medios (1500 a 3000 m s.n.m.) con un pico entre los 2000 y 2500 m s.n.m., aunque cabe indicar que numerosos estudios tuvieron amplios rangos de evaluación, incluyendo tanto niveles altitudinales bajos (500 a $1000 \mathrm{~m}$ s.n.m.) como altos (4500 a 5000 m s.n.m.). En el caso de la distribución por países (literal c), destacaron Ecuador y Colombia con más de 20 publicaciones cada uno. De los 72 estudios, 69 se restringieron a un país, dos evaluaron Bolivia, Ecuador y Perú en conjunto; y uno Colombia y Venezuela. Por último, el literal (d) indica que la cantidad de estudios realizados a menor escala fue mayor, destacando la escala de parcela (39 publicaciones), seguida por microcuenca (20) y cuenca (13), siendo esta última donde se realizaron principalmente los estudios de caudal, aunque hay evaluaciones de diversos procesos hidrológicos en ambas escalas.

Figura 3. Número de estudios empíricos en los Andes Tropicales por año (a), rango altitudinal (b), país (c) y escala de estudio (d) $(\mathrm{N}=72)$.

(a)

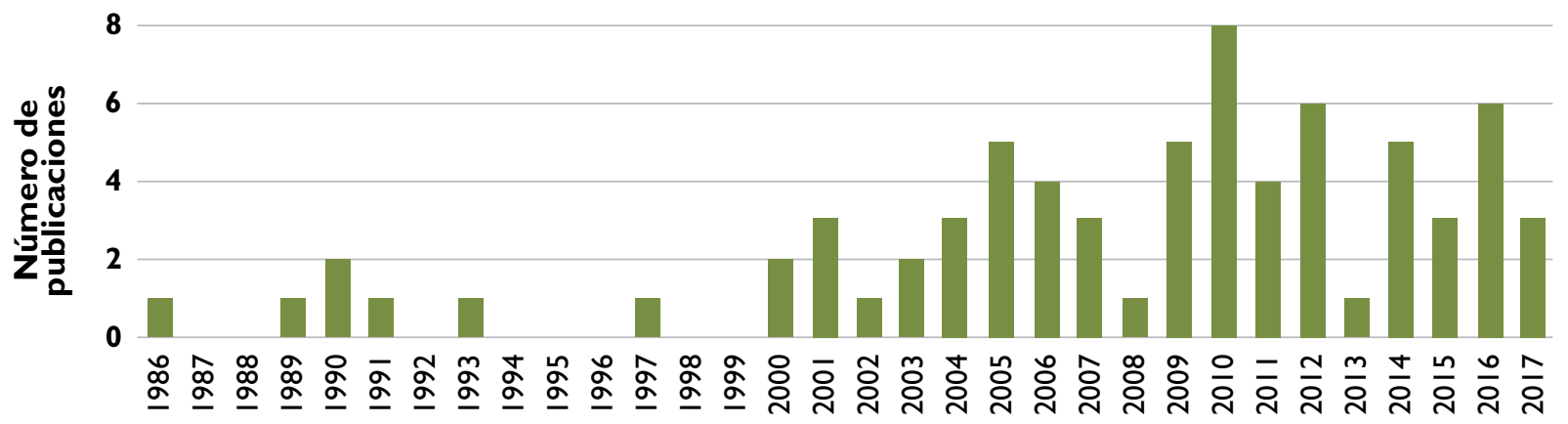

(b)

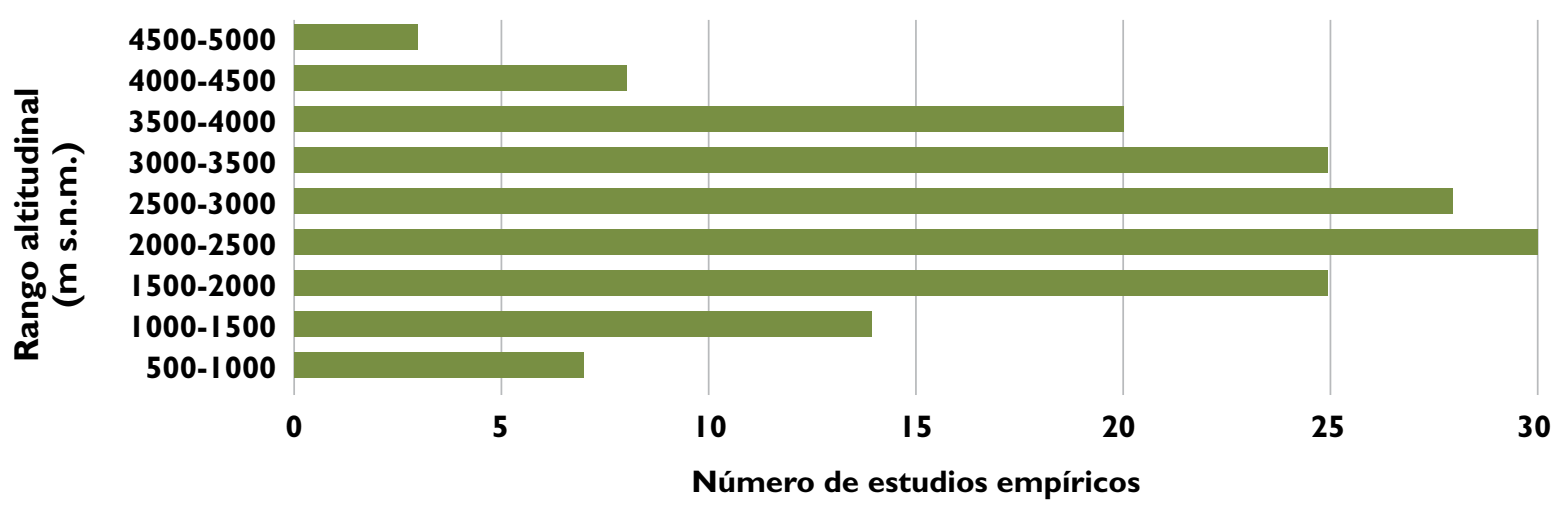


(c)

35

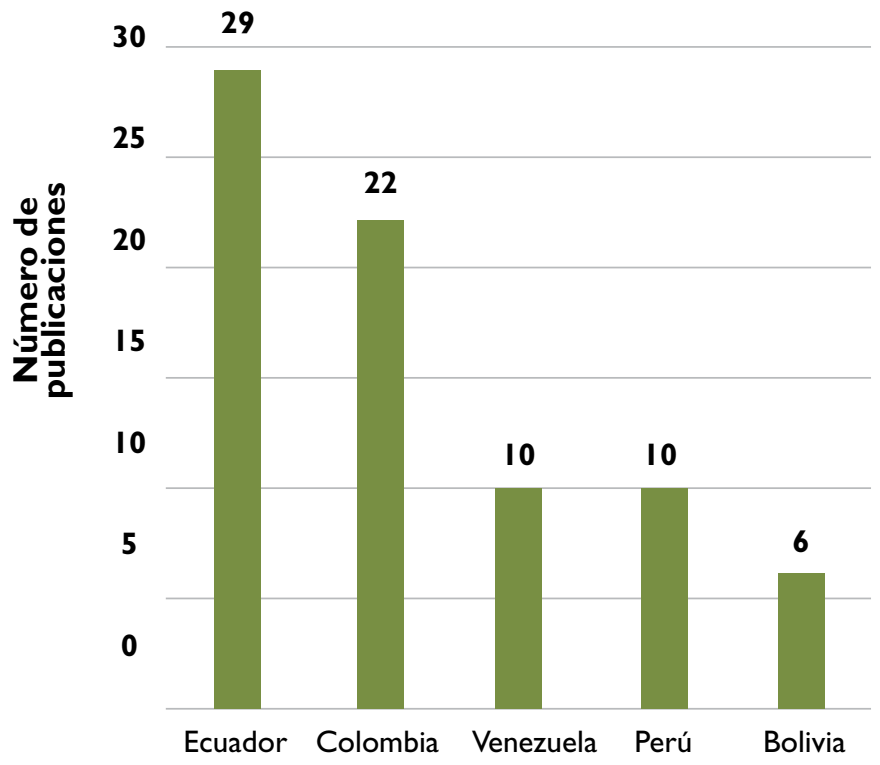

(d)

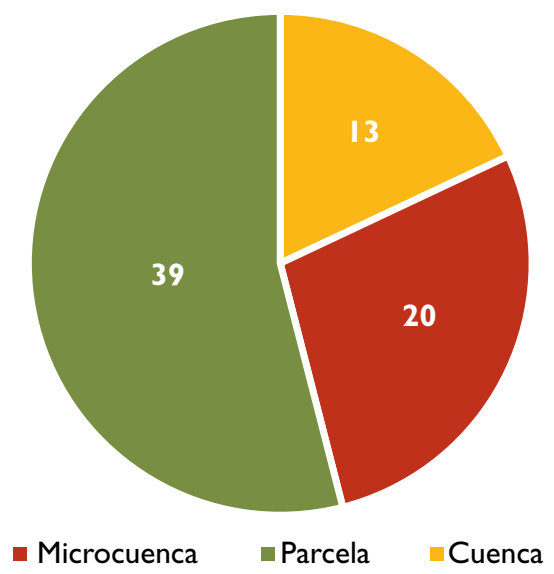

Con respecto a las categorías de "Coberturas/ usos generales de la tierra" y "Procesos hidrológicos", se extrajeron los resultados de la matriz de sistematización de estudios empíricos en los Andes, obteniéndose las cantidades observadas en la Tabla 8.

Tabla 8. Número de publicaciones sobre estudios experimentales en los Andes por tipo de cobertura/uso de la tierra y proceso hidrológico $(\mathrm{N}=64)$.

\begin{tabular}{|c|c|c|c|c|c|c|c|c|c|c|c|c|c|c|}
\hline \multirow{2}{*}{$\begin{array}{l}\text { Cobertura/ } \\
\text { uso general } \\
\text { de la tierra }\end{array}$} & \multicolumn{7}{|c|}{ Provisión hídrica } & \multicolumn{5}{|c|}{ Regulación hídrica } & \multirow{2}{*}{$\begin{array}{c}\text { Provisión } \\
\text { de agua } \\
\text { de calidad } \\
\text { CAH }\end{array}$} & \multirow{2}{*}{ Total } \\
\hline & $\mathrm{PEH}$ & INT & EVA & PN & FC & FD & REN & ESC & INF & RE & PE & CAU & & \\
\hline Bosques naturales & 4 & 8 & 2 & 5 & 6 & 6 & 1 & $\mid 1$ & 7 & 5 & 3 & 9 & 12 & 42 \\
\hline $\begin{array}{l}\text { Bosques } \\
\text { reforestados }\end{array}$ & 0 & 0 & 0 & 0 & 0 & 0 & 0 & 0 & I & 0 & 0 & 0 & 0 & 1 \\
\hline Páramo & 0 & I & I & 0 & I & 0 & 2 & I & I & 3 & 0 & 2 & I & 7 \\
\hline Agroforestería & 0 & 3 & I & I & 0 & I & 0 & 4 & 2 & 0 & I & 0 & 2 & 7 \\
\hline Área forestada & 0 & 3 & 3 & I & 3 & I & 6 & 5 & 8 & 7 & 2 & 8 & I & 24 \\
\hline Área cultivada & 0 & I & 2 & 1 & I & I & 3 & 9 & 3 & 0 & I & 2 & 3 & 17 \\
\hline Pastizal & 2 & 4 & 2 & 0 & 0 & 0 & 5 & 11 & 7 & 2 & 0 & 6 & 5 & 25 \\
\hline Área deforestada & 0 & 0 & 0 & 0 & 0 & 0 & I & 0 & 0 & 0 & 0 & I & 3 & 5 \\
\hline Tierra degradada & 0 & 0 & 0 & 0 & 0 & 0 & 0 & I & I & 0 & 0 & 0 & I & 2 \\
\hline Total & 4 & II & 5 & 6 & 7 & 6 & 7 & 20 & 13 & 8 & 3 & 15 & 13 & 64 \\
\hline
\end{tabular}

Nota: PEH: Precipitación horizontal, INT: Intercepción, EVA: Evapotranspiración, PN: Precipitación neta, FC: Flujo caulinar, FD: Flujo de caída, ESC: Escorrentía superficial, INF: Infiltración, RE: Retención hídrica, PE: Percolación; CAU: Caudal, REN: Rendimiento hídrico, CAH: Calidad hídrica. 
A partir de la Tabla 8, se identificaron 43 publicaciones de bosques nativos (naturales y reforestados), siete de páramos, siete de agroforestería, 24 de áreas forestadas y 37 de otros usos de la tierra. De éstos, en relación a los servicios hidrológicos se identificaron 31 publicaciones de provisión hídrica, 38 de regulación hídrica y 11 de provisión de agua de calidad. Cabe resaltar que la mayoría de publicaciones comparan entre sí cambios de cobertura y usos de la tierra y su efecto en uno o más servicios hidrológicos, por lo tanto, el número total de estudios experimentales mencionados para cada categória líneas arriba no son necesariamente excluyentes unas de otras.

\subsection{Impacto de los cambios de cobertura y usos de la tierra en los servicios hidrológicos en los Andes}

\subsubsection{Bosques nativos comparados con otros usos de la tierra}

\section{a) Provisión hídrica}

\section{a.1 Los bosques nativos registran valores de captura de agua de niebla que son influenciados por diversos factores}

La captura de agua de niebla en los bosques nublados varió entre el 9 y $12,2 \%$ de la precipitación total, registrado en Venezuela y Colombia a 2300 y 2400 m s.n.m. (Ataroff y Rada 2000; Fonseca y Ataroff 2005). Asimismo, Cavelier y Goldstein (1989) al evaluar la captación de agua de niebla en los bosques nublados de Colombia (815-987 m s.n.m.) y Venezuela (3100 m s.n.m.), registraron que los valores dependen de la velocidad del viento, las horas de presencia de niebla, el tamaño de las gotas de agua de niebla y la inclinación de las hojas. Este último factor presenta una relación directa con la captura de la niebla, ya que las hojas con ángulos más pronunciados tienen una mayor exposición de área foliar para capturar las gotas de agua de niebla. Asimismo, Bruijnzeel (2005) menciona que hay estudios que han demostrado que el aporte de agua de niebla aumenta significativamente la precipitación neta más allá de la precipitación. Sin embargo, Gomez-Peralta et al. (2008) indica que no está claro que todos los bosques nublados, en sentido amplio, reciban una cantidad significativa de agua de niebla.

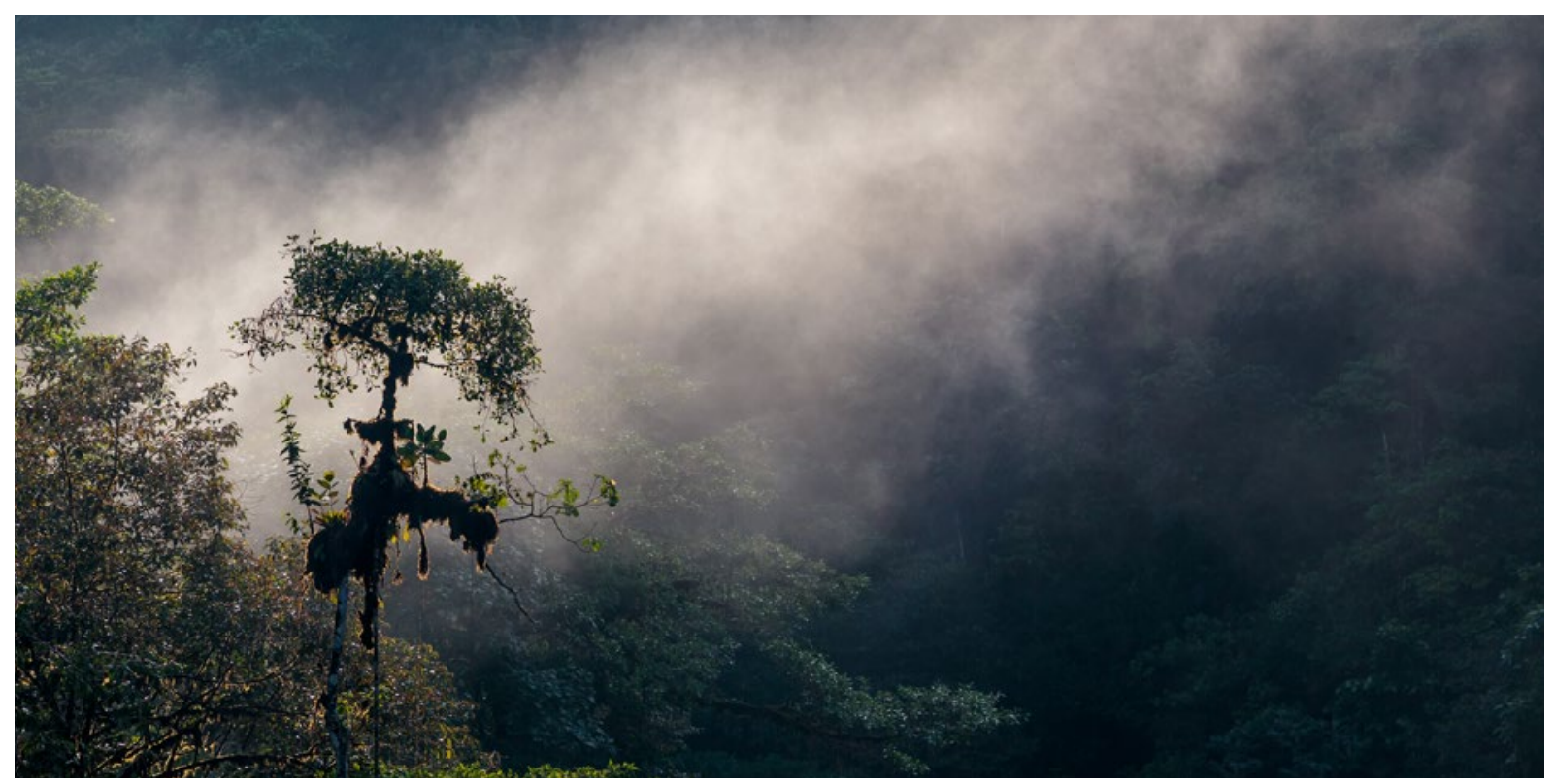

Foto 2. Crédito S. Crespo 


\section{HALLAZGOS EN OTROS ECOSISTEMAS DE MONTAÑA}

Las características de los bosques nativos influyen en el ingreso neto de agua

Los bosques nublados representan el 6,6\% de los bosques montanos tropicales del mundo (Bruijnzeel et al. 2011). Estos ecosistemas se caracterizan por las dinámicas asociadas a la formación e interceptación de la precipitación horizontal. Asimismo, estos bosques aportan al ingreso neto de agua al ecosistema al reducir la evapotranspiración pues la permanente presencia de niebla reduce la incidencia de los rayos solares (Bruijnzeel 2004). Otro factor clave es que albergan una masa de epífitas que captura, almacena y libera agua lentamente, dependiendo de la dinámica de la precipitación y del microclima del dosel (Gotsch et al. 2016). Esto último apenas fue abordado en el estudio de Mulligan et al. (2011), por lo que es un aspecto a estudiar a mayor profundidad.

Bruijnzeel (2005) y González (2000) indicaron que es muy complejo simular las condiciones de la cubierta arbórea dado que hay factores claves como la estructura y tamaño del dosel, biomasa, orientación, y las características físicas de las hojas y de las epífitas, y por ello aún no existe un método estándar de evaluación, por lo que hay que tener cuidado al realizar interpretaciones y generalizaciones.

\section{a.2 Los bosques nativos en su mayoría registran una mayor captura de agua de niebla a mayor altitud, con algunas excepciones}

Al comparar bosques nativos a diferentes altitudes, se registró que a medida que aumenta la altitud, se incrementa la captura de agua de niebla. Estas diferencias pueden explicarse por una menor evaporación, debido a las menores temperaturas medias anuales y a una cobertura nubosa casi permanente a mayor altitud, y por la captura de la humedad de las nubes, lo que provoca el goteo del agua de niebla (Vis 1986, Gomez-Peralta et al. 2008).

\section{HALLAZGOS EN OTROS ECOSISTEMAS DE MONTAÑA}

Existen factores meteorológicos y vinculados al bosque que influyen en la intercepción

Se ha identificado que la cantidad, intensidad y duración de la precipitación, la velocidad y dirección del viento, la temperatura, la humedad atmosférica y la radiación solar; así como la densidad y altura de árboles, la capacidad de almacenamiento de agua del dosel, las ramas y la capa de restos orgánicos en el suelo, la masa de epífitas, la hidrofobicidad de las hojas y de la madera, la densidad y ángulo de las ramas, el ángulo y forma de las hojas, el índice de área foliar y el área de albura influyen en la intercepción (Crockford y Richardson 2000, Hölscher 2010).

\section{El tipo de bosque es fundamental en la evapotranspiración y transpiración}

El tipo de bosque determina diferencias en la evapotranspiración, habiéndose registrado porcentajes de 20 y $30 \%$ para bosques caducifolios y de hoja acicular, respectivamente (van Dijk y Keenan 2007), así como una menor transpiración en bosques nublados 
tropicales montanos que en bosques lluviosos tropicales de zonas bajas (Bruijnzeel et al. 2011). Al respecto, Bruijnzeel (2005) indica que, para investigaciones previas a 1993, la evapotranspiración era de 1155-1380 mm/año en bosques montanos bajos ecuatoriales, de 980 mm/año en bosques montanos bajos con moderada incidencia de niebla, y de 310-390 $\mathrm{mm} / \mathrm{año}$ en bosques montanos altos con alta incidencia de niebla

\section{La remoción de cobertura forestal reduce la intercepción y la evapotranspiración}

Ha sido demostrado que la remoción del bosque reduce la intercepción y la evapotranspiración (Hamilton y King 1983, Bruijnzeel 1990, HIFM 2008), las cuales se incrementan en áreas con alta precipitación y disminuyen en áreas con precipitación menor a 500 mm/año (Zhang et al. 2001). De manera similar, el manejo como la poda selectiva puede reducir significativamente sus valores, lo que podría resultar clave en ambientes secos (Ilstedt et al. 2016).

\section{a.3 Los bosques nativos registran valores variables de precipitación neta en función al tipo de bosque, observándose un mayor aporte del flujo de caída}

En relación a la precipitación neta, se identificaron resultados contrastantes que no necesariamente están relacionados con la altitud, sino más bien podrían estar influenciadas por las características del dosel del bosque evaluado. Así, se registró que en los bosques nublados de Colombia entre 2300-2350 m s.n.m., la precipitación neta varió entre 35 y $61 \%$ de la precipitación total (Fonseca y Ataroff 2005), en un bosque premontano húmedo en Colombia ubicado a 1870 m s.n.m fue de 82,8\% (BurbanoGarcés et al. 2014) y en otros bosques montanos de Perú entre 2468 y 2815 m s.n.m. fue de 70,4 y $92,4 \%$ (Gomez-Peralta et al. 2008); donde el principal componente fue el flujo de caída, ya que el flujo caulinar representó entre el 0,2 y 1,1\% de la precipitación neta, registrado en Ecuador y Perú (Fleischbein et al. 2005; Gomez-Peralta et al. 2008). Asimismo, al evaluar la estabilidad temporal de la variabilidad espacial del flujo de caída, se determinó que la heterogeneidad de la estructura del dosel (diversidad de especies) es el principal factor que influyó en este flujo en comparación con la intensidad de la precipitación (Wullaert et al. 2009; Oesker et al. 2011). De otro lado, en Ecuador entre 1900 y 2000 m s.n.m. se registró una diferencia entre el flujo de caída anual promedio entre un Bosque Montano Bajo no alterado y uno manejado, siendo éste último mayor (67\%); en contraste al bosque no alterado (58\%), debido a una mayor apertura del dosel inducida por el adelgazamiento del bosque (Wullaert et al. 2009). 


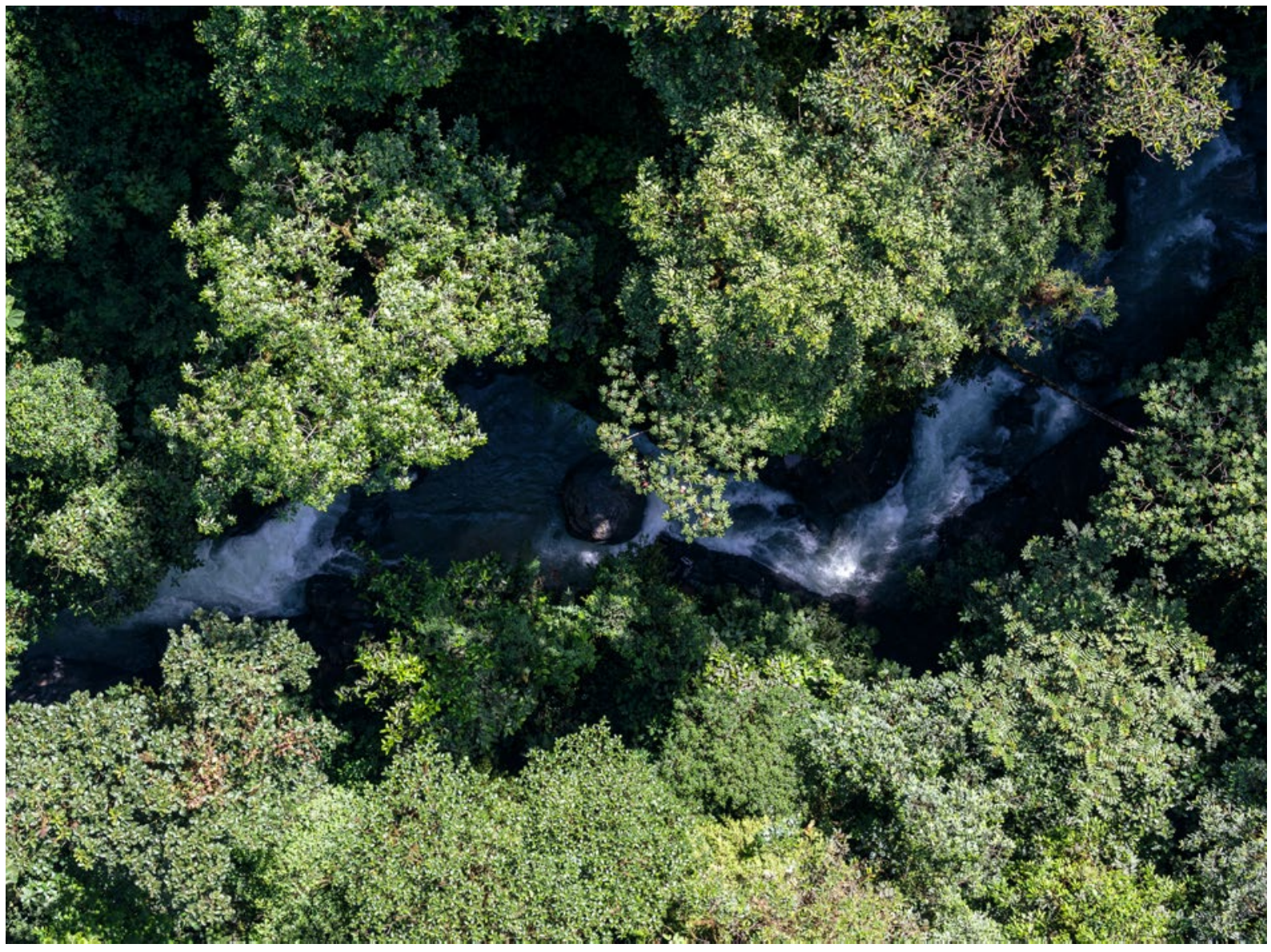

Foto 3. Crédito S. Crespo

\section{HALLAZGOS EN OTROS ECOSISTEMAS DE MONTAÑA}

Cambios de cobertura arbórea a otros usos de la tierra incrementan el flujo de caída

Si bien no se reportaron estudios experimentales comparativos para los Andes, cabe indicar que Ponette-González et al. (2014) evaluaron Bosques Montanos de Latinoamérica, el Caribe y Hawái, hallando que la sustitución de bosques o sistemas agroforestales por cultivos o pastizales incrementó el flujo de caída en $20 \%$ y $4 \%$, respectivamente.

\section{La incorporación de un análisis a escala mayor es indispensable en los Andes}

Es importante tener en cuenta escalas mayores de análisis. Blanco (2017) y Ellison et al. (2017) indican que a pesar de que la humedad atmosférica, y en consecuencia la contribución de la evapotranspiración a la precipitación siguen patrones y movimientos a escala continental, dicho fenómeno ha sido tradicionalmente abordado desde una escala local, lo que limita la comprensión integral de las relaciones entre bosques y el agua. En ese marco, también es importante incorporar análisis a nivel de Andes y cómo fenómenos meteorológicos y cambios de uso de la tierra a gran escala influyen en los patrones de evapotranspiración a nivel regional y local. 


\section{a.4 Los bosques nativos registran resultados variables de intercepción de follaje en comparación con pastizales}

Al comparar un bosque nublado con un área de pastizal que antes fue bosque entre los 2300 y 2400 m s.n.m en Venezuela, se registró que la intercepción del follaje fue de $1751 \mathrm{~mm} / \mathrm{año}$ (51\%) en contraste con el pastizal ( $7 \%)$, lo cual indica una mayor llegada de agua al horizonte superior en el pastizal, lo que podría generar mayor escorrentía (Ataroff y Rada 2000). Sin embargo, en los bosques nublados estudiados en Colombia entre los 2300 y 2350 m s.n.m, registró una intercepción de follaje de $44 \%$, valores vinculados a la alta densidad de epífitas; mientras que en el pastizal la intercepción fue del $58 \%$ como consecuencia de la arquitectura de las plantas dominantes y del sistema de medición (Fonseca y Ataroff 2005).

\section{a.5 Las cuencas con bosques nativos registran resultados variables en relación a la influencia del porcentaje de cobertura sobre el caudal temporal}

Al establecer una comparación entre dos microcuencas ubicadas en un Bosque Montano Nuboso en Perú entre 2370-2600 m s.n.m., se encontró que la cuenca con cobertura de bosque primario del $90 \%$ tuvo niveles mayores de caudal en comparación con la cuenca con una cobertura de 30\% (un parche de bosque primario así como pasturas y campos de cultivo abandonados), posiblemente debido al aporte por precipitación horizontal (Molina 2001); sin embargo, dichos resultados no deberían ser generalizados ya que fueron registrados en tan solo 22 días. En contraste, al evaluar diez microcuencas con diferentes porcentajes de cobertura de bosques en Bolivia entre 1590 y 2381 m s.n.m., no se halló una influencia positiva entre la cobertura y el caudal promedio mensual para todas las microcuencas evaluadas, lo cual pudo deberse al reducido período de estudio (34 meses) y a la calidad de la información colectada, ya que la ubicación de algunos pluviómetros no fueron óptimos debido al difícil acceso al dosel de los bosques nubosos y al método deficiente de medición de las estaciones de caudal (Le Tellier et al. 2009).

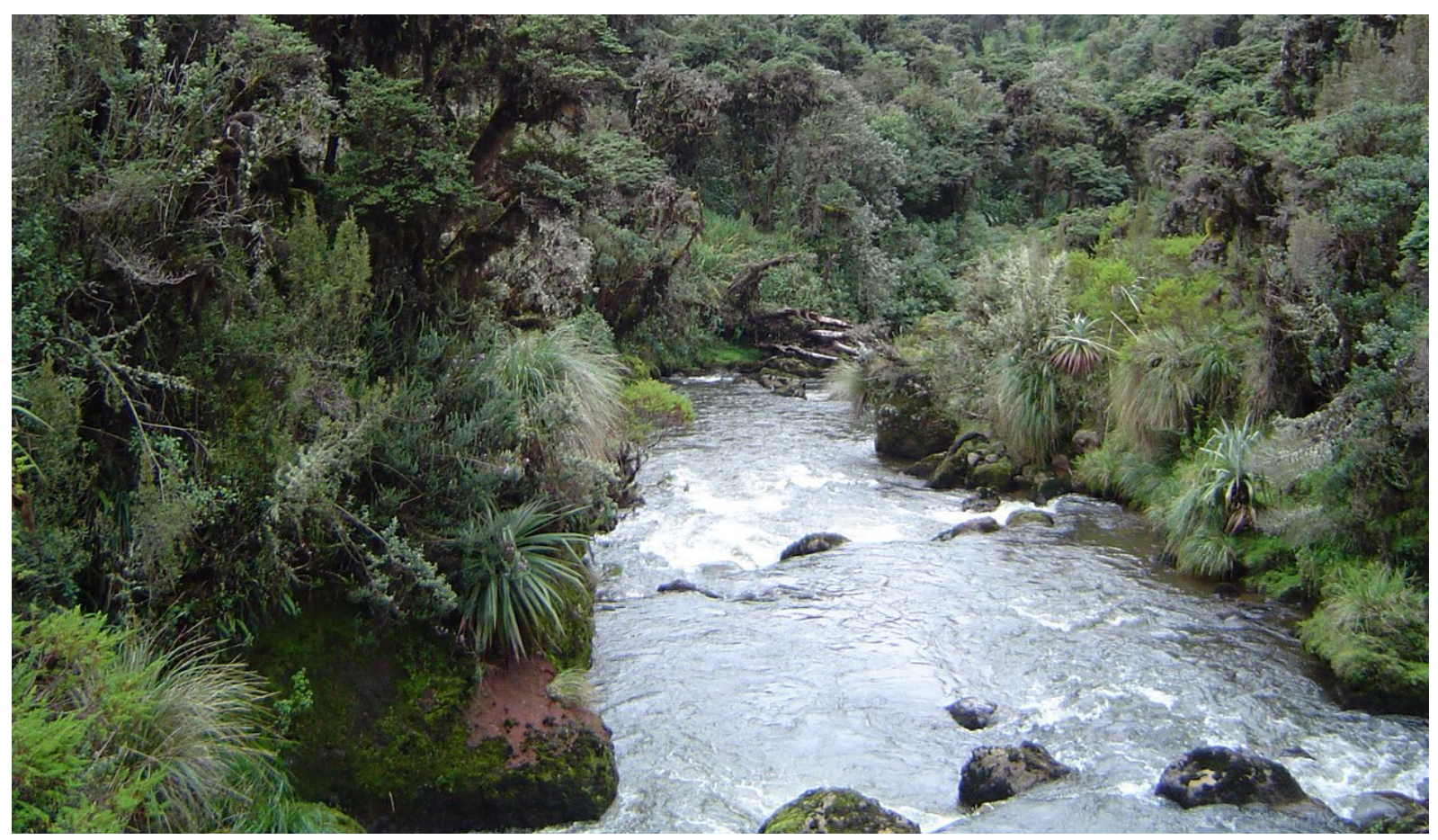

Foto 4. Crédito M. Peralvo 


\section{a. 6 Las cuencas con bosques nativos registran resultados variables de caudal anual al ser comparados con otros usos y coberturas no forestales}

En un primer caso, en la cuenca Orinoco en Colombia entre 1550 y 2490 m s.n.m., se encontró que la cuenca con $87 \%$ de área boscosa registró la mayor precipitación en las épocas seca y húmeda, el mayor caudal anual en época seca y la menor variación intra-anual; mientras que en la cuenca deforestada con $27 \%$ de superficie con pastizales, el caudal anual fue mayor durante la época húmeda y la respuesta precipitación-caudal fue la más rápida, lo que se explica por la afectación en la regulación hídrica que provee la cobertura vegetal (Ramírez et al. 2017). De otro lado, Roa-García et al. (2011) al comparar tres microcuencas en Colombia entre 2000 y 2200 m s.n.m., registraron un mayor caudal anual en el pastizal, seguido del bosque ribereño y del pastizal con humedal; no obstante, los mayores caudales en los últimos días de la época seca se registraron en el bosque, además de la mejor capacidad de reducir la variabilidad de caudal anual. Sin embargo, en Ecuador al comparar otros usos y coberturas (bosques montanos, pastizales, áreas de cultivo, plantaciones, sub-páramo, matorrales, entre otros), se registró que el caudal anual no estuvo influenciado por los cambios de uso de la tierra, sino por la precipitación anual, el régimen de precipitación, la pendiente y las propiedades físicas del suelo como la secuencia y conductividad hídrica (Crespo et al. 2011).

\section{b) Regulación hídrica}

\section{b. 1 La pérdida de cobertura boscosa registra valores variables con respecto al flujo base del caudal}

En la cuenca Jadán en Ecuador, al evaluar el cambio en el caudal en trayectorias de deforestación (principalmente de bosque nativo a campos de cultivo y pastizales), forestación (con plantas exóticas) y regeneración natural (crecimiento espontáneo de vegetación nativa), se registró un incremento general del rendimiento hídrico anual por incremento de la media y del flujo base debido a la pérdida de cobertura, y una reducción del flujo pico posiblemente debido a las plantaciones y a la recuperación espontánea de áreas deforestadas (Molina et al. 2012). Sin embargo, en la cuenca Pango en Ecuador (1434-4333 m s.n.m.), al evaluar el impacto de la pérdida de cobertura boscosa para expansión de tierra agrícola, se encontró una notable disminución en el caudal mensual y en el flujo base, asociado a un menor ingreso de agua por precipitación horizontal originada por la cobertura arbórea, lo que habría superado las ganancias por menor evapotranspiración de árboles, mientras que la precipitación media de la cuenca aumenta (Molina et al. 2015). Al respecto, el mismo autor menciona que los cambios observados en el caudal mensual no son resultado del cambio a largo plazo en la precipitación, ya que es más probable que sea resultado de la perturbación asociada al cambio de cobertura.

\section{b.2 Los bosques nativos registran una menor escorrentía superficial que los pastizales y áreas de cultivo, con algunas excepciones}

Al comparar un bosque nublado y un pastizal que tuvo un pasado de bosque hace 35 años, entre los 2300 y 2350 m s.n.m en Colombia, se registró un valor promedio de escorrentía superficial de $1,79 \%$ de la precipitación total para un bosque nublado y de $11,6 \%$ para pastizal, lo que fue atribuido a la modificación del sistema radicular, la fauna edáfica y la compactación del suelo por el ganado (Fonseca y Ataroff 2005). Diferencias marcadas se encontraron también en la región de Antioquia en Colombia entre 2370 y $2850 \mathrm{~m}$ s.n.m., donde se halló un promedio de $0,69 \%$ para un bosque montano y $20,8 \%$ para una zona de pastizal, explicado por la alta 
presencia de macroporos en el bosque (Ortega 2014). Sin embargo, en dos casos se encontraron valores cercanos y sin diferencias significativas, siendo el primero un estudio realizado en el Parque Nacional Sierra Nevada en Venezuela (2300 y 2400 m s.n.m) entre un bosque nublado y un pastizal con historial de bosque, que registraron valores de escorrentía de 1,1\% y 1,6\%, respectivamente (Ataroff y Rada 2000); y el segundo en Colombia, donde al comparar un bosque en sucesión natural y un pastizal se halló un valor promedio de escorrentía superficial de $0,5 \%$ y sin diferencias significativas entre ambos usos de la tierra, explicado por la alta porosidad y buena capacidad de infiltración del suelo y la ausencia de grandes eventos lluviosos.

De otro lado, al realizar la comparación entre bosques y áreas de cultivos, en Colombia (2370 y 2850 m s.n.m.) se registró que el bosque montano tuvo un promedio de $0,69 \%$ de escorrentía y una baja variabilidad anual, mientras que un área de cultivo obtuvo un promedio de $14,8 \%$ con una alta variabilidad, explicándose por la alta presencia de macroporos en el bosque, favoreciendo así la retención capilar, la recarga del subsuelo y reduciendo la escorrentía (Ortega 2014). En contraste, Rodríguez y Camargo (2009) registraron en Quindío, Colombia, a 1100 m s.n.m., valores de escorrentía promedio de 0,5\% y sin diferencias significativas entre un bosque en sucesión natural y un campo de cultivo de maíz (Zea mays) y frijol (Phaseolus vulgaris), explicado por la alta porosidad y buena capacidad de infiltración de los suelos y a la ausencia de grandes eventos lluviosos.

Asimismo, dos estudios compararon bosques secundarios con pastizales y áreas de cultivo. En un primer caso, Mena et al. (2011) encontraron en Colombia, a 2710 m s.n.m., un rango de escorrentía superficial entre 0,09 y $0,39 \mathrm{~mm}$ para un bosque secundario con especies introducidas, entre 0,06 y $0,85 \mathrm{~mm}$ en un área de cultivo de papa, y entre 0,07 y $1,73 \mathrm{~mm}$ para un área de pastizal, lo cual es explicado por la compactación, la reducción de la porosidad y de la infiltración. De forma similar, Suescún et al. (2017) compararon en la cuenca del Río Grande en Colombia a 2800 m s.n.m. la escorrentía en un bosque secundario de roble, dos tipos de áreas de cultivo, uno permanente con mijo perla (Pennisetum americanum) y otro temporal con agricultura intensiva con papa, maíz y frijol, y en un pastizal, encontrando valores de $0,5 \%, 0,2 \%$ (para ambos cultivos) y $1,5 \%$, respectivamente, debido a la compactación y poca permeabilidad del suelo, y a la menor cobertura vegetal.

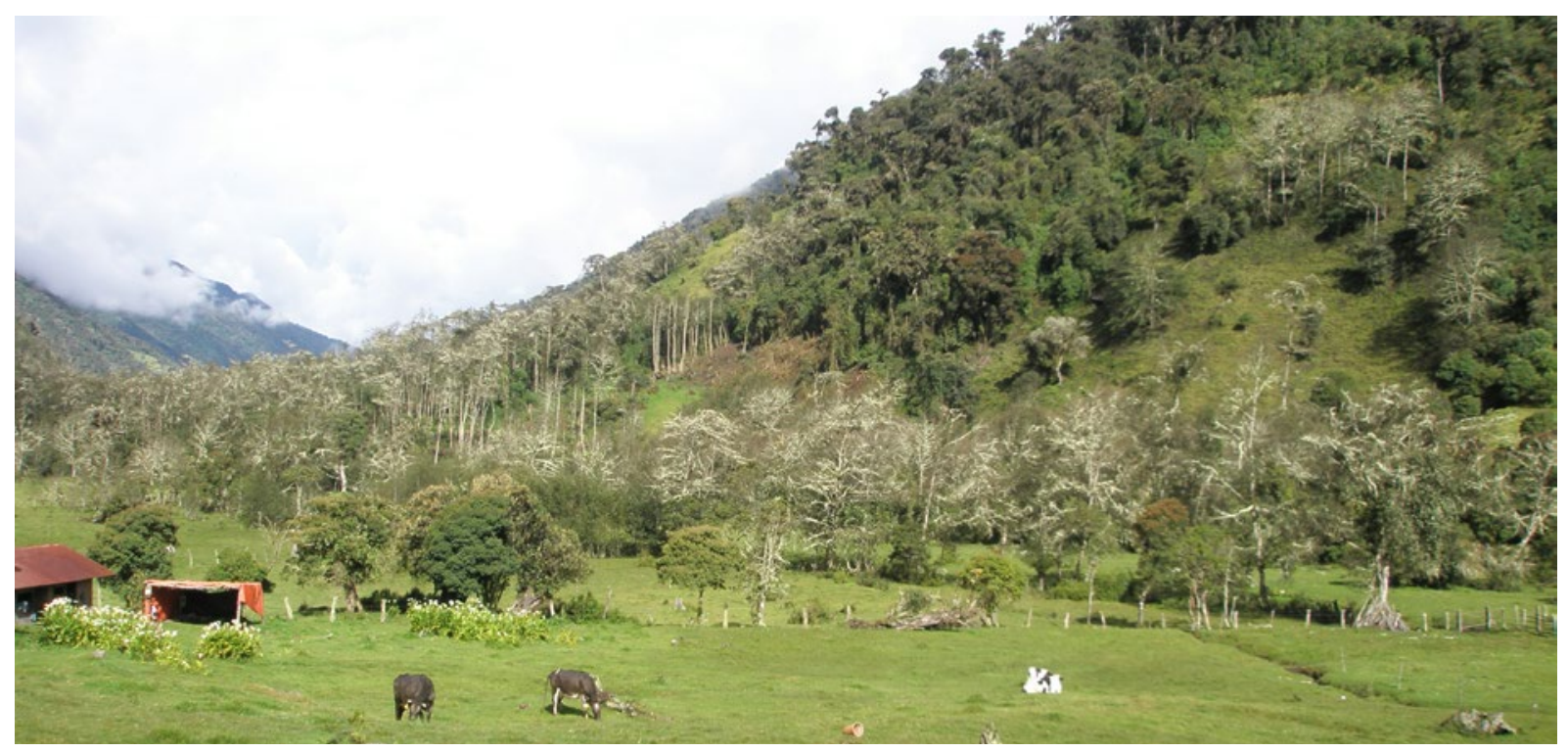

Foto 5. Crédito M. Peralvo 


\section{HALLAZGOS EN OTROS ECOSISTEMAS DE MONTAÑA}

\section{La conversión de bosques a otros usos de la tierra incrementa la escorrentía}

La conversión de bosques puede tener mayores efectos cuando se realiza en cabeceras de cuenca, afectando la recarga del agua subterránea e incrementando la compactación (Greenwood y McKenzie 2001, Little et al. 2009). Además puede incrementar el traslado de sedimentos, como se detectó en bosques altoandinos (Tobón 2009). En el caso específico de los Andes, Ataroff y Rada (2000) hallaron un incremento promedio de escorrentía del $2 \%$ al evaluar el cambio de uso desde bosque a pastizal, aunque indican que si las propiedades físicas del suelo se mantienen y se controla su degradación y compactación, las diferencias en escorrentía pueden llegar a ser insignificantes. De otro lado, cuando se convierten bosques a pastizales para ganadería, el impacto se incrementa cuando la presión es fuerte, generando mayor compactación, lo que afecta la infiltración y promueve la escorrentía superficial (Gilmour et al. 1987, Bruijnzeel 1990).

\section{b.3 Los bosques nativos presentan mayor capacidad de retención hídrica que los pastizales y áreas de cultivo}

En Colombia, entre los 2000 y 2200 m s.n.m., Roa-García et al. (2011) registraron que los bosques ribereños presentaron una mayor capacidad para almacenar y liberar agua que los pastizales, lo cual contribuyó más al flujo base. En Colombia Mena et al. (2011), observaron que a 2710 m s.n.m., el bosque secundario registró el valor promedio más alto de lámina de infiltración (2,59 mm/min) en comparación con los pastos $(1,13 \mathrm{~mm} / \mathrm{min})$, explicado por el aporte constante de la materia orgánica en los bosques, lo cual mejoró la capacidad del suelo para almacenar y retener agua. De igual manera, en Colombia entre los 2370 y 2850 m s.n.m., Ortega (2014) al realizar una comparación entre bosque primario, bosque secundario, cultivo limpio y pastos, encontró que el bosque secundario presentó el mayor valor de lámina de infiltración superficial con $3606,87 \mathrm{~mm} /$ año, seguida por el cultivo limpio (1670,94 mm/año), el pastizal (1562,22 $\mathrm{mm} / \mathrm{año}$ ) y el bosque primario $(103,81 \mathrm{~mm} / \mathrm{año})$. Con respecto a este último, los valores obtenidos se deben probablemente al consumo de agua por la vegetación y a la retención de agua en el dosel.

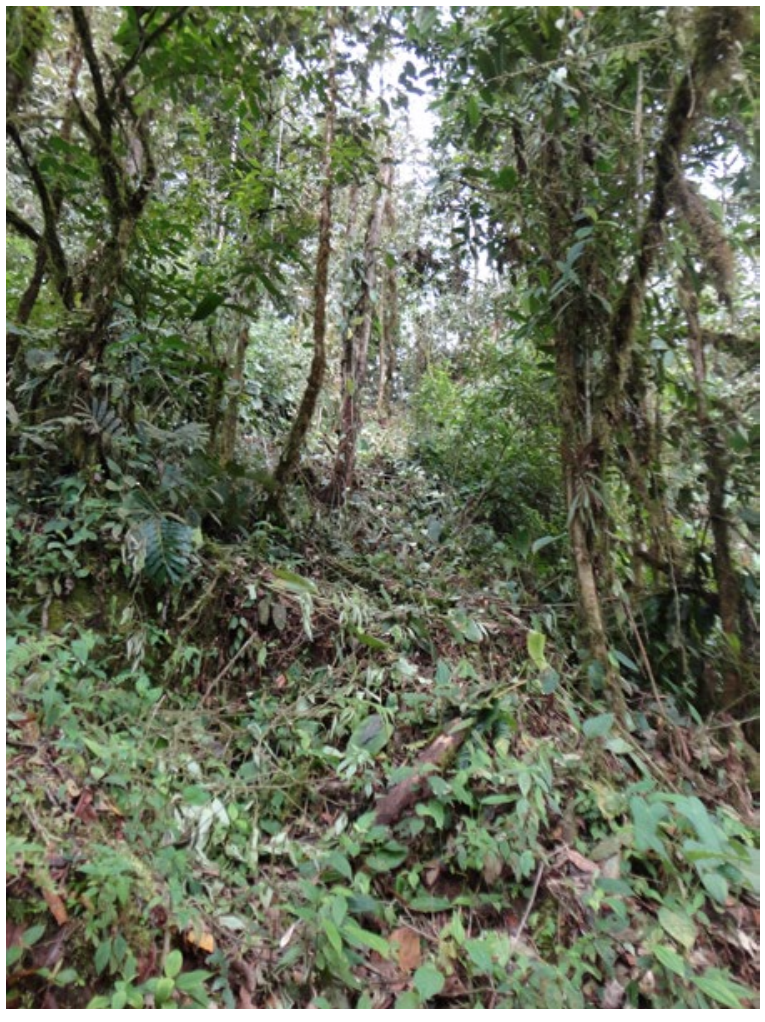

Foto 6. Crédito E. Guerrón

En Perú, Alfaro (2015) presenta un caso particular al comparar un área reforestada y un pastizal entre los 3800 y 4460 m s.n.m., encontrando que los suelos con cubierta forestal (Polylepis spp.) registraron mayor valor de lámina de infiltración acumulada que los suelos sin cobertura forestal 
(pastizal). De manera específica, bosques de Polylepis racemosa de 11 años con manejo registraron mayor lámina infiltrada $(15,8 \mathrm{~cm} / \mathrm{min})$ que Polylepis spp. de 29 años (12,6 cm/min), $P$. racemosa de 11 años sin manejo $(12 \mathrm{~cm} / \mathrm{min})$ y pastos $(10,5 \mathrm{~cm} / \mathrm{min})$, a pesar de los resultados encontrados, estadísticamente no hay diferencias significativas entre Polylepis. Cabe resaltar que los suelos con cobertura arbórea presentaron un alto contenido de materia orgánica debido a que mantienen una cubierta vegetal de forma constante dado el comportamiento caducifolio del Polylepis, lo que aportó a retener el agua, aumentando la tasa de infiltración y el agua disponible en el suelo.

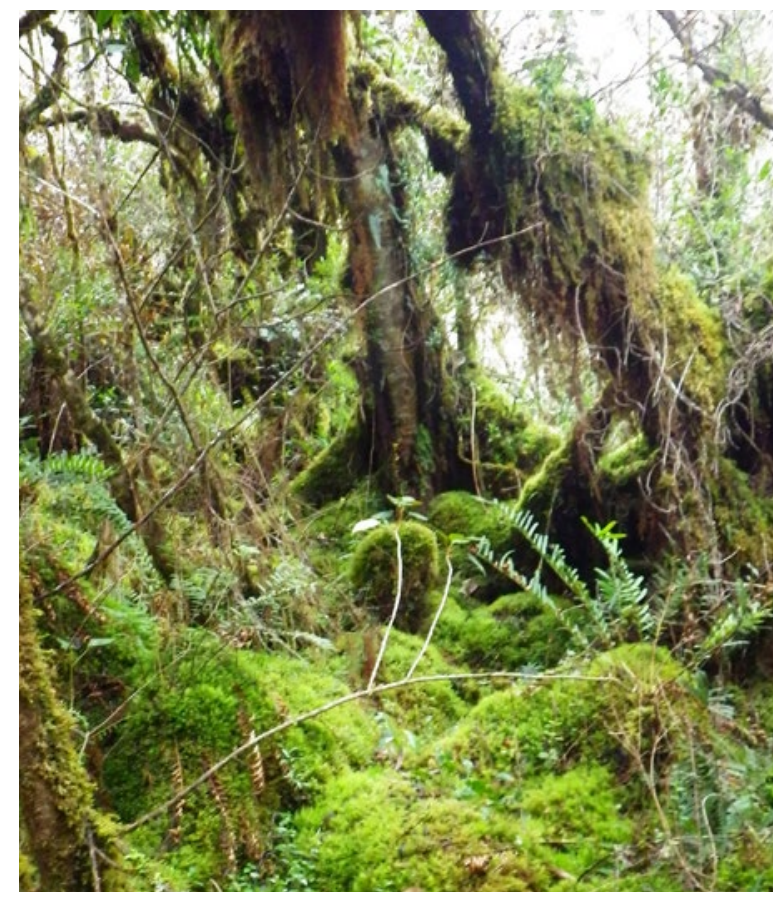

Foto 7. Crédito E. Pinto

\section{HALLAZGOS EN OTROS ECOSISTEMAS DE MONTAÑA}

\section{La conversión de bosques a otros usos de la tierra reduce la infiltración y capacidad de retención hídrica}

La conversión del bosque a otros usos de la tierra como cultivos o pastos promueve la degradación del suelo, reduciendo el carbono orgánico del suelo y empobreciendo la estructura del suelo, lo que a su vez reduce la infiltración del suelo y la capacidad de retención (Lal 1996, Nyberg et al. 2012, Zimmermann y Elsenbeer 2008); mientras que Muñoz-Villers et al. (2015) indican que los Bosques Nublados Montanos parecen exhibir mayores tasas de infiltración y flujo de estación seca que las tierras convertidas a la agricultura. De otro lado, aunque sin referencia directa a reforestaciones, hay literatura que indica que coberturas intermedias pueden generar infiltración y maximizar la recarga de aguas subterráneas al ser menor la transpiración y la interceptación (llstedt et al. 2016), Bruijnzeel (2004) menciona que esto puede variar significativamente según las condiciones locales, por lo que se debe tener cuidado al generalizar.

\section{c) Provisión de agua de calidad}

\section{c. 1 El agua que atraviesa el dosel presenta cambios en la concentración de nutrientes en función a las características del bosque y condiciones del sitio}

En un primer caso, Veneklaas y Van Ek (1990) registraron en Colombia (2550 y 3370 m s.n.m.) una correlación positiva entre flujos netos de la mayoría de los elementos evaluados $(\mathrm{Ca}$, $\mathrm{Mg}, \mathrm{K}, \mathrm{Na}, \mathrm{Cl}, \mathrm{NH}_{4}-\mathrm{N}, \mathrm{PO}_{4}-\mathrm{P}$ y $\mathrm{SO}_{4}-\mathrm{S}$ ) y los volúmenes de precipitación al evaluar cambios en la composición química de la precipitación al atravesar el dosel de un bosque montano, 
sugiriendo así que el proceso de lixiviación fue dominante en la mayoría de los casos, a excepción del N y P a 3370 m. De otro lado, Wilcke et al. (2001) registraron en un bosque lluvioso montano de Ecuador entre 1900 y 2200 m s.n.m. que las concentraciones medias de $\mathrm{Ca}, \mathrm{Mg}, \mathrm{Mn}$, Na y $\mathrm{P}$ en el flujo de caída, y la mediana de las concentraciones de $\mathrm{Ca}$ y $\mathrm{Mg}$ en el lixiviado de la hojarasca se correlacionaron significativamente con las concentraciones de estos elementos en los horizontes. Por otra parte, las concentraciones de elementos en el caudal fueron menores que en el lixiviado de la hojarasca, lo que indica que la mayoría de los elementos fueron absorbidos por la vegetación o retenidos en el suelo; sin embargo, durante eventos de alto flujo, el pH del caudal disminuyó y las concentraciones de carbono orgánico total, $\mathrm{Al}$, $\mathrm{Cu}, \mathrm{Mn}$ y $\mathrm{Zn}$ aumentaron, lo que ilustra que estos eventos pueden contribuir significativamente a la exportación de estos elementos hacia otros lugares de la cuenca.

En un tercer caso, Burbano-Garcés et al. (2014) al realizar un estudio sobre el depósito total de compuestos nitrogenados a través del dosel en un bosque premontano húmedo de Colombia a 1870 m s.n.m., registraron altos flujos de $\mathrm{N}-\mathrm{NH}_{4}$ y $\mathrm{N}-\mathrm{NO}_{3}$ en el flujo de caída total, lo cual podría explicarse por la etapa intermedia sucesional del bosque estudiado, cuyo dosel tiene una presencia moderada de biomasa epífita viva y senescente. De otro lado, al evaluar la composición química y la dinámica temporal de los flujos caulinar y de caída entre un bosque primario y otro secundario en Venezuela entre 800-1500 m s.n.m., Dezzeo y Chacón (2006) encontraron que las concentraciones medias anuales de nutrientes en el flujo caulinar y de caída fueron similares, lo cual indica que las diferencias en la estructura y la composición florística no influyeron en la dinámica de los nutrientes en el nivel del dosel. Asimismo, la aportación del flujo caulinar tendió a disminuir con la disminución de la densidad de árboles, aunque ese no fue el caso para el volumen anual del flujo de caída y sus aportes de nutrientes. De igual manera, las concentraciones de $\mathrm{K}$ aumentaron considerablemente durante el paso por el bosque, señalando la alta movilidad de este elemento, lo que no se reportó para el $\mathrm{N}$, que tuvo concentraciones similares en la precipitación, el flujo caulinar y de caída.

\section{c.2 La pérdida de cobertura forestal no registra resultados concluyentes en la concentración de nutrientes en el caudal}

Por un lado, Wilcke et al. (2009) al realizar un estudio en Ecuador entre 1900 y 2200 m s.n.m., encontraron que la zona de bosque perturbado (después de la tala) registró un incremento de la concentración de nutrientes en el lixiviado de la hojarasca en comparación con un bosque sin perturbación, probablemente debido a que la primera presentó una alta mineralización como producto del aumento de la temperatura y del aporte de nutrientes de las plantas residuales después de la tala. De otro lado, Lindell et al. (2010) al realizar un estudio en Perú entre los 250 y 3000 m s.n.m., determinó que la elevación promedio de la cuenca hidrográfica fue el predictor más fuerte y con una correlación directa con los elementos disueltos en el agua de la corriente; mientras que la cubierta forestal, que disminuyó río abajo como resultado de las actividades humanas, no tuvo un impacto estadísticamente significativo en las concentraciones de solutos en la corriente, y a pesar de la deforestación generalizada (hasta el $93 \%$ de la cuenca hidrográfica), la calidad del agua en general obtuvo valores satisfactorios con respecto a los elementos principales y elementos traza. Por último, Bücker et al. (2011), al realizar un estudio en Ecuador entre los 1800 y 3140 m s.n.m., reportaron resultados que contradicen la suposición de que la exportación de nutrientes aumenta con la pérdida de la cubierta forestal, ya que la cuenca deforestada solo mostró exportaciones ligeramente superiores para $\mathrm{Ca}$, similares para $\mathrm{Mg}$ y $\mathrm{Na}$ e inferiores para $\mathrm{K}, \mathrm{NO}_{3}$, $\mathrm{SO}_{4}$ y carbono orgánico total en comparación con las cuencas boscosas. Sin embargo, solo para $\mathrm{NO}_{3}$ se observó una correlación positiva entre el valor de exportación y el porcentaje de cobertura forestal. 


\section{HALLAZGOS EN OTROS ECOSISTEMAS DE MONTAÑA}

\section{Los bosques nativos registran buena calidad de agua}

Hamilton (2009) indica que los bosques presentan buena calidad de agua debido a la retención de contaminantes la hojarasca y el sotobosque, y a la reducción de la erosión del suelo en los bosques. Además, menciona que la presencia de bosques no previene la contaminación del agua subterránea, lo que debe tratarse mediante buenas prácticas en zonas de cultivos y ganadería. La vegetación ribereña reduce la erosión y filtra parte de los fertilizantes y contaminantes provenientes de cultivos, antes que estos lleguen al río (Anbumozhi et al. 2005, Olley et al. 2010).

\section{c.3 Los caudales en zonas de bosques presentan mayor concentración de nutrientes que los pastizales y las áreas de cultivo, con algunas excepciones}

Ortega (2014), al realizar un estudio en Colombia entre los 2370 y 2850 m s.n.m. para determinar el flujo de nutrientes en bosques, cultivo limpio y pastos, registró que todos los usos de la tierra mostraron aportes importantes de nutrientes; sin embargo, el bosque tuvo una entrada adicional debido al contacto del agua con el dosel, destacando las entradas de N, Ca y K. De otro lado, Suescún et al. (2017) registraron que las áreas cultivadas (cultivos permanentes y transitorios) presentaron concentraciones de nutrientes solubles ligeramente superiores que el bosque secundario (bosque dominado por Quercus humboldti) y pastizales en la cuenca del río Grande ubicado en Colombia a 2800 m s.n.m. Sin embargo, la mayor pérdida de nutrientes solubles se observó en los pastizales, siendo el doble que en el bosque secundario y seis veces más alto que en los cultivos (basado en las diferencias en producción de escorrentía, la cual es mayor en pastizales como resultado de la compactación del suelo por el pisoteo del ganado).

En otro caso, Plamondon et al. (1991) al realizar un estudio en tres cuencas de Oxapampa ubicada en Perú entre los 1905 y 2450 m s.n.m., encontraron que las concentraciones de sedimentos suspendidos en las corrientes que drenaban las cuencas con cobertura mixta (cultivo-pasto-bosque) y pastos fueron $20 \mathrm{mg} / \mathrm{L}$ y $15 \mathrm{mg} / \mathrm{L}$, respectivamente, en comparación con el bosque $(5 \mathrm{mg} / \mathrm{L})$. Así, el $\mathrm{pH}$ y las concentraciones de oxígeno disuelto se modificaron ligeramente al remover el bosque, concluyendo así que para conservar la calidad del agua es importante mantener una cubierta forestal para las tierras con pendientes superiores al 40\%; asimismo, cuando las pendientes varían entre 10 y $40 \%$ es necesario tomar medidas de conservación del suelo para minimizar la alteración del suelo y retener algunos nutrientes. De otro lado, al comparar cuencas con cobertura mixta (bosque, sub páramo y pastos) en Ecuador entre los 1800 y 3250 m s.n.m., Crespo et al. (2012) registraron que el caudal se correlacionaba con $\mathrm{Al}$ y $\mathrm{Na}$, mientras que esta relación fue variable y menos visible para $\mathrm{Ca}, \mathrm{Mg}$, Mn y K; mientras que al aumentar el caudal, se incrementó la concentración de Al pero disminuyó las de $\mathrm{Na}, \mathrm{Ca}$ y $\mathrm{Mg}$.

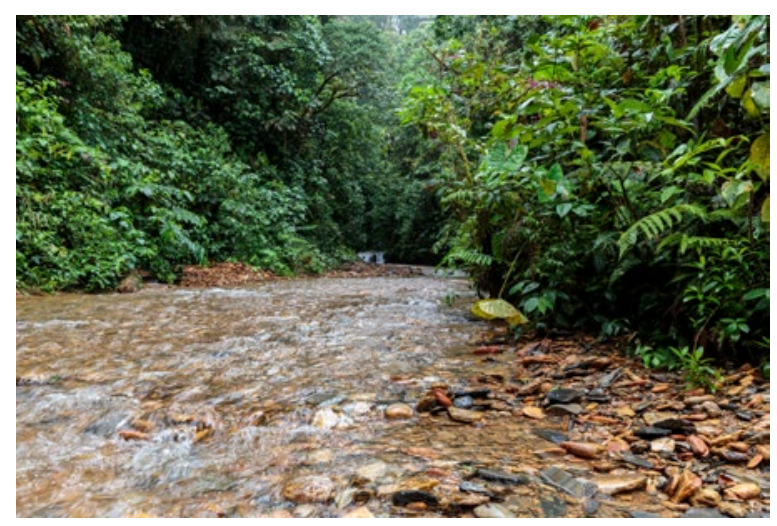

Foto 8. Crédito S. Crespo 


\subsubsection{Páramos comparados con otros usos de la tierra}

\section{a) Provisión hídrica}

\section{a. 1 Los páramos registran mayor intercepción que otros usos de la tierra}

En un estudio llevado a cabo en los páramos aledaños al volcán Pichincha en Quito, Ecuador, entre los 3200 a 4200 m s.n.m, en el cual se simularon eventos de precipitación en cuatro usos de la tierra: un matorral cercano al bosque andino, un área de cultivo (papa y maíz), y dos páramos a alta y media altitud, Janeau et al. (2015) encontraron que las especies del páramo interceptan más precipitación (hasta un $58,8 \%$ ) que los demás usos de la tierra, indicando un nivel de adaptación mayor a las variaciones de precipitación del lugar, por encima de las especies arbustivas en el matorral.

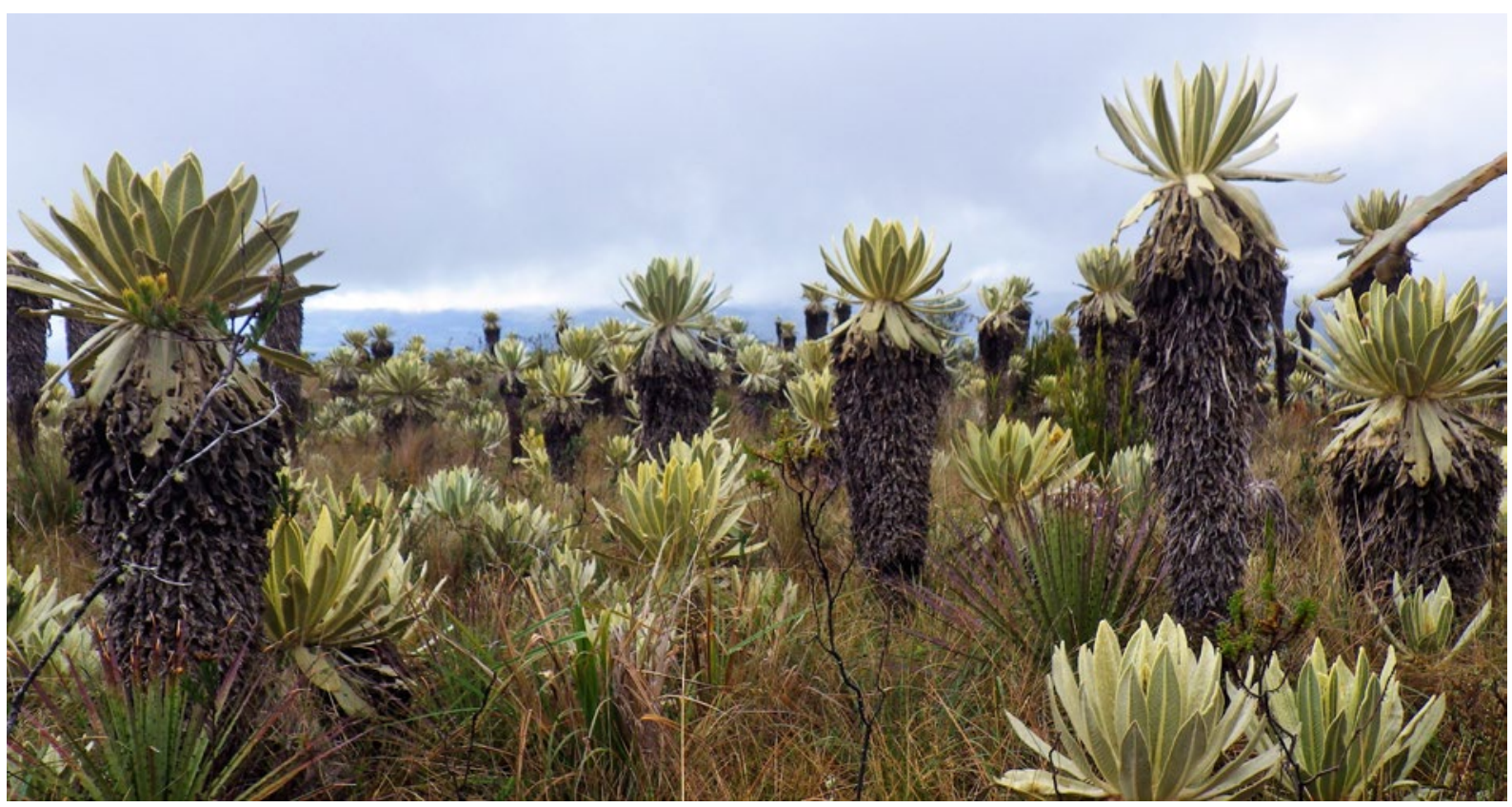

Foto 9. Crédito E. Pinto

\section{a.2 Los páramos a menor altitud registran mayor evapotranspiración que áreas de cultivos, pastizales y páramos a mayor altitud}

Buytaert et al. (2007) al comparar microcuencas en Ecuador entre los 2980 y 4100 m s.n.m., dos con páramo a diferentes alturas y otra con pastoreo intensivo y áreas de cultivo, encontraron que la evapotranspiración del páramo a menor altitud fue del $51 \%$ de la precipitación $(522 \mathrm{~mm} /$ año), seguido del área de cultivo y pastoreo (38\%, 395 mm/año) y por el páramo a mayor altitud $(27 \%$ y $353 \mathrm{~mm})$. La diferencia entre las dos zonas de páramos se atribuyó a la mayor temperatura, la menor cobertura de nubes y la menor intensidad de precipitación en la zona más baja, lo cual favoreció la intercepción.

\section{a.3 Los páramos registran diferencias de flujo caulinar por la altitud e intensidad de la lluvia}

Al comparar en Ecuador, entre los 3200 y 4200 m s.n.m, especies arbustivas del páramo y un área de cultivo (maíz y papa), Janeau et al. (2015) registraron que las especies del páramo 
conducen más agua de lluvia, principalmente a través del flujo caulinar (hasta un 50\%), siendo más eficiente en zonas de mayor altitud
(3800-4200) cuando la intensidad de lluvia es baja, mientras que lo opuesto sucedió en las zonas de menor altitud (3200-3800).

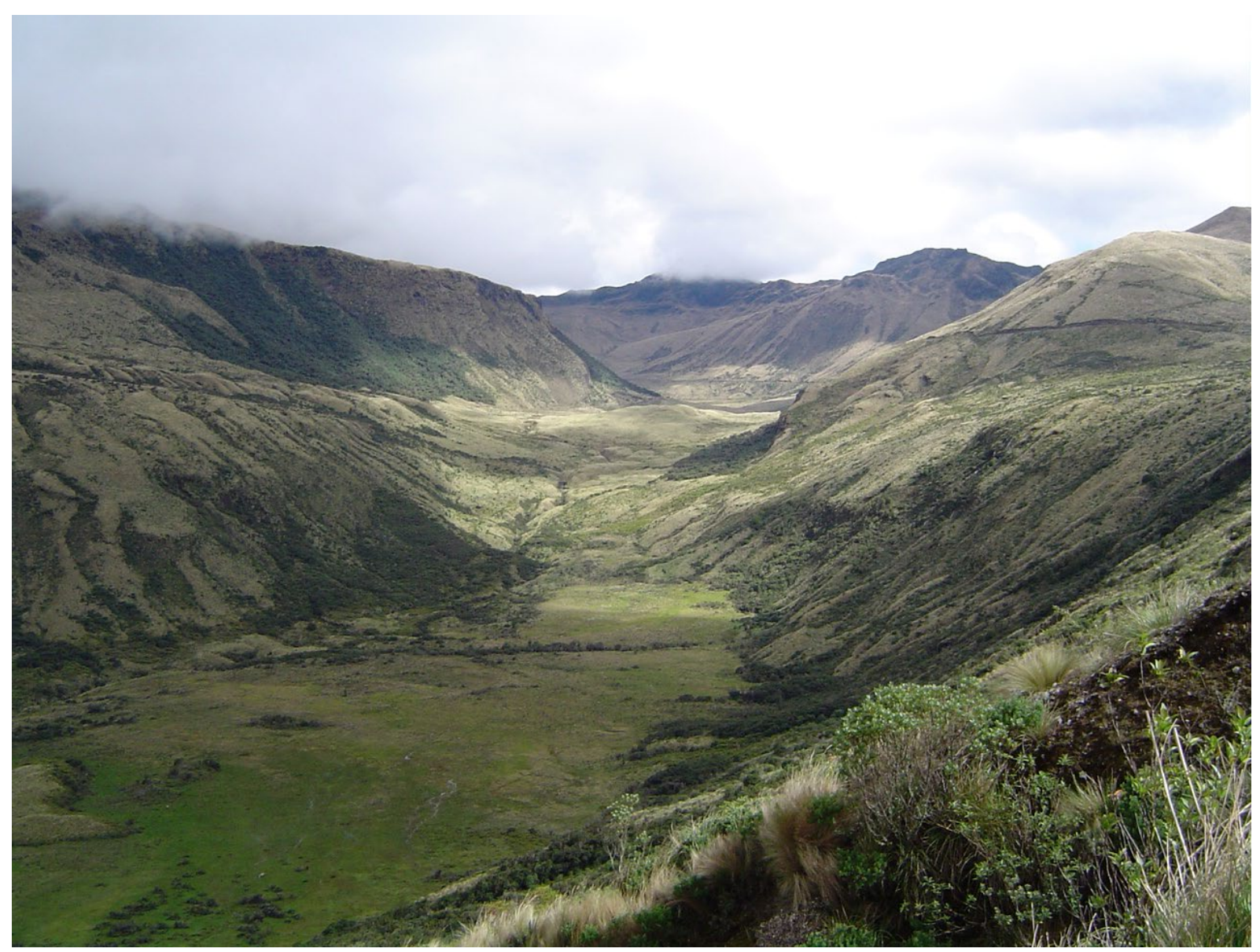

Foto 10. Crédito M. Peralvo

\section{b) Regulación hídrica}

\section{b. 1 Los páramos registran un mayor flujo base y un menor flujo máximo que las áreas de cultivo}

Empleando un enfoque de cuencas pareadas, Buytaert et al. (2005) compararon la respuesta hidrológica de un páramo natural y una microcuenca con áreas de cultivo, observándose un cambio significativo en el régimen hidrológico, con una fuerte reducción del flujo base (hasta $50 \%)$ y un aumento en el flujo máximo (20\%) en la microcuenca con cultivos. De igual manera, un análisis de las curvas de duración del flujo indicó una pérdida del $40 \%$ en la capacidad de regulación en el área de cultivos.

\section{b.2 Los páramos registran una mayor retención hídrica que las plantaciones con exóticas}

Al comparar páramos y áreas forestadas con pino (Pinus radiata y P. patula) en Ecuador entre los 3299 y 3625 m s.n.m, Harden et al. (2013) registraron que la vegetación del páramo redujo la tasa de movimiento del agua en el suelo debido a las raíces uniformes, densas y finas 
(<2 mm de diámetro) que se extienden a través de los horizontes. En contraste, las plantaciones de pino alteraron las propiedades del suelo al presentar raíces más grandes, leñosas, espacialmente no uniformes, y concentradas en el perfil superior del suelo, que al profundizar facilitaron el rápido movimiento del agua. De manera similar, Farley et al. (2004) registraron en la provincia de Cotopaxi, Ecuador, entre los 3000 y 3800 m s.n.m., que la introducción de pino en páramos influyó en la capacidad de retención de agua de los suelos, hallando que los contenidos de agua son más altos en los páramos y decrecientes en rodales de pino (Pinus radiata) sucesivamente más viejos (20-25 años), lo que podría deberse a la disminución de materia orgánica del suelo, especialmente en el horizonte $A$.

\section{b.3 Los páramos registran mayor regulación hídrica que otros usos de la tierra}

Célleri et al. (2004) y Buytaert et al. (2007)

hallaron que la regulación hídrica en las microcuencas con páramos es mayor que otros usos de la tierra, explicado por las mejores propiedades físicas y químicas del suelo, la tasa de evapotranspiración y la estacionalidad de la precipitación en las áreas de páramos evaluadas (Buytaert et al. 2006). De forma similar, en las cuencas de los ríos Paute y Jubones en Ecuador, entre los 2900 y 3960 m s.n.m., Crespo et al. (2010) encontraron, al comparar tres trayectorias de uso del suelo sobre los páramos en siete microcuencas, incluyendo plantaciones de pino (Pinus radiata), pastoreo extensivo con quema anual, y pastoreo intensivo con cultivos de papa, que la plantación redujo el rendimiento hídrico por incremento de la evapotranspiración (cerca del $50 \%$ ), los cultivos con pastoreo intensivo afectaron la regulación al incrementar el flujo pico y reducir el flujo base por la compactación de suelos y la construcción de canales artificiales, mientras que el pastoreo extensivo no generó impactos significativos, afectando el rendimiento hídrico hasta en un $15 \%$.

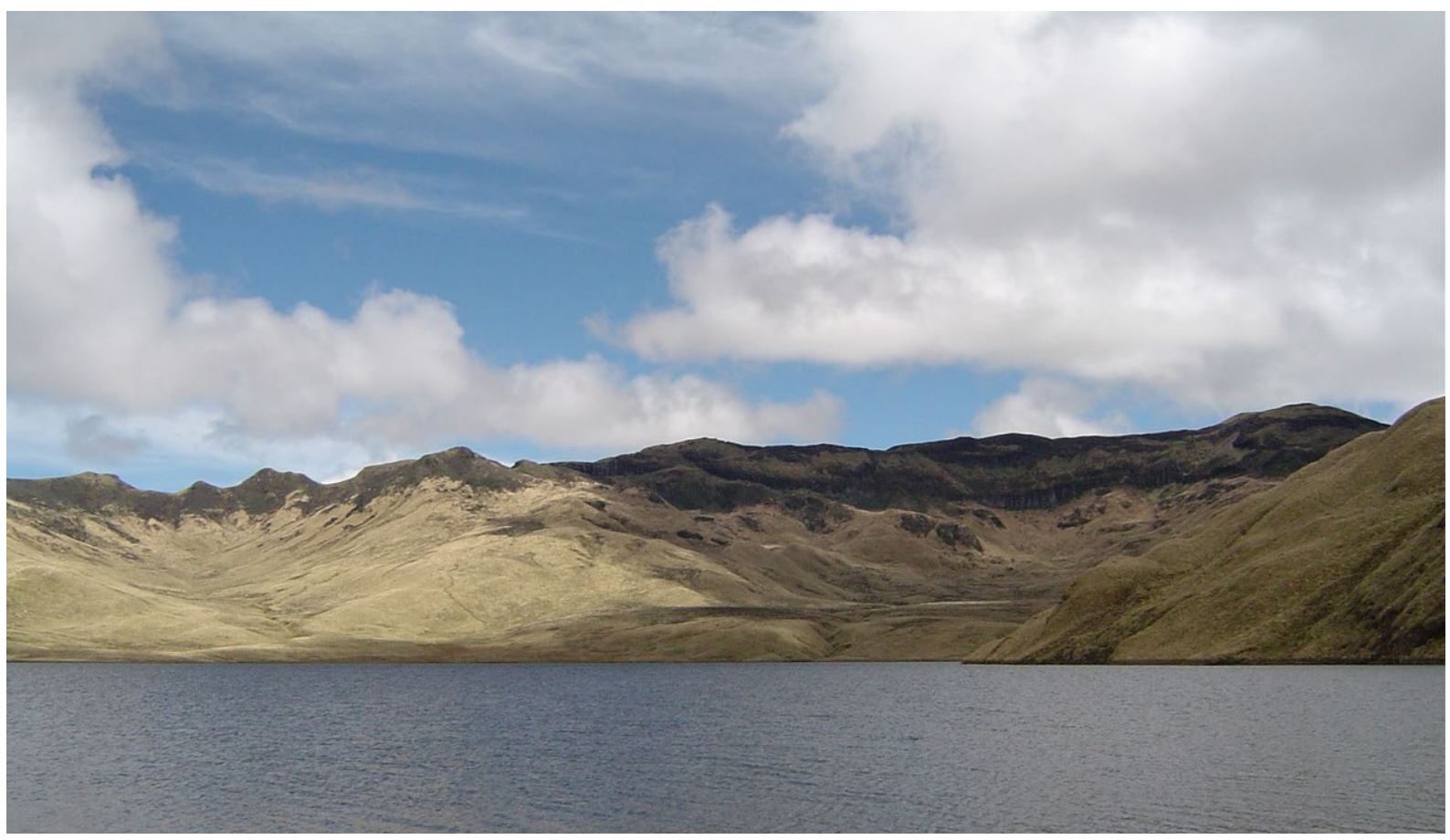

Foto I I. Crédito M. Peralvo 


\section{HALLAZGOS EN OTROS ECOSISTEMAS DE MONTAÑA}

\section{El cambio de uso de páramos a áreas de cultivo disminuye la capacidad de retención} hídrica del suelo

En otros estudios en ecosistemas de montaña, Célleri y Feyen (2009) citan hallazgos de Buytaert et al. (2002) y Poulenard et al. (2004), quienes indican que la conversión de páramo a áreas de cultivo incrementó la exposición directa de los suelos Andosoles oscuros a la luz solar, provocando el secado, contracción y repelencia del suelo al agua, causando una disminución de la retención hídrica hasta un $40 \%$. Adicionalmente, Díaz y Paz (2002) hallaron reducciones en el contenido de agua en saturación y punto de marchitez de 100 y $77 \%$ a 85 y $63 \%$, respectivamente.

\section{c) Provisión de agua de calidad}

\section{c. 1 El cambio de cobertura de páramos a áreas forestadas no registra diferencias en ciertos parámetros de calidad del agua}

Aichholzer y Durán (2010) al evaluar en Ecuador entre los 2900 y $3700 \mathrm{~m}$ s.n.m el efecto de las plantaciones de pino (Pinus patula) en páramos, determinaron que no hubo diferencias en el $\mathrm{pH}$, la conductividad eléctrica y la turbidez del agua.

\subsubsection{Agroforestería comparados con otros usos de la tierra}

\section{a) Provisión hídrica}

\section{a.1 Los sistemas agroforestales con café (SAF café) presentan menor intercepción que los bosques y mayor intercepción en relación a monocultivos de café}

Al comparar cuatro SAF café, un bosque secundario y dos monocultivos de café en Quindío, Colombia entre 1250 y 1310 m s.n.m., se registró que la intercepción varió entre $46 \%$ y $59 \%$ de la precipitación total, con los valores más altos en el bosque (59\%) y en las parcelas de SAF café asociado con Inga sp. (58\%) y Cordia alliodora (56\%), seguidos de SAF café asociado con Pinus oocarpa (52\%), Eucalyptus grandis (51\%), y monocultivos de café (49 y $46 \%$ ), los altos valores registrados en cafetales se debieron a la alta densidad de los individuos de café y de los árboles asociados (Jaramillo-Robledo 2003). Asimismo, al comparar en Venezuela entre 1700 y 2300 m s.n.m. un bosque nublado, un bosque siempreverde seco y un SAF café asociado con Inga oesrtediana, se registraron valores de interceptación de $45 \%$ de la precipitación total para el bosque nublado, $27 \%$ para el bosque siempreverde seco, y $21 \%$ para el SAF café, posiblemente debido a la mayor hetereogeneidad estructural del dosel en el bosque (Ataroff 2002). Por último, Arroyave (2012) al evaluar tres SAF café en Quindío, Colombia a 1203 m s.n.m., encontró que el SAF café asociado con Pinus oocarpa registró el mayor valor de intercepción (24,7\% de la precipitación total) debido a su mayor área foliar y menor albedo, seguido de lejos por el SAF café asociado con Eucalyptus grandis (8,6\%), con Cordia alliodora (7,8\%), y el monocultivo de café, que obtuvo el menor valor.

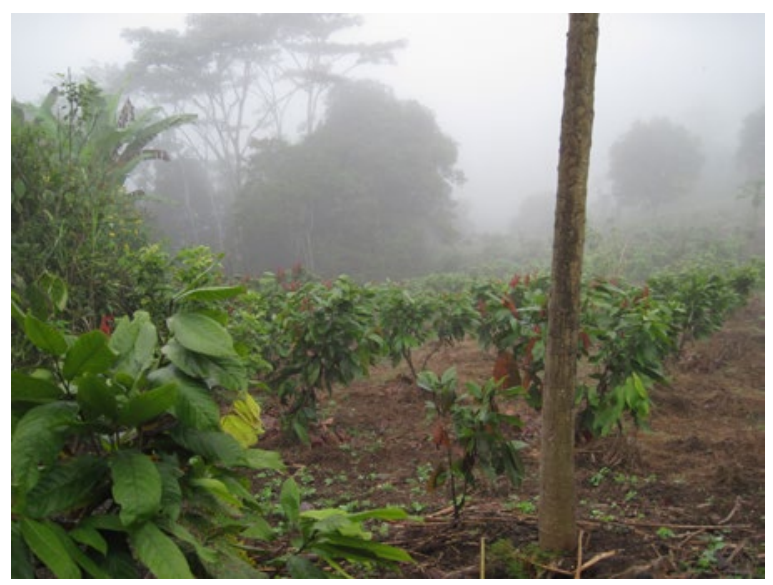

Foto I 2. Crédito C. Suárez 


\title{
HALLAZGOS EN OTROS ECOSISTEMAS DE MONTAÑA
}

\section{Las diferencias en la evapotranspiración entre sistemas agroforestales y otros usos de} la tierra no son claras

\begin{abstract}
Las diferencias de valores encontrados para evapotranspiración en los estudios antes mencionados son recogidos de manera general por el estudio desarrollado para Latinoamérica y la isla de Hawai por Ponette-González et al. (2014), quienes resaltaron que aunque en promedio hay una reducción del $1 \%$ en la evapotranspiración de sistemas agroforestales a otros usos diferentes del bosque, en realidad las diferencias no son claras, ya que en algunos casos se incrementa entre $1 \%$ y $7 \%$ y en otros se reduce entre $2 \%$ y $7 \%$.
\end{abstract}

\section{a.2 Los SAF café no registran diferencias significativas de precipitación neta en comparación con monocultivos de café}

Al comparar tres SAF café y un monocultivo de café en Quindío, Colombia a 1203 m s.n.m no se registraron diferencias significativas en la precipitación neta; sin embargo, se encontraron ciertas tendencias, siendo el monocultivo de café el que presentó mayor precipitación neta con $105,9 \%$ de la precipitación total, comparado al $92,2 \%$ registrado por el SAF café asociado con nogal (Cordia alliodora), seguido por el SAF café con eucalipto (Eucalyptus grandis) con $91,4 \%$ y por último el SAF café asociado con pino (Pinus oocarpa) con $75,5 \%$. Los resultados encontrados en el monocultivo de café fueron probablemente influenciados por la frecuencia de nieblas en la parte baja de la zona evaluada durante horas de la mañana, donde la humedad es más alta sobre las hojas del café. De otro lado, los resultados obtenidos en el caso del café con pino pueden tener relación con la mayor área foliar del pino, que posee una mayor superficie de evaporación y menor albedo, y por consiguiente, una mayor capacidad de intercepción del agua, mayor disponibilidad de energía solar para la evaporación y un mayor consumo de agua en comparación con las especies latifoliadas (Arroyave 2012).

\section{a.3 Los SAF café registran menor flujo de caída que monocultivos de café y bosque secundario, y sus valores son influenciados por las características del dosel}

Gaitán et al. (2016) realizaron un estudio en Cauca, Colombia entre 1340 y 1430 m s.n.m., registrando un menor flujo de caída en el SAF café en comparación con un monocultivo de café y un bosque secundario, a pesar que este último presentó una mayor densidad de tallos y una mayor cobertura de copas. Asimismo, en el SAF café se observó una alta variabilidad del flujo de caída, que no fue el caso para el bosque secundario ya que éste presentó una estructura natural y aleatoriamente distribuida que se asemeja a un bosque adulto. De otro lado, en los SAF café, el flujo de caída fue significativamente mayor por debajo del mango (Mangifera indica) con un promedio de $63,1 \%$ de la precipitación total en comparación con Inga spp. con 39,1\% lo cual se puede atribuir a su menor extensión de ramas y a una superficie foliar bastante lisa, parámetros estructurales de la planta antes que factores vinculados a la lluvia. La tendencia a incrementar el flujo de caída con el incremento de la intensidad de lluvia solo fue registrada en el caso del bosque secundario donde un evento de lluvia en el rango de 20-30 mm/día contribuyó al $60,7 \%$ en el flujo de caída. 


\section{b) Regulación hídrica}

\section{b. 1 Los SAF café registran una mayor escorrentía que monocultivos de café}

En un primer caso, Arellano (2001) comparó en la subcuenca del río Castán en Venezuela, la escorrentía superficial en tres sistemas de cultivos del café, uno (variedad caturra fruto rojo) asociado principalmente con Inga sp., otro (caturra fruto amarillo) asociado con frutales (Citrus cinensis), y un último (caturra fruto rojo) en monocultivo, todos con deshierbe dos o tres veces al año. Se registraron valores de escorrentía que variaron entre $0,58 \%$ y $2,59 \%$ de la precipitación total, valores que difieren en función a las actividades de manejo (abono, deshierbe, cosecha y sin intervención). Sin embargo, a pesar de las diferencias registradas, se presentó una tendencia recurrente de mayor escorrentía en el SAF café con frutales, seguido por el SAF café con Inga sp, y finalmente monocultivo de café. En un segundo caso, Arroyave (2012) al comparar en Quindío,
Colombia cuatro sistemas con café registró que el SAF café asociado con Pinus oocarpa obtuvo el mayor valor de escorrentía con $8,89 \%$ de la precipitación total, seguido por el SAF café asociado con Cordia alliodora (5,61\%), SAF café asociado con Eucalyptus grandis (5,51\%), y por último, el monocucltivo de café $(4,11 \%)$, resultado que habría sido influenciado por la pendiente del terreno y la cobertura vegetal del suelo.

Por último, Jaramillo-Robledo (2003) al comparar en Quindío, Colombia entre 1250 y 1310 m s.n.m. seis sistemas de café y un bosque secundario registró un valor promedio de escorrentía superficial de $6 \%$ de la precipitación total, con picos en las parcelas de SAF café con nogal y eucalipto (8\%), seguidos por el SAF café con pino $(7 \%)$, el monocultivo de café en ambas locaciones (6\%), el bosque secundario $(5 \%)$ y el SAF café con guamo ( $4 \%)$, valores explicados por las altas tasas de infiltración y las reducidas pendientes (menores al 10\%).

\section{HALLAZGOS EN OTROS ECOSISTEMAS DE MONTAÑA}

\section{No existen diferencias significativas de escorrentía superficial entre SAF café y} bosques secundarios

Los resultados hallados por Jaramillo-Robledo (2003) fueron respaldados por Bellanger et al. (2004), quienes al comparar transiciones entre SAF café y ecosistemas no boscosos en altas elevaciones en Latinoamérica no encontraron diferencias en la escorrentía superficial, excepto en un caso en el cual fue $19 \%$ en un campo descubierto; asimismo, PonetteGonzález et al. (2014) determinaron que no existían diferencias de escorrentía superficial cuando se daba un cambio de uso de bosque a sistemas agroforestales.

\section{b. 2 Los SAF café no registran diferencias significativas de infiltración en comparación con monocultivos de café}

Al cuantificar la infiltración en SAF café y monocultivos de café en Quindío, Colombia a 1203 m s.n.m, Arroyave (2012) no registró diferencias significativas entre los sistemas de café, lo cual puede deberse a que todas las parcelas estaban ubicadas en el mismo tipo de suelo, con textura franco arenosa, materia orgánica entre el $3 \%$ y $5 \%$, similar profundidad del suelo, y entre media y baja retención de humedad. Sin embargo, se registaron algunas tendencias, siendo el monocultivo de café el que registró el mayor valor de infiltración con $96,11 \%$ de la precipitación neta, seguido de SAF café asociado con Cordia alliodora (95,42\%), 
SAF café asociado con Eucalyptus grandis $(93,62 \%)$ y por último el SAF café asociado con Pinus oocarpa (88,18\%). En el caso del SAF café con pino, puede deberse a la estructura y disposición de las acículas que favorecen la escorrentía y dificultan la infiltración, así como a las características de la cutícula hidrófoba, que rechaza la acumulación en la hojarasca. De otro lado, la mayor infiltración en los SAF café con Eucalyptus grandis y Cordia alliodora puede deberse al diseño de las hojas de estas especies, las cuales pueden concentrar mayor cantidad de agua en la hojarasca que no se pierde por escorrentía, sino se dirige a las capas inferiores del suelo.

\section{b.3 Los SAF café manejados y en estado de abandono registran menor infiltración inicial que monocultivos de cítricos y valores similares en relación a un área forestada}

Al realizar un estudio en Junín, Perú entre 900 y $1500 \mathrm{~m}$ s.n.m. para determinar la influencia de cuatro usos de la tierra en la infiltración inicial, Reyes (2014) encontró que la lámina infiltrada fue mayor en el cultivo de cítricos (Citrus sinensis y C. reticulata) con 4,8 mm en comparación con los otros usos: SAF café manejado, SAF café en estado de abandono (ambos con Coffea arabica e Inga sp.) y la plantación de teca (Tectona grandis) cuyos valores fueron similares y oscilaron entre 4,3 y $4,4 \mathrm{~mm}$. Los resultados obtenidos en los cítricos pueden atribuirse al mayor valor de porosidad y bajo contenido de humedad de sus suelos. Con respecto a la infiltración inicial (llamada también sortividad) se registraron los siguientes valores en función al estrato, en el caso del estrato escarpado (31-60\% pendiente) la plantación de teca presentó el mayor valor con una media de $0,4206 \mathrm{~mm} / \mathrm{seg}^{1 / 2}$ debido a su abundante cantidad de hojarasca en comparación con el SAF café en estado de abandono que presentó menor valor promedio $\left(0,4088 \mathrm{~mm} / \mathrm{seg}^{1 / 2}\right)$ debido a que la cobertura vegetal que posee fue menos abundante y que las condiciones del suelo fueron menos propicias para la captación de agua. De otro lado, en el caso del estrato fuertemente inclinado $(10-15 \%$ pendiente) el monocultivo de cítricos presentó el mayor valor promedio con $0,4882 \mathrm{~mm} / \mathrm{seg}^{1 / 2}$ debido al mantenimiento constante del suelo, traduciéndose éste en su alto porcentaje de porosidad, permitiendo que el agua ingrese más fácilmente; asimismo, el SAF café manejado presentó un valor promedio de $0,3871 \mathrm{~mm} / \mathrm{seg}^{1 / 2}$ a pesar de contar con un alto contenido de materia orgánica, lo cual puede deberse a que el mantenimiento del suelo fue escaso.

\section{HALLAZGOS EN OTROS ECOSISTEMAS DE MONTAÑA}

Los SAF café registran tendencias variables de infiltración en relación a bosques y áreas de cultivo

En relación a los resultados obtenidos por los estudios anteriores, llstedt et al. (2007) mencionaron que en los trópicos, la agroforestería genera una mayor capacidad de infiltración, ya que el sombreado y la hojarasca bajo los árboles, junto con un flujo más preferencial pueden reducir aún más las pérdidas por evaporación del suelo; sin embargo, a pesar que las plantaciones y los sistemas agroforestales no presentaron diferencias significativas, registraron una tendencia de la agroforestería a exhibir valores más bajos de infiltración en comparación con las áreas forestadas. 


\begin{abstract}
Un nuevo paradigma propone la existencia de un óptimo de cobertura arbórea intermedia en la cual se maximiza la recarga de agua subterránea, y por lo tanto, el flujo en la estación seca
\end{abstract}

Ilstedt et al. (2016) al realizar un estudio en África, encontraron que en zonas degradadas, una cobertura arbórea intermedia puede maximizar la recarga de aguas subterráneas, permitiendo una mayor infiltración, al mismo tiempo que la evapotranspiración y la intercepción son moderadas. Sin embargo, generalizar tal suposición es problemático pues el flujo depende en gran medida del tipo y la profundidad del suelo, y las características locales de la topografía y la precipitación (Bruijnzeel 2004). Al respecto, Gyenge et al. (2008) registraron en parcelas ubicadas en Patagonia, Argentina entre los 600 y 3776 m s.n.m. que un sistema silvopastoril con pino (Pinus ponderosa) no afectó el contenido de agua superficial en comparación con los pastizales, excepto después de pequeños eventos de lluvia. Asimismo, durante el verano, había menos agua disponible en las capas profundas del suelo en parcelas boscosas en comparación con los pastizales, lo cual indica un uso diferencial del agua de las reservas profundas de los árboles en comparación con la vegetación nativa del sitio estudiado. Este conocimiento podría aplicarse en áreas degradadas de los Andes tropicales, principalmente en la época de estiaje, y tomando en cuenta las condiciones del sitio.

\section{c) Provisión de agua de calidad}

\section{c. 1 Los SAF café, monocultivos de café y bosques secundarios registran dinámicas complejas de nutrientes al atravesar el dosel}

En un primer caso, Arroyave (2012) al evaluar la concentración de nutrientes en tres SAF café y un monocultivo de café en Quindío, Colombia a 1203 m s.n.m., registró de manera general un aumento en la concentración de los nutrientes ( $\mathrm{K}, \mathrm{Ca}, \mathrm{Mg}$ y $\mathrm{P}$ ) al atravesar el dosel como producto del lavado de la deposición atmosférica, de la deposición seca o la exudación o excreción de elementos por las hojas o en los procesos de senescencia, o a factores de manejo de los sistemas productivos en la zona, como fertilización, quema de leña para consumo doméstico o vientos con arrastre de polvillo enriquecido. Asimismo, encontró que el SAF café asociado con nogal presentó la mayor concentración de $\mathrm{P}, \mathrm{Mg}$ y Ca después de atravesar la hojarasca en comparación con los otros sistemas de café, siendo el SAF café asociado con pino el sistema que obtuvo la menor cantidad de nutrientes por debajo de la capa de hojarasca. De otro lado, solamente el K se presentó en mayor cantidad y concentración en el monocultivo de café presentó la mayor cantidad y concentración de $\mathrm{K}$, que proviene de la precipitación total y de las hojas del café, y se infiltra una vez que llega al suelo. Esto es explicado por la composición y producción de biomasa de las especies forestales.

En otro caso, Jaramillo-Robledo (2003) al comparar en Quindío, Colombia entre 1250 y 1310 m s.n.m. seis sistemas de café y un bosque secundario registró un incremento de $\mathrm{K}$ al atravesar la parte aérea en todos los sistemas evaluados; asimismo, el bosque secundario registró la mayor concentración de K, Ca y Mg en comparación con los otros sistemas de café y los menores valores de estos nutrientes fueron registrados por los SAF café con pino y eucalipto. Cabe resaltar que las cantidades de $\mathrm{K}$, Ca y Mg son superiores a las registradas en las entradas de agua (precipitación total) solo en el bosque secundario y SAF café asociado con 
nogal y en el caso de los monocultivos de café, la concentración de $\mathrm{Ca}, \mathrm{Mg}$ y nitratos fueron menores a las registradas en la precipitación total. Las variaciones en la concentración de los nutrientes obtenidos en los diferentes sistemas evaluados esta directamente relacionado con la cobertura aérea, ya que éstas difieren significativamente en la composición de la biomasa.

\section{HALLAZGOS EN OTROS ECOSISTEMAS DE MONTAÑA \\ La conversión de SAF café a otros sistemas no forestales influye en la concentración de $\mathrm{NO}_{3}$}

En nuestra búsqueda no se hallaron estudios experimentales que determinaran el efecto del cambio de SAF café a otros sistemas no forestales en relación a la concentración de $\mathrm{NO}_{3}$; sin embargo, estudios realizados en otras zonas podrían ser utilizadas como referencia para los Andes tropicales. En relación a ello, Ponette-González et al. (2014) indicaron que la conversión de un SAF café a otros sistemas no forestales causó un aumento neto de $51 \%$ en la entrega de $\mathrm{NO}_{3}$ al suelo. Asimismo, Harmand et al. (2007) al comparar un SAF café y monocultivos de café bajo niveles similares de fertilización, encontraron que este último registró las tasas más altas de lixiviación.

\subsection{4 Áreas forestadas comparadas con otros usos de la tierra}

\section{a) Provisión hídrica}

\section{a.1 Las áreas forestadas reducen la provisión hídrica en la mayoría de casos}

En un estudio de 25 cuencas en Ecuador, Perú y Bolivia, el cual analizó el impacto de las plantaciones, el pastoreo y la agricultura sobre áreas con puna, jalca, páramo y bosques (OchoaTocachi et al. 2016b), se registró una reducción en el rendimiento hídrico de más del $50 \%$ en las áreas con plantaciones de pino (Pinus sp.) con respecto a los páramos, afectando tanto la media como el flujo base. De forma similar, Ochoa-Tocachi et al. (2016a) observaron en un estudio de 24 cuencas, que la presencia de cobertura vegetal de mayor altura (incluyendo plantaciones), así como la ganadería, redujeron el rendimiento hídrico. En otros estudios de menor escala también se reportaron reducciones del rendimiento hídrico cercanas al $50 \%$ en microcuencas con plantaciones de pino (Pinus patula y $P$. radiata), en comparación con otras con páramos y otros usos como el pastoreo y la agricultura (Buytaert et al. 2007, Crespo et al. 2010, Célleri et al. 2004). Otros estudios no hallaron tendencias claras. En dos evaluaciones se comparó la respuesta hídrica de microcuencas a períodos de deforestación, recuperación y forestación ocurridos entre 1974 y 2008 (Molina et al. 2012, 2015), no hallándose tendencias significativas por la instalación de plantaciones de especies exóticas, aunque sí se establece que la deforestación de bosques nativos incrementó el caudal medio y el flujo base. 


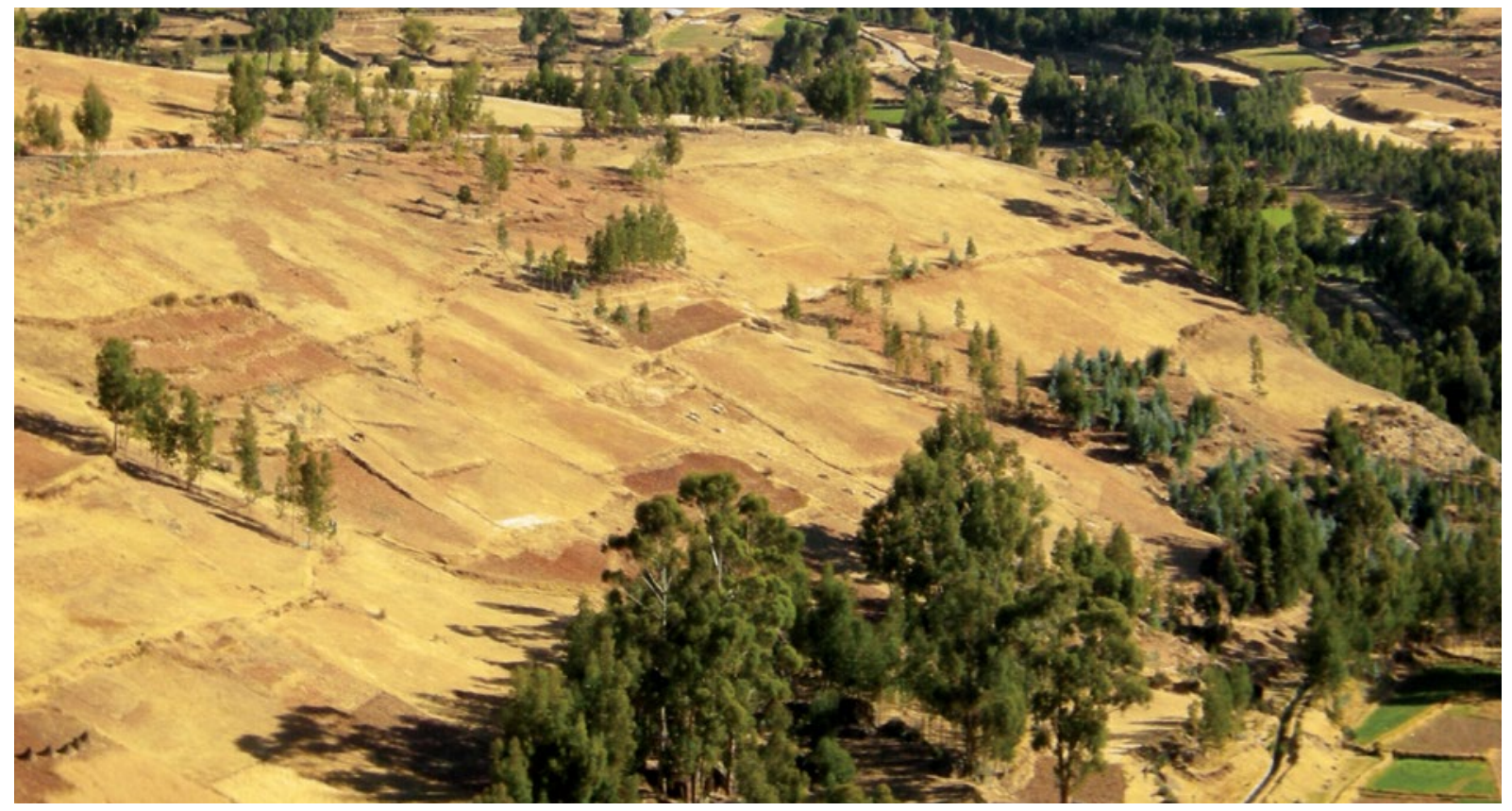

Foto I 3. Crédito SL Mathez

\section{HALLAZGOS EN OTROS ECOSISTEMAS DE MONTAÑA}

Las áreas forestadas reducen la provisión hídrica al compararla con bosques nativos, pero el efecto es atenuado por el manejo forestal

Los resultados registrados previamente coinciden con lo hallado por Hirsch et al. (2011), quienes encontraron que el reemplazo de especies coníferas como el pino por especies caducifolias mejoró el rendimiento hídrico dado la reducida transpiración e intercepción, y la mayor tasa de infiltración. De manera similar, Oyarzún et al.(2012) y Lara et al. (2009) registraron en Chile mayores caudales en bosques nativos que en plantaciones de Pinus radiata, Eucalyptus globulus y E. nitens, aunque el efecto de estas especies fue atenuado por raleos y podas de hasta el $40 \%$ del área basal total.

\section{a.2 Las plantaciones con especies exóticas interceptan menos que los bosques nativos}

Según un estudio desarrollado entre los 3000 y 3600 m s.n.m. (García 2007), en las plantaciones de eucalipto (Eucalyptus globulus) y ciprés (Cupressus lusitánica) se interceptó menos cantidad de agua de lluvia que en el bosque nativo cercano (34 y $47 \%$ vs. $52 \%$, respectivamente). Otro estudio registró una intercepción del $42 \%$ en una plantación de pino laso (Retrophyllum rospigliosii) y de $52 \%$ en un bosque de selva nublada; mientras que en un bosque siempreverde seco se obtuvo un valor de $27 \%$, posiblemente debido a la menor complejidad de su dosel (Ataroff 2002). No obstante, estas diferencias no se reflejaron claramente en la precipitación neta según un estudio de De las Salas y García (2000), quienes identificaron porcentajes de 46 y $80 \%$ en plantaciones de ciprés (Cupressus sp.) y eucalipto (Eucalyptus globulus), y de $72 \%$ para un bosque montano nativo. De otro lado, apenas un $0,8 \%$ 
de la precipitación neta llegó al suelo vía el flujo caulinar, no hallándose diferencias entre los usos de la tierra, pero dependiendo de la ramificación y la cantidad de árboles que alcanzan el dosel superior (De las Salas y García 2000, León et al. 2010, Hölscher et al. 2003).

\section{HALLAZGOS EN OTROS ECOSISTEMAS DE MONTAÑA}

Las áreas forestadas registran una precipitación neta mayor que los bosques nativos

Comparando una plantación de pino (Pinus ponderosa) y un bosque nativo de ciprés (Austrocedrus chilensis) en Argentina, y una plantación de eucalipto (Eucalyptus sp.) con un bosque nativo en Brasil, se encontró que la precipitación neta fue consistentemente mayor en las plantaciones (Licata et al. 2011, Salemi et al. 2013). En relación a esto, se registraron flujos caulinares de hasta $13,1 \%$ en plantaciones de pino (Crockford y Richardson 1990), explicado por la arquitectura de ramas y hojas, y por la intensidad y ángulo de la precipitación (Crockford y Richardson 2000).

\section{a.3 No existen diferencias claras en relación a la evapotranspiración entre plantaciones con especies exóticas y otros usos de la tierra}

Una plantación de pino (Pinus patula) obtuvo un porcentaje de evapotranspiración mucho mayor $(81 \%)$ que dos áreas de páramo y otra con cultivos y pastoreo (27 y $51 \%)$, en un área de cuatro microcuencas entre los 2980 y $4100 \mathrm{~m}$ s.n.m. (Buytaert et al. 2007); mientras que en otro estudio, una plantación de eucalipto (Eucalyptus urophylla) evapotranspiró entre 2,4 y 1,9 veces menos que una sabana durante el día y la noche, respectivamente, explicado por el mayor índice de área foliar de Trachypogon vestitus, presente en la sabana (Herrera et al. 2012).

\section{HALLAZGOS EN OTROS ECOSISTEMAS DE MONTAÑA}

\section{Las áreas forestadas registran altas tasas de evapotranspiración}

En otros estudios sí se hallaron diferencias en la evapotranspiración, registrándose mayores valores en plantaciones. Oyarzún et al. (2012) encontraron que una plantación de Eucalyptus globulus presentó una mayor tasa de transpiración y menor eficiencia de uso del agua que otras especies nativas perennes y caducifolias. De manera similar, Jones et al. (2017) indicaron en una revisión para toda Sudamérica que la evapotranspiración puede llegar al $90 \%$ de la precipitación en plantaciones de eucalipto y pino, valor cercano a lo hallado por Buytaert et al. (2007) en una plantación de pino (Pinus patula) en Ecuador con 81\%. 


\section{b) Regulación hídrica}

\section{b. 1 Las áreas forestadas reducen el flujo base y aumentan el flujo pico en comparación con páramos y bosques nativos, aunque reducen el flujo pico en comparación con áreas degradadas}

Al comparar el efecto de plantaciones con especies exóticas en áreas con páramos, bosques y pastizales en 25 cuencas de Perú y Ecuador, se registró una reducción en el flujo base (Ochoa-Tocachi et al. 2016b), aunque se indicó que otros factores como el régimen de precipitación, el suelo, la geología y la topografía afectaron las respuestas hidrológicas. Para el caso específico del pino (Pinus patula y $P$. radiata), también se determinó su impacto negativo a nivel de microcuencas sobre el flujo base en comparación con bosques nativos y páramos, en parte explicado por el alto consumo de agua por evapotranspiración del pino (Buytaert et al. 2007, Crespo et al. 2010, Célleri et al. 2004). De manera similar, al comparar el impacto de tres coberturas sobre el caudal durante la época de estiaje en una cuenca en Ecuador entre los 2900 y 3700 m s.n.m (Aichholzer y Durán 2010), se registró el menor caudal en la plantación con pino (Pinus patula) con 0,034 l/s/ ha, seguido por el páramo con poca diferencia, y por el bosque nativo, que presentó un promedio tres veces mayor. En esa misma línea, en un estudio en Colombia se registraron mayores flujos pico y menores flujos base en áreas forestadas con eucalipto (Eucalyptus globulus) y ciprés (Cupressus lusitanica) en comparación con un bosque nativo, siendo más pronunciado el efecto en la plantación de pino (García 2007). Por otro lado, otros estudios hallaron que las plantaciones con especies exóticas redujeron el flujo pico en áreas previamente degradadas (Molina et al. 2012, 2015).

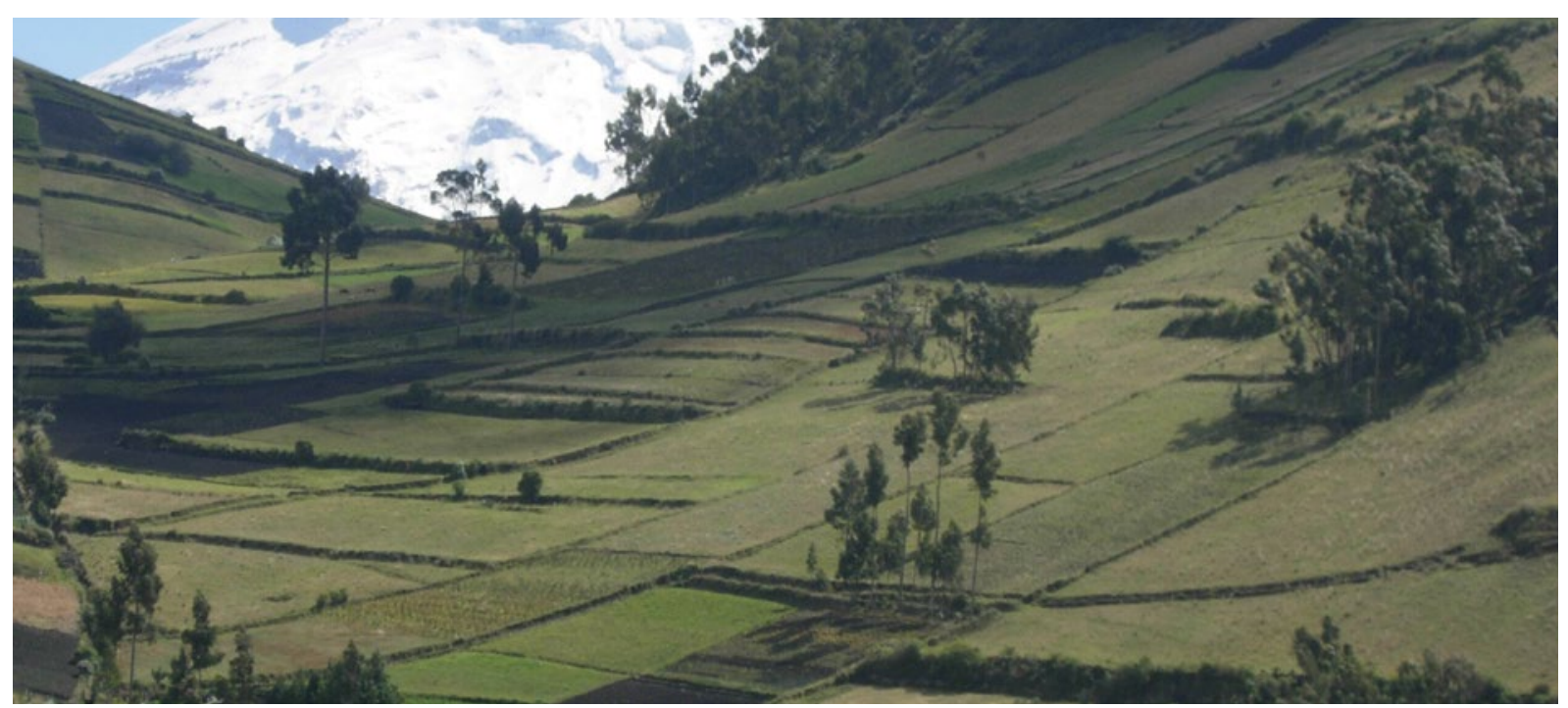

Foto 14. Crédito S.L. Mathez

\section{HALLAZGOS EN OTROS ECOSISTEMAS DE MONTAÑA}

EI manejo forestal puede atenuar el impacto de las áreas forestadas sobre el flujo base

Si bien Oyarzún et al. (2012) y Lara et al. (2009) registraron en Chile mayores caudales en bosques nativos que en plantaciones de Pinus radiata, Eucalyptus globulus y E. nitens, el manejo forestal con podas y raleos redujo el impacto de éstas sobre el flujo base, debido a la reducción de la intercepción y evapotranspiración, que permitía una mayor infiltración. 


\section{b.2 Las áreas forestadas registran menor infiltración y retención hídrica que bosques nativos y páramos, aunque mayor que otros pastizales naturales}

Las áreas con plantaciones tuvieron, en general, menor infiltración y retención hídrica que los bosques nativos, siendo el ciprés la especie con el peor desempeño. En un caso, se registró $46 \%$ de agua almacenada en el espacio capilar en el bosque montano, mientras que en las áreas forestadas con eucalipto (Eucalyptus globulus) y ciprés (Cupressus sp.) registraron un $42 \%$ y $36 \%$ (De las Salas y García 2000). En otro estudio se compararon las mismas coberturas, hallándose una mayor infiltración en el bosque, aunque con una percolación similar entre el bosque y el área forestada con eucalipto $(7,4$ y $8,9 \%$ ) y nula para la forestada con ciprés, debido a que el agua infiltrada quedó retenida en la capa orgánica superior de $20 \mathrm{~cm}$ de profundidad (García 2007). Al incorporar áreas forestadas con pino (Pinus patula) a las comparaciones, se encontró que el ciprés presentó altas y rápidas pérdidas de agua por percolación, lo que si bien redujo el almacenamiento superficial, aportó en la regulación al recargar los acuíferos; mientras que el bosque, en este caso de roble maduro (Quercus humboldtii), presentó mejores tendencias de infiltración y retención, con menor drenaje profundo (León et al. 2010).

Con respecto a la comparación entre áreas forestadas y páramos, se determinó en general un efecto negativo de las plantaciones de pino sobre la retención hídrica. Así, una comparación registró que las áreas forestadas con pino (Pinus radiata y $P$. patula) disminuyen la humedad del suelo y aumentan las tasas de movimiento del agua a través del suelo dado que sus raíces son más grandes, leñosas, espacialmente no uniformes en comparación con la vegetación del páramo, que tiene raíces uniformes, densas y finas ( $<2 \mathrm{~mm}$ de diámetro), incrementando los meso y microporos, reduciendo el movimiento rápido del agua (Harden et al. 2013). Esto fue apoyado por otros estudios, que registraron un contenido de agua mayor en el páramo que en plantaciones de pino (Pinus radiata), con un efecto más marcado conforme aumenta la edad de la plantación (Farley et al. 2004, Célleri et al. 2004). Además, se registró menor infiltración en las plantaciones de pino en comparación con otras coberturas nativas como bosques nativos, de Polylepis, pajonales y matorrales, explicado por la correlación positiva entre la infiltración y el contenido de materia orgánica del suelo (Moreno 2012, Aichholzer y Durán 2010).

De otro lado, se registró una velocidad de infiltración de dos a cuatro veces mayor en áreas forestadas con pino (Pinus radiata) que en pastizales naturales, explicado por la mayor materia orgánica y masa radicular de las plantaciones (Roncal 2006). Resultados similares se encontraron al comparar áreas forestadas con pino y tierras degradadas, lo que puede llevar a emplear plantaciones para recuperar la capacidad de infiltración en áreas erosionadas (Ochoa-Tocachi et al. 2016b).

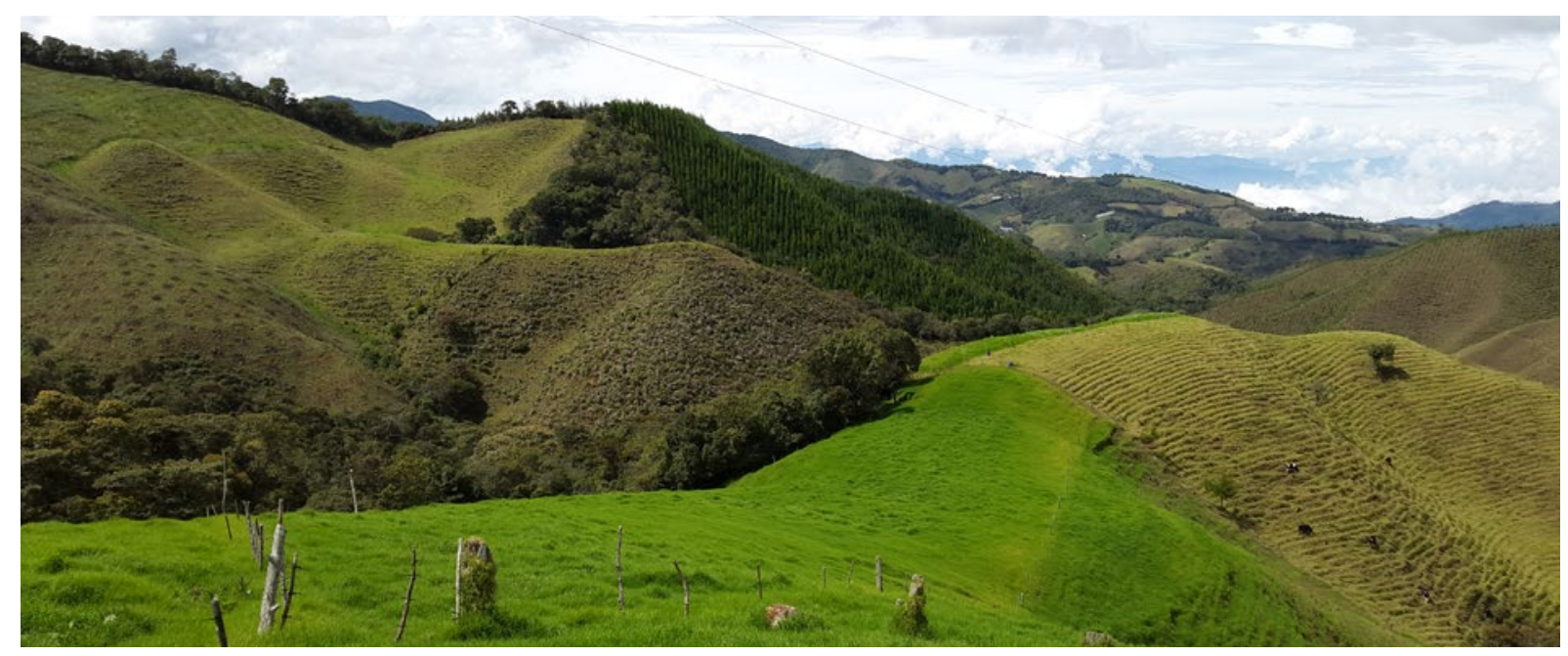

Foto I5. Crédito M. Peralvo 


\section{DISCUSIONES EN BASE A HALLAZGOS EN OTROS ECOSISTEMAS DE MONTAÑA}

Las áreas forestadas generan menos infiltración y retención hídrica que bosques y páramos, pero aportan en la recuperación de áreas degradadas

No obstante lo hallado en nuestra revisión, llstedt et al. (2007) y van Dijk y Keenan (2007) indicaron que la forestación en paisajes degradados puede mejorar la infiltración solo si los suelos son lo suficientemente resistentes, pues puede haber una mayor degradación en los suelos más antiguos, según el método de establecimiento del árbol (Walker y Reddell 2006). Cabe indicar además que de manera similar a lo hallado para la provisión hídrica, las podas y raleos pueden reducir el efecto perjudicial de las plantaciones sobre la percolación, como lo hallado por Huber y Trecaman (2004) en una plantación de pino (P. radiata), ya que se reduce las pérdidas de lluvia por evapotranspiración.

\section{b.3 Las áreas forestadas registran similares escorrentías superficiales en comparación con bosques nativos, y menores en comparación con pastizales para ganadería}

En comparaciones entre bosques nativos, plantaciones de eucalipto (Eucalyptus globulus) y ciprés (Cupressus sp.); y bosques en sucesión natural con plantaciones de nogal (Cordia alliodora), dinde (Chlorophora tinctoria), caracolí (Anacardium excelsum) y guadua (Guadua angustifolia), se hallaron porcentajes de escorrentía con un máximo de $0,5 \%$ y sin diferencias significativas entre las diferentes coberturas de la tierra, explicado por la alta porosidad, la buena capacidad de infiltración de los suelos y a la ausencia de grandes eventos Iluviosos (De las Salas y García 2000, Rodríguez y Camargo 2009). En contraste, una comparación entre un bosque de roble (Quercus humboldtii), con una plantación de pino (Pinus patula) y otra de ciprés (Cupressus lusitanica), registró porcentajes de escorrentía de 1,07\% para el roble, $1,61 \%$ para el pino y $11,05 \%$ para el ciprés
(Ruiz Suescún et al. 2005), debido a que esta última presentó la menor intercepción, la capa de hojarasca más delgada y cierta repelencia al agua, limitando la infiltración.

Comparando con pastizales empleados para pastoreo, las plantaciones presentaron una menor escorrentía. En un estudio se registró que las plantaciones de pino (Pinus patula) y aliso (Alnus acuminata) presentaron menores valores (29-38 mm/año) que pastizales para pastoreo en uso o abandonados (75-77 mm/año) debido a la predominante intercepción en las plantaciones, que reduce la cantidad de agua que llega a la superficie, y al nivel de compactación del suelo, mayor en los pastizales para pastoreo (Knoke et al. 2014). En ambos casos los porcentajes variaron entre el 2 y $4 \%$. De forma similar, en otro estudio se encontró una menor escorrentía en una plantación de pino (Pinus radiata) en comparación con un pastizal para ganadería, explicado por la mayor infiltración en la plantación, causada por la mayor concentración de materia orgánica $(11,6 \%)$ y de masa radicular (Roncal 2006). 


\section{HALLAZgos EN OTROS ECOSISTEMAS DE MONTAÑA}

\section{Las áreas forestadas incrementan la escorrentía en cabeceras de cuenca, pero la reducen en comparación con pastizales para ganadería}

Greenwood y McKenzie (2001) y Little et al. (2009) indicaron que la deforestación y su reemplazo por plantaciones, particularmente en cabeceras de cuenca, pueden incrementar la compactación del suelo y, por lo tanto, la escorrentía superficial, reduciendo la recarga del agua subterránea y afectando la regulación hídrica. Por otro lado, Benegas et al. (2014) indicaron que la conversión de pastizales a plantaciones puede incrementar la macroporosidad e infiltración, reduciendo la escorrentía superficial especialmente ante eventos normales de precipitación, variando con la cantidad de materia orgánica que llega al suelo (Ilstedt et al. 2007); dicho incremento incluso llega a ser más grande en magnitud frente a la pérdida de bosques (Ponette-González et al. 2014). No obstante, en áreas con pendiente pronunciada, Gayoso e Iroume (1995) indicaron que las plantaciones con E. globulus pueden generar más escorrentía superficial que pastizales, debido al poco mantillo y hojarasca que desarrolla la plantación.

\section{c) Provisión de agua de calidad}

\section{c. 1 Las áreas forestadas reducen la erosión en áreas degradadas, y no presentan diferencias al compararlas con páramos y bosques nativos}

Una comparación de diversas coberturas en una cuenca (Vanacker et al. 2005), determinó que en aquellas áreas degradadas en las cuales se presentó un aumento en la cobertura vegetal de contacto, se redujo el transporte de agua y sedimentos. Asimismo, una comparación del efecto de plantaciones de pino (Pinus patula) en páramos y en comparación con un bosque nativo, no registró diferencias en el pH, la conductividad eléctrica y la turbidez del agua (Aichholzer y Durán 2010).

\section{HALLAZGOS EN OTROS ECOSISTEMAS DE MONTAÑA}

\section{Las áreas forestadas reducen la erosión en áreas degradadas, aunque la aumentan al reemplazar bosques nativos}

Ponette-González et al. (2015) y van Dijk y Keenan (2007) indicaron que dependiendo del nivel de degradación de un área, la instalación de plantaciones puede reducir el volumen de sedimentos en los ríos, aunque no necesariamente sus concentraciones. No obstante, Lara et al. (2003) indicó que en casos de conversión de bosques a plantaciones, sí hay un aumento en la carga de sedimentos asociada a las talas rasas en plantaciones de pino y eucalipto manejadas bajo rotaciones. 


\subsection{Conocimiento local sobre la relación entre especies leñosas y servicios hidrológicos}

La información de los estudios sistematizados en este subcapítulo procede de la percepción de las comunidades locales con respecto a la mención de algunas especies leñosas y usos de la tierra, y su relación con la conservación y producción de agua.

\section{a.1 Se reconoce que las especies leñosas nativas aportan en la conservación del agua}

Mathez-Stiefel (2016), al realizar la identificación de prácticas y especies agroforestales en las comunidades de Ccerabamba, Andina y Pacchani en Apurímac (Perú) a partir de inventarios, entrevistas y talleres, registró que las especies prioritarias para la conservación del agua en la zona alta son el aliso o lambras (Alnus acuminata), sauco, layan, yareta, taraka (Verbesina semidecurrens) y pisonay (Erythrina falcata). En la zona baja las especies priorizadas fueron el basul (Erythrina edulis), pisonay (Erythrina falcata) y paruto (Ficus citrifolia), este último en ambas zonas. Las especies se ubicaron en los ojos de manantes y en el borde de los ríos. Por otra parte, Hartman et al. (2016) al realizar entrevistas en las comunidades indígenas Ayllu Majasaya-Aransaya-Urunsaya de Bolivia, reportó que se considera necesaria la plantación de
Buddleja incana en las rocas para incrementar la retención de agua y la creación de bofedales. De manera similar, León et al. (2006) reportaron que la comunidad emplea a Xanthosoma sp. para la producción de agua en una parcela en Loja, Ecuador, lo cual es mencionado tanto por jóvenes como adultos y ancianos.

Mientras tanto, Kessler (2006) registró en la región Chiquisaca de Bolivia que, ante la escasez de agua, las familias decidieron plantar árboles nativos, pues se percibe que contribuyen con la infiltración del agua; sin embargo, no mencionaron una especie leñosa específica. En dicha línea, en la cuenca Loma Alta en Ecuador, Becker y Ghimire (2003), al explorar cómo influyó el conocimiento científico transmitido por una organización no gubernamental en el conocimiento ecológico indígena sobre acciones colectivas para la preservación de servicios ecosistémicos, registraron que la población local percibe que la deforestación podría ocasionar la reducción en la provisión hídrica, y por tanto era importante conservar los bosques nativos, lo que eventualmente llevó a crear una reserva forestal comunitaria. Asimismo, Granda y Yánez (2017) encontraron en Ecuador, a través de encuestas abiertas en comunidades indígenas, que el 35\% de personas consideraba que los bosques nativos permiten la regeneración y el mantenimiento del ciclo hidrológico local, proveyendo diariamente de agua no contaminada

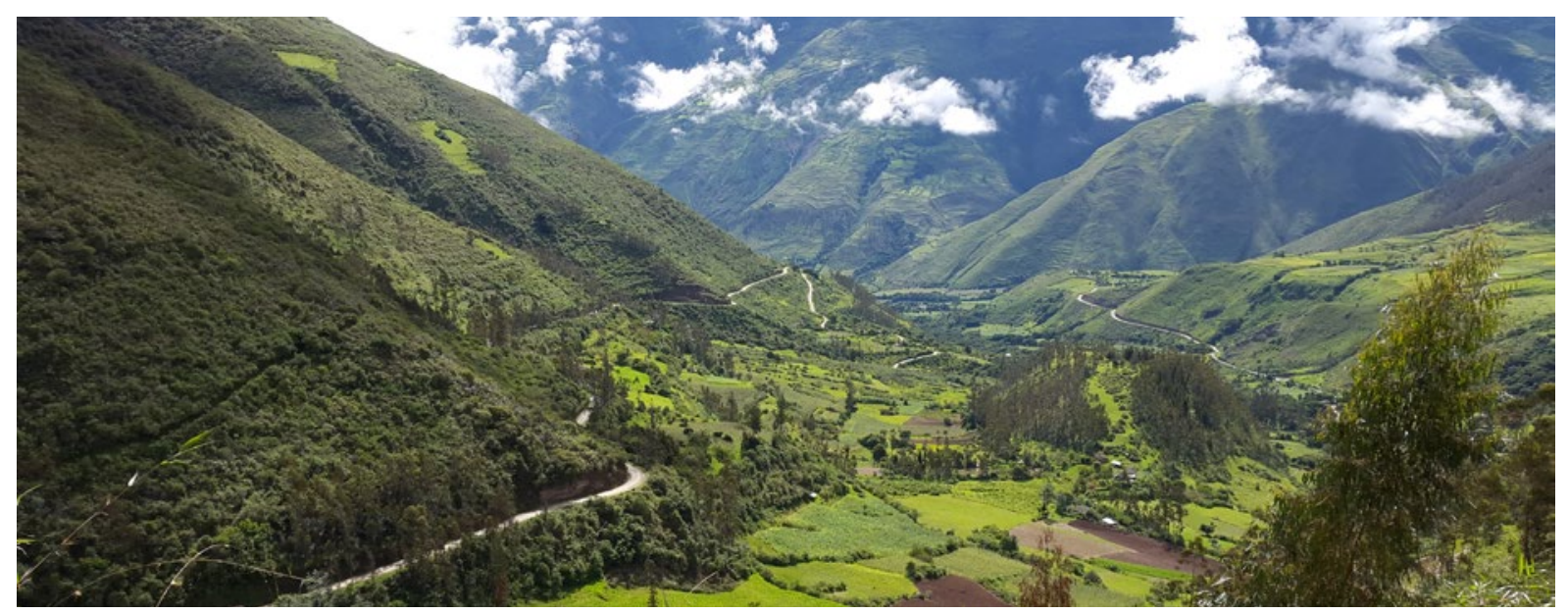

Foto 16. Crédito M. Peralvo 


\section{a.2 Se reconocen especies que afectan la conservación del agua}

A pesar que el eucalipto (Eucalyptus globulus) es reconocido por su importancia económica, la comunidad indígena Tres Cruces localizada en Bolivia indicó que esta especie, a diferencia de otras leñosas, afecta la condición hídrica de sus áreas agroforestales al reducir la humedad del suelo por su alto consumo de agua (Brandt et al. 2012).

\section{Síntesis y vacíos de conocimiento}

\subsection{Bosques nativos comparados con otros usos de la tierra}

\begin{tabular}{|c|c|c|}
\hline $\begin{array}{c}\text { Servicio } \\
\text { hidrológico }\end{array}$ & $\begin{array}{l}\text { Impacto registrado en } \\
\text { el proceso hidrológico }\end{array}$ & Vacíos de conocimiento \\
\hline \multirow{5}{*}{$\begin{array}{l}\text { Provisión } \\
\text { hídrica }\end{array}$} & $\begin{array}{l}\text { Los bosques nativos registran valores } \\
\text { de captura de agua de niebla que son } \\
\text { influenciados por diversos factores }\end{array}$ & $\begin{array}{l}\text { Con respecto a algunos factores se indicó que la } \\
\text { velocidad del viento, las horas de presencia de niebla, } \\
\text { el tamaño de las gotas de agua de niebla y la inclinación } \\
\text { de las hojas influyen en la captura del agua de niebla; sin } \\
\text { embargo, dichas variables no fueron abordados a partir } \\
\text { de mediciones y comparaciones. }\end{array}$ \\
\hline & $\begin{array}{l}\text { Los bosques nativos registran valores } \\
\text { variables de precipitación neta en función } \\
\text { al tipo de bosque, observándose un mayor } \\
\text { aporte del flujo de caída }\end{array}$ & $\begin{array}{l}\text { La elevación es un factor de base que se asocia a otras } \\
\text { variables físicas, las cuales en conjunto influyen en la } \\
\text { vegetación; sin embargo, no hay suficiente información } \\
\text { experimental en relación a la influencia de la fisonomía } \\
\text { de la vegetación, estructura del dosel y de comunidades } \\
\text { específicas como epifitas en la captura del agua de niebla. } \\
\text { En el caso del flujo de caída, se identifica a la } \\
\text { heterogeneidad del dosel como un factor determinante } \\
\text { en contraste a la intensidad de la precipitación; sin } \\
\text { embargo, esta relación no se ha estudiado a detalle. }\end{array}$ \\
\hline & $\begin{array}{l}\text { Los bosques nativos registran resultados } \\
\text { variables de intercepción de follaje en } \\
\text { comparación con pastizales }\end{array}$ & $\begin{array}{l}\text { Las diferencias encontradas entre estos dos usos no } \\
\text { fueron definitivas, ya que dependen de la estructura y } \\
\text { composición de la vegetación de cada una, la cual debería } \\
\text { ser estudiada en un horizonte de tiempo más amplio. }\end{array}$ \\
\hline & $\begin{array}{l}\text { Las cuencas con bosques nativos registran } \\
\text { resultados variables en relación a la } \\
\text { influencia del porcentaje de cobertura sobre } \\
\text { el caudal temporal }\end{array}$ & $\begin{array}{l}\text { No se identificó una tendencia clara entre el porcentaje } \\
\text { de cobertura boscosa y el caudal temporal, que podría } \\
\text { deberse al reducido período de evaluación y la deficiente } \\
\text { calidad de la información de los casos evaluados. }\end{array}$ \\
\hline & $\begin{array}{l}\text { Las cuencas con bosques nativos registran } \\
\text { resultados variables de caudal anual al ser } \\
\text { comparados con otros usos y coberturas no } \\
\text { forestales }\end{array}$ & $\begin{array}{l}\text { A pesar que varios estudios de revisión indican que solo } \\
\text { en el caso del cambio de uso de bosque nublado a otros } \\
\text { como pastizal o área cultivada está demostrado que se } \\
\text { reduce el caudal anual, no se han registrado muchos } \\
\text { estudios sobre ello en la zona andina. }\end{array}$ \\
\hline
\end{tabular}




\begin{tabular}{|c|c|c|}
\hline $\begin{array}{c}\text { Servicio } \\
\text { hidrológico }\end{array}$ & $\begin{array}{l}\text { Impacto registrado en } \\
\text { el proceso hidrológico }\end{array}$ & Vacíos de conocimiento \\
\hline \multirow{3}{*}{$\begin{array}{l}\text { Regulación } \\
\text { hídrica }\end{array}$} & $\begin{array}{l}\text { La pérdida de cobertura boscosa registra } \\
\text { valores variables con respecto al flujo base } \\
\text { del caudal }\end{array}$ & $\begin{array}{l}\text { El impacto de trayectorias de deforestación en el } \\
\text { flujo base solo fueron indicados en dos casos sin } \\
\text { tendencias concluyentes, lo cual requiere un análisis } \\
\text { más holístico que involucre no solo la evaluación } \\
\text { periódica de variables de intensidad de precipitación, } \\
\text { sino la perturbación asociada al cambio de cobertura a } \\
\text { largo plazo. }\end{array}$ \\
\hline & $\begin{array}{l}\text { Los bosques nativos registran una menor } \\
\text { escorrentía superficial que los pastizales y } \\
\text { áreas de cultivo, con algunas excepciones }\end{array}$ & $\begin{array}{l}\text { La mayoría de estudios indican que los bosques nativos } \\
\text { registran menor escorrentía superficial que los otros } \\
\text { usos; sin embargo, es indispensable mayor indagación } \\
\text { en los factores que influyen dichos resultados, } \\
\text { tales como: propiedades del suelo, intensidad de } \\
\text { precipitación y tipo de vegetación. }\end{array}$ \\
\hline & $\begin{array}{l}\text { Los bosques nativos presentan mayor } \\
\text { capacidad de retención hídrica que los } \\
\text { pastizales y áreas de cultivo }\end{array}$ & $\begin{array}{l}\text { Si bien se indica que los bosques nativos presentan } \\
\text { mayor capacidad de retención hídrica que otros usos, } \\
\text { es importante realizar mayor investigación en cómo y } \\
\text { cuánto contribuye al flujo base del caudal. }\end{array}$ \\
\hline \multirow{3}{*}{$\begin{array}{l}\text { Provisión } \\
\text { de agua de } \\
\text { calidad }\end{array}$} & $\begin{array}{l}\text { El agua que atraviesa el dosel presenta } \\
\text { cambios en la concentración de nutrientes } \\
\text { en función a las características del bosque y } \\
\text { condiciones del sitio }\end{array}$ & $\begin{array}{l}\text { La mayoría de casos registran diferentes valores de } \\
\text { concentración de nutrientes al atravesar el dosel } \\
\text { en función a las características del bosque y las } \\
\text { condiciones del sitio evaluado. Sin embargo, no todos } \\
\text { los casos son concluyentes, por lo tanto, es necesario } \\
\text { investigar más acerca de qué factores climáticos y } \\
\text { edáficos influyen en los cambios de concentración de } \\
\text { nutrientes en los flujos de salida. }\end{array}$ \\
\hline & $\begin{array}{l}\text { La pérdida de cobertura forestal no registra } \\
\text { resultados concluyentes en la concentración } \\
\text { de nutrientes en el caudal }\end{array}$ & $\begin{array}{l}\text { Al comparar bosques nativos (sin perturbación) y } \\
\text { áreas deforestadas no se registró en todos los casos } \\
\text { la tendencia general de la suposición del incremento } \\
\text { de la concentración de nutrientes del caudal con } \\
\text { la pérdida de la cobertura forestal; por lo tanto, es } \\
\text { necesario identificar los factores que afectan estos } \\
\text { resultados a fin de aclarar la relación entre los } \\
\text { porcentajes de coberturas boscosas y la exportación } \\
\text { de nutrientes. }\end{array}$ \\
\hline & $\begin{array}{l}\text { Los caudales en zonas de bosques presentan } \\
\text { mayor concentración de nutrientes que los } \\
\text { pastizales y las áreas de cultivo, con algunas } \\
\text { excepciones }\end{array}$ & $\begin{array}{l}\text { En la mayoría de casos, la concentración } \\
\text { de nutrientes del caudal de los bosques fue } \\
\text { mayor que en pastizales y áreas de cultivo, con } \\
\text { algunas excepciones, que podrían deberse a las } \\
\text { características del bosque evaluado, el manejo de los } \\
\text { otros usos de la tierra y los métodos de medición } \\
\text { en época seca y húmeda. Por ello, es importante } \\
\text { evaluar el efecto de la transición de bosques a } \\
\text { otros usos de la tierra, sobre todo en relación a } \\
\text { las prácticas agrícolas (intensidad, distribución de } \\
\text { cultivos o pastos, fertilización entre otras). }\end{array}$ \\
\hline
\end{tabular}




\subsection{Páramos comparados con otros usos de la tierra}

\begin{tabular}{|c|c|c|}
\hline $\begin{array}{l}\text { Servicio } \\
\text { hidrológico }\end{array}$ & $\begin{array}{l}\text { Impacto registrado en } \\
\text { el proceso hidrológico }\end{array}$ & Vacíos de conocimiento \\
\hline \multirow{3}{*}{$\begin{array}{l}\text { Provisión } \\
\text { hídrica }\end{array}$} & Los páramos registran mayor intercepción & \multirow{7}{*}{$\begin{array}{l}\text { Los estudios registrados en nuestra búsqueda se } \\
\text { enfocan en comparaciones a nivel de parcelas y } \\
\text { microcuencas con páramos y otros usos a fin de } \\
\text { cuantificar los valores de los procesos hidrológicos en } \\
\text { cada una y obtener un panorama que permita identificar } \\
\text { el efecto de las intervenciones; sin embargo, se apreció } \\
\text { la escasez de datos meteorológicos de largo plazo, } \\
\text { dificultando la comprensión de la hidrología de los } \\
\text { páramos, así como su variabilidad temporal y espacial. } \\
\text { Adicionalmente, a pesar de las generalidades } \\
\text { encontradas del efecto de las intervenciones y } \\
\text { cambios de uso en los procesos hidrológicos en los } \\
\text { páramos, la aplicación de éstos a gran escala necesita } \\
\text { de mayor investigación y métodos estandarizados } \\
\text { comparables. }\end{array}$} \\
\hline & $\begin{array}{l}\text { Los páramos a menor altitud registran } \\
\text { mayor evapotranspiración que áreas de } \\
\text { cultivos, pastizales y páramos a mayor } \\
\text { altitud }\end{array}$ & \\
\hline & $\begin{array}{l}\text { Los páramos registran diferencias de flujo } \\
\text { caulinar en función a la altitud e intensidad } \\
\text { de lluvia }\end{array}$ & \\
\hline \multirow{3}{*}{$\begin{array}{l}\text { Regulación } \\
\text { hídrica }\end{array}$} & $\begin{array}{l}\text { Los páramos registran un mayor flujo base } \\
\text { y un menor flujo máximo que las áreas de } \\
\text { cultivo }\end{array}$ & \\
\hline & $\begin{array}{l}\text { Los páramos registran una mayor retención } \\
\text { hídrica que las plantaciones con exóticas }\end{array}$ & \\
\hline & $\begin{array}{l}\text { Los páramos registran mayor regulación } \\
\text { hídrica que otros usos de la tierra }\end{array}$ & \\
\hline $\begin{array}{l}\text { Provisión } \\
\text { de agua de } \\
\text { calidad }\end{array}$ & $\begin{array}{l}\text { El cambio de cobertura de páramos a áreas } \\
\text { forestadas no registra diferencias en ciertos } \\
\text { parámetros de calidad del agua }\end{array}$ & \\
\hline
\end{tabular}

\subsection{Agroforestería comparada con otros usos de la tierra}

\section{Servicio hidrológico \\ Impacto registrado en el proceso hidrológico}

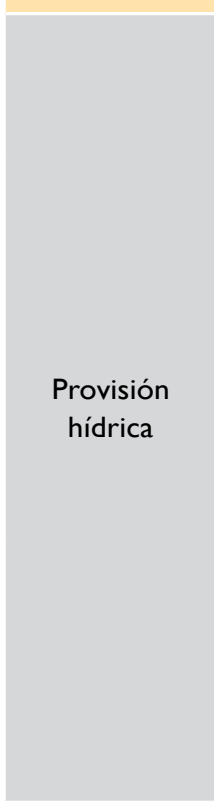

Los SAF café presentan menor intercepción que los bosques y mayor intercepción en relación a monocultivos de café

Los SAF café no registran diferencias significativas de precipitación neta en comparación con monocultivos de café

Los SAF café registran menor flujo de caída que monocultivos de café y bosque secundario, $y$ sus valores son influenciados por las características del dosel

\section{Vacíos de conocimiento}

En líneas generales existe un vacío de conocimiento considerable con respecto al efecto de los diversos sistemas y prácticas agroforestales en los procesos del ciclo hidrológico en los Andes tropicales. Los estudios identificados se enfocaron mayormente en comparaciones entre sistemas agroforestales de café (SAF café) asociado con especies exóticas (Eucalyptus sp. y Pinus sp. principalmente) y en otros casos con especies nativas (Inga sp.y Cordia alliodora), monocultivos de café y en menor proporción con bosques nativos. Asimismo, hay ausencia de tipologías de SAF café que plantea una diversidad de asociaciones no descritas con capacidades de provisión y regulación hídrica.

Solo un estudio indicó la influencia de los parámetros estructurales de la especie arbórea asociada al café en el flujo de caída, tales como: densidad de tallo, estructura y disposición de las ramas en contraste a la intensidad de la precipitación, que solo fue relacionado directamente en el caso del bosque secundario. 


\begin{tabular}{|c|c|c|}
\hline $\begin{array}{c}\text { Servicio } \\
\text { hidrológico }\end{array}$ & $\begin{array}{l}\text { Impacto registrado en } \\
\text { el proceso hidrológico }\end{array}$ & Vacíos de conocimiento \\
\hline \multirow[b]{2}{*}{$\begin{array}{l}\text { Regulación } \\
\text { hídrica }\end{array}$} & $\begin{array}{l}\text { Los SAF café registran una mayor } \\
\text { escorrentía que monocultivos de café } \\
\text { Los SAF café no registran diferencias } \\
\text { significativas de infiltración en } \\
\text { comparación con monocultivos de café }\end{array}$ & $\begin{array}{l}\text { Se identificaron pocos estudios que examinaron el } \\
\text { efecto de las especies en las propiedades físicas del } \\
\text { suelo; entre ellas podemos mencionar al pino (Pinus } \\
\text { oocarpa), nogal (Cordia alliodora) y eucalipto (Eucalyptus } \\
\text { grandis), las cuales afectaron el comportamiento de la } \\
\text { escorrentía superficial y la infiltración. }\end{array}$ \\
\hline & $\begin{array}{l}\text { Los SAF café manejados y en estado de } \\
\text { abandono registran menor infiltración } \\
\text { inicial que monocultivos de cítricos y } \\
\text { valores similares en relación a un área } \\
\text { forestada }\end{array}$ & $\begin{array}{l}\text { El nivel de conocimiento sobre las tasas de infiltración } \\
\text { bajo diferentes condiciones de manejo del suelo fue } \\
\text { escaso, ya que solo dos estudios resaltaron la influencia } \\
\text { de las actividades de manejo como el abono, deshierbe, } \\
\text { cosecha y mantenimiento del suelo en dicho proceso. } \\
\text { De otro lado, existe un paradigma de un óptimo } \\
\text { de cobertura a niveles intermedios en los cuales se } \\
\text { maximiza la recarga de agua subterránea en la estación } \\
\text { seca permitiendo una mayor infiltración al mismo } \\
\text { tiempo que la evapotranspiración y la intercepción son } \\
\text { moderadas. Sin embargo, generalizar tal suposición es } \\
\text { problemático, porque el flujo de la corriente depende } \\
\text { en gran medida del tipo y la profundidad del suelo, y las } \\
\text { características locales de la topografía y la precipitación. }\end{array}$ \\
\hline $\begin{array}{l}\text { Provisión } \\
\text { de agua de } \\
\text { calidad }\end{array}$ & $\begin{array}{l}\text { Los SAF café, monocultivos de café y } \\
\text { bosques secundarios registran dinámicas } \\
\text { complejas de nutrientes al atravesar el } \\
\text { dosel }\end{array}$ & $\begin{array}{l}\text { Los estudios identificados se enfocaron en caracterizar } \\
\text { la concentración de los nutrientes } \mathrm{Ca}, \mathrm{K}, \mathrm{Mg} \text { y } \mathrm{P} \text { en los } \\
\text { flujos de entrada y salida de los SAF café, monocultivos } \\
\text { de café y bosque secundario a fin de identificar la } \\
\text { dinámica de estos al atravesar el dosel. Entre los } \\
\text { factores que influyeron la dinámica se identificaron: } \\
\text { deposición atmosférica, deposición seca o la exudación } \\
\text { de elementos por las hojas o en los procesos de } \\
\text { senescencia, factores de manejo de los sistemas } \\
\text { productivos en la zona y composición de la hojarasca } \\
\text { principalmente. }\end{array}$ \\
\hline
\end{tabular}

\section{4 Áreas forestadas comparadas con otros usos de la tierra}

\section{Servicio hidrológico \\ Impacto registrado en el proceso hidrológico}

Provisión hídrica

\section{Vacíos de conocimiento}

A diferencia de lo estudiado en otros ecosistemas de montaña, hace falta estudiar el impacto de diferentes medidas de manejo forestal como las podas y raleos en el caudal.Asimismo, son pocos los estudios que tuvieron un enfoque de largo plazo y gran escala, lo que refleja la necesidad de afinar los métodos e instalar sistemas de monitoreo continuo.

Si bien hay una tendencia en los estudios registrados, hace falta incrementar la cantidad de los mismos, buscando una mejor representación, y abordando factores como la intensidad e inclinación de la lluvia, la arquitectura del dosel, y la influencia de medidas de manejo forestal.

Siendo que apenas se registraron dos estudios al respecto, es necesario ampliar la investigación al respecto, a fin de dilucidar incertidumbres actuales, tal como parece suceder en los estudios registrados en otros ecosistemas. 


\begin{tabular}{|c|c|c|c|}
\hline $\begin{array}{c}\text { Servicio } \\
\text { hidrológico }\end{array}$ & \multicolumn{2}{|c|}{$\begin{array}{l}\text { Impacto registrado en } \\
\text { el proceso hidrológico }\end{array}$} & Vacíos de conocimiento \\
\hline \multirow{3}{*}{$\begin{array}{l}\text { Regulación } \\
\text { hídrica }\end{array}$} & \multicolumn{2}{|c|}{$\begin{array}{l}\text { Las áreas forestadas reducen el flujo base e } \\
\text { incrementan el flujo pico en comparación } \\
\text { con páramos y bosques nativos, aunque } \\
\text { reduce el flujo pico en comparación con } \\
\text { áreas degradadas }\end{array}$} & $\begin{array}{l}\text { Hacen falta estudios que permitan diferenciar los } \\
\text { impactos causados por el cambio de cobertura vegetal, } \\
\text { de aquellos generados por otras variables (régimen de } \\
\text { precipitación, topografía y geología del área), además } \\
\text { del impacto de medidas de manejo forestal.Asimismo, } \\
\text { fortalecer sistemas de monitoreo en diferentes pisos } \\
\text { altitudinales. }\end{array}$ \\
\hline & \multicolumn{2}{|c|}{$\begin{array}{l}\text { Las áreas forestadas registran menor } \\
\text { infiltración y retención hídrica que bosques } \\
\text { y páramos, aunque mayor que otros } \\
\text { pastizales naturales }\end{array}$} & $\begin{array}{l}\text { Si bien ya se determinan tendencias claras al comparar } \\
\text { áreas forestadas con otros usos de la tierra, hace } \\
\text { falta indagar su impacto en la recuperación de } \\
\text { áreas y suelos degradados, a fin de determinar en } \\
\text { qué condiciones sí es positiva la plantación para la } \\
\text { regulación. }\end{array}$ \\
\hline & \multicolumn{2}{|c|}{$\begin{array}{l}\text { Las áreas forestadas registran similares } \\
\text { escorrentías superficiales en comparación } \\
\text { con bosques nativos, y menores en } \\
\text { comparación con pastizales para ganadería }\end{array}$} & $\begin{array}{l}\text { Así como en los estudios registrados en otros } \\
\text { ecosistemas de montaña se hace la salvedad que la } \\
\text { instalación de plantaciones en cabeceras de cuenca } \\
\text { incrementa la escorrentía, es importante estudiar el } \\
\text { impacto de las áreas forestadas en otras ubicaciones } \\
\text { claves en la cuenca. }\end{array}$ \\
\hline $\begin{array}{l}\text { Provisión } \\
\text { de agua de } \\
\text { calidad }\end{array}$ & \multicolumn{2}{|c|}{$\begin{array}{l}\text { Las áreas forestadas reducen la erosión } \\
\text { en áreas degradadas, y no presentan } \\
\text { diferencias al compararlas con páramos y } \\
\text { bosques nativos }\end{array}$} & $\begin{array}{l}\text { Se recomienda precaución sobre estos resultados ya } \\
\text { que la búsqueda para este servicio no fue exhaustiva. } \\
\text { Estudios en otros ecosistemas de montaña corroboran } \\
\text { la tendencia, pero se debe realizar mayor investigación } \\
\text { sobre esta relación. }\end{array}$ \\
\hline \multicolumn{4}{|c|}{5 Especies leñosas y su influencia } \\
\hline \multicolumn{2}{|c|}{ Tipo de estudio } & Especies leñosas & Vacíos de conocimiento \\
\hline \multirow{11}{*}{$\begin{array}{l}\text { Estudios } \\
\text { experim }\end{array}$} & & Cordia alliodora & \multirow{11}{*}{$\begin{array}{l}\text { Las especies leñosas* mencionadas en los estudios } \\
\text { fueron citados solo bajo los usos de tierra de SAF } \\
\text { café y áreas forestadas, las cuales fueron comparadas } \\
\text { con otras coberturas y usos tales como: bosques } \\
\text { nativos, SAF café, áreas forestadas, pastizales y áreas } \\
\text { de cultivos. Dichos estudios establecieron que } \\
\text { ciertas características de las especies relacionadas } \\
\text { a su fisonomía y estructura del dosel influyeron en } \\
\text { los procesos hidrolólogicos medidos. Asimismo, se } \\
\text { aprecia que son principalmente las especies exóticas } \\
\text { las más evaluadas, evidenciándose un gran vacío de } \\
\text { conocimiento en relación a las especies nativas. }\end{array}$} \\
\hline & & Cuppressus lusitanica & \\
\hline & & Cuppressus sp. & \\
\hline & & Eucalyptus globulus & \\
\hline & mpíricos & Eucalyptus grandis & \\
\hline & entales & Mangifera indica & \\
\hline & & & \\
\hline & & Pinus patula & \\
\hline & & Pinus radiata & \\
\hline & & Polylepis racemosa & \\
\hline & & Tectona grandis & \\
\hline
\end{tabular}




\begin{tabular}{|c|c|c|}
\hline Tipo de estudio & Especies leñosas & Vacíos de conocimiento \\
\hline \multirow{8}{*}{$\begin{array}{l}\text { Estudios de conocimiento } \\
\text { local }\end{array}$} & Alnus acuminata & \multirow{8}{*}{$\begin{array}{l}\text { No se identificaron muchos estudios que permitan } \\
\text { tener una visión más amplia del conocimiento local } \\
\text { de las comunidades en relación a la influencia de } \\
\text { especies leñosas en los servicios hidrológicos bajo } \\
\text { diferentes usos de la tierra. Por lo tanto, las especies } \\
\text { leñosas mencionadas por los comuneros están } \\
\text { sujetas a la percepción positiva de su influencia en la } \\
\text { conservación y producción de agua y solo un caso } \\
\text { de percepción negativa en la conservación del agua, } \\
\text { siendo ésta el Eucalyptus globulus. }\end{array}$} \\
\hline & Buddleja incana & \\
\hline & Erythrina edulis & \\
\hline & Erythrina falcata & \\
\hline & Eucalyptus globulus & \\
\hline & Ficus citrifolia & \\
\hline & Verbesina semidecurrens & \\
\hline & Xanthosoma sp. & \\
\hline
\end{tabular}

(*)La influencia de las especies leñosas en los procesos hidrológicos se encuentran a detalle en el Anexo 4.

\section{Recomendaciones}

\section{Sobre la conservación de bosques y páramos}

1. Debido a la alta capacidad de interceptar precipitación horizontal, resulta clave conservar la integridad de los bosques nublados, los que además albergan una gran biomasa de epífitas que incrementan la captación de agua de niebla. No obstante, es clave que estos bosques sean estudiados a mayor detalle, mejorando y estandarizando los métodos de medición, a fin de evitar errores en la estimación de su contribución a la provisión y regulación hídrica.

2. De forma similar, los páramos mostraron una mayor regulación hídrica que otros usos de la tierra, especialmente las plantaciones, al mantener flujos base y mayores flujos durante el año; y aún más, debido a la arquitectura de varias de sus especies, como el Polylepis, promovieron mayores tasas de precipitación neta, por lo que su conservación también debería ser considerada clave para la seguridad hídrica.

\section{Sobre el manejo forestal, agroforestal y silvopastoril}

3. Considerando que los bosques aportan en la regulación hídrica debido a su capacidad de infiltración y percolación con respecto a otros usos de la tierra, y que hay excepciones en las cuales ciertos usos llegan a tener niveles de infiltración similares o incluso superiores a los bosques, es importante evaluar y asegurar aquellas propiedades físicas del suelo y medidas de control de su degradación y compactación, de modo que puedan mantener una provisión y regulación de agua de calidad similar a los bosques.

4. Considerar límites en el aprovechamiento forestal de bosques nativos de tal modo que la reducción de la cobertura no afecte procesos hidrológicos como el caudal. Para esto, es preciso ejecutar investigaciones que estudien y evalúen, si fuese el caso, el tipo y nivel de aprovechamiento, de acuerdo al ecosistema, contexto local y necesidades de poblaciones indígenas o campesinas que dependan de este recurso. 
5. De forma similar, al implementar una plantación o un sistema agroforestal, es importante considerar densidades medias de árboles, pues podrían reducir la intercepción y posterior evaporación, incrementar el flujo de caída y la infiltración, y con ello recargar el agua subterránea. Asimismo, es importante considerar el uso de especies caducifolias que aporten materia orgánica al suelo de forma constante, reduciendo la escorrentía y favoreciendo la retención superficial del agua, lo que puede verse fortalecido mediante prácticas como la construcción de pequeñas zanjas de infiltración, entre otras. De esta forma, se puede llegar a recuperar importantes servicios en áreas degradadas o de otros usos como cultivos o pastos.

6. En el caso de las áreas cultivadas, es importante tener en cuenta sistemas de producción alternativos que permitan reducir el empleo de insumos químicos, parte de los cuales se infiltran y llegan al agua subterránea y al caudal. Una opción es la promoción de prácticas agroforestales que suplan parte de los beneficios obtenidos a través de la aplicación de dichos insumos. Otra medida es asegurar la existencia de formaciones boscosas ribereñas, de modo que se retiene parte de los fertilizantes y contaminantes antes de su llegada a algún curso de agua.

7. Por otro lado, evaluar opciones como la rotación del pastoreo para que el ganado no compacte excesivamente el suelo de los pastizales de modo que se favorece la infiltración, evitando la evaporación y promoviendo la recarga de agua subterránea.

8. A pesar del impacto negativo de las plantaciones con especies exóticas sobre varios procesos del ciclo hidrológico en comparación con bosques nativos y páramos, estas podrían resultar beneficiosas para recuperar tierras con altos niveles de degradación físico química del suelo, especialmente la infiltración y la calidad hídrica, lo que debiera corresponder con una identificación de zonas con potencial de recuperación, así como adecuadas técnicas de manejo, como el raleo, la densidad de árboles, entre otras.

\section{Sobre el conocimiento local}

9. Existen pocos estudios sobre los conocimientos que las poblaciones locales tienen de las funciones hidrológicas de las especies leñosas y su relación con el uso de la tierra; por ello, es importante documentar y analizar dichos conocimientos locales, ya que pueden contribuir a recomendaciones sobre prácticas de manejo ante la ausencia de estudios experimentales.

10. Por otro lado, se recomienda incluir a actores locales en el diseño de intervenciones de manera participativa, a fin de tomar en cuenta sus conocimientos, necesidades y preferencias (p. ej. especies de interés), y generar una relación sinérgica entre la comunidad y otros actores externos.

\section{Sobre los vacíos de conocimiento}

11. Si bien estas recomendaciones parten de lo evaluado en la literatura existente, es importante resaltar que una constante en esta investigación ha sido la falta de información de largo plazo en diferentes variables importantes como la precipitación o el caudal, por lo que se hace necesario mejorar los sistemas de evaluación hidrometeorológica. Asimismo, un sistema de monitoreo para evaluar los cambios en los procesos del ciclo hidrológico por cambios en los usos de la tierra y bajo diferentes acciones de manejo será importante para dilucidar algunos patrones que no resultan claros en esta investigación.

\section{Además, son necesarios estudios} comparativos sistemáticos, que no solo comparen los efectos de cobertura y uso del suelo en servicios hidrológicos sino también tomen en cuenta la historia del cambio de cobertura y uso de la tierra en un determinado lugar. 


\section{Referencias bibliográficas}

- $\quad$ Aichholzer, F. y W. Durán. 2010.

Caracterización y comportamiento de un ecosistema de páramo bajo la influencia de un bosque de Pino (Pinus patula), bosque nativo y de pajonal. Tesis, Universidad de Cuenca, Ecuador. 79 p.

- Alfaro, G. 2015. Caracterización de la infiltración en bosques plantados con Polylepis spp. de 11 y 29 años, Parque Nacional Huascarán, Quebrada Quilcayhuanca, Huaraz, Ancash. Tesis. Universidad Nacional Agraria La Molina, Lima, Perú. 134 p.

- Anbumozhi, V., J. Radhakrish and E. Yamaji. 2005. Impact of riparian buffer zones on water quality and associated management considerations. Ecological Engineering 24: 517-523.

- Arellano, R. 2001. Evaluación del escurrimiento y pérdida de suelo en agroecosistemas de café. Revista Forestal Venezolana 45:9-14.

- Arroyave, M. 2012. Dinámica del agua y los nutrientes solubles en agrosistemas cafeteros. Mg. Sc. Tesis. Universidad Nacional de Colombia, Medellín. 95 p.

- Ataroff, M. 2002. Precipitación e intercepción en ecosistemas boscosos de los andes venezolanos. Ecotropicos 15:195-202.

- Ataroff, M. and F. Rada. 2000. Deforestation impact on water dynamics in a Venezuelan Andean cloud forest. A Journal of the Human Environment 29:440-444.

- Becker, C. D. and K. Ghimire. 2003. Synergy between Traditional Ecological Knowledge and Conservation Science Supports Forest Preservation in Ecuador. Conservation Ecology 8 (1).
- Bellanger, B., S. Huon, F. Velasquez, V. Vallés. C. Girardin and A. Mariotti. 2004. Monitoring soil organic carbon erosion with $\delta 13 \mathrm{C}$ and $\delta 15 \mathrm{~N}$ on experimental field plots in the Venezuelan Andes. CATENA 58(2): 125-150.

- Benegas, L., U. Ilstedt, O. Roupsard, J. Jones and A. Malmer. 2014. Effects of trees on infiltrability and preferential flow in two contrasting agroecosystems in Central America. Agriculture, Ecosystems \& Environment 183: 185-196.

- Blanco, J. A. 2017. Bosques, suelo, agua y sus interacciones. Ecosistemas 26:1-9.

- Brandt, R., H. Zimmermann, I. Hensen, J. C. Mariscal Castro and S. Rist. 2012. Agroforestry species of the Bolivian Andes: an integrated assessment of ecological, economic and socio-cultural plant values. Agroforestry Systems 86:1-16.

- Bruijnzeel, L. A. 1990. Hydrology of moist tropical forests and effects of conversion: A state of knowledge review. United Nations Educational, Scientific and Cultural Organization. Holanda. 230 p.

- Bruijnzeel, L. A. 2004. Hydrological functions of tropical forests: not seeing the soil for the trees? Agriculture, Ecosystems \& Environment 104:185-228.

- Bruijnzeel, L. A. 2005. Tropical montane cloud forest: a unique hydrological case. Forest, Water and People in the Humid Tropics. Cambridge University Press. New York, USA. $23 \mathrm{p}$.

- Bruijnzeel, L. A., D. A. Gilmour, M. Bonell and D. Lamb. 2005. Conclusion - Forests, water and people in the humid tropics: an emerging view. Forest, Water and People in the Humid Tropics. Cambridge University Press, New York, USA. 23 p. 
- Bruijnzeel, L. A., M. Mulligan and F. N. Scatena. 2011. Hydrometeorology of tropical montane cloud forests: emerging patterns. Hydrological Processes 25:465-498.

- $\quad$ Bücker, A., P. Crespo, H.-G. Frede and L. Breuer. 2011. Solute behaviour and export rates in neotropical montane catchments under different land-uses. Journal of Tropical Ecology 27:305-317.

- Burbano-Garcés, M., A. Figueroa-Casas and M. Peña. 2014. Bulk precipitation, throughfall and stemflow deposition of $\mathrm{N}-\mathrm{NH}_{4}, \mathrm{~N}-\mathrm{NH}_{3}$ and $\mathrm{N}-\mathrm{NO}_{3}$ in an Andean forest. Journal of Tropical Forest Science 26:446-457.

- $\quad$ Buytaert, W., J. Deckers, G. Dercon, B. De Bièvre, J. Poesen and G. Govers. 2002. Impact of land use changes on the hydrological properties of volcanic ash soils in South Ecuador. Soil Use and Management 18 (2): 94-100.

- Buytaert, W., G. Wyseure, B. De Bièvre and J. Deckers. 2005. The effect of land-use changes on the hydrological behaviour of Histic Andosols in south Ecuador. Hydrological Processes 19:3985-3997.

- $\quad$ Buytaert, W., R. Célleri, B. De Bièvre, F. Cisneros, G. Wyseure, J. Deckers and R. Hofstede. 2006. Human impact on the hydrology of the Andean páramos. EarthScience Reviews 79:53-72.

- Buytaert, W., V. Iñiguez and B. D. Bièvre. 2007. The effects of afforestation and cultivation on water yield in the Andean páramo. Forest Ecology and Management 251:22-30.

- $\quad$ Cavelier, J. and G. Goldstein. 1989. Mist and fog interception in elfin cloud forests in Colombia and Venezuela. Journal of Tropical Ecology 5:309-322.
- $\quad$ Célleri, R., B. De Bièvre y V. Iñiguez. 2004. Efectos de la cobertura vegetal en la regulación hidrológica de microcuencas de páramo. Cuenca, Ecuador. 23 p.

- Célleri, R. and J. Feyen. 2009. The Hydrology of Tropical Andean Ecosystems: Importance, Knowledge Status, and Perspectives.

Mountain Research and Development 29: 350-355.

- $\quad$ Chazdon, R. L., P. H. S. Brancalion, L. Laestadius, A. Bennett-Curry, K. Buckingham, C. Kumar, J. Moll-Rocek, I. C. G. Vieira and S. J. Wilson. 2016. When is a forest a forest? Forest concepts and definitions in the era of forest and landscape restoration. Ambio 45:538-550.

- $\quad$ Chokkalingam, U. and W. De Jong. 2001. Secondary forest: a working definition and typology. Center for International Forestry Research (CIFOR). International Forestry Review 3:8.

- Crespo, P., R. Célleri, W. Buytaert, J. Feyen, V. Iñiguez, P. Borja and B. De Bièvre. 2010. Land use change impacts on the hydrology of wet Andean páramo ecosystems. Status and Perspectives of Hydrology in Small Basins. Goslar-Hahnenklee, Alemania. p: 1-7.

- $\quad$ Crespo, P. J., J. Feyen, W. Buytaert, A. Bücker, L. Breuer, H.-G. Frede and M. Ramírez. 2011. Identifying controls of the rainfall-runoff response of small catchments in the tropical Andes (Ecuador). Journal of Hydrology 407:164-174.

- Crespo, P., A. Bücker, J. Feyen, K. B. Vaché, H.-G. Frede and L. Breuer. 2012. Preliminary evaluation of the runoff processes in a remote montane cloud forest basin using Mixing Model Analysis and Mean Transit Time: Identification of the runoff generation processes in cloud forest. Hydrological Processes 26:3896-3910. 
- $\quad$ Crockford, R. H. and D. P. Richardson. 1990. Partitioning of rainfall in a eucalypt forest and pine plantation in southeastern Australia: I throughfall measurement in a eucalypt forest: Effect of method and species composition. Hydrological Processes 4(2): 131-144.

- Crockford, R. H. and D. P. Richardson. 2000. Partitioning of rainfall into throughfall, stemflow and interception: effect of forest type, ground cover and climate. Hydrological Processes 14:2903-2920.

- De las Salas, G. y C. García. 2000. Balance hídrico bajo tres coberturas vegetales contrastantes en la cuenca del Río San Cristóbal, Bogotá. Revista Académica Colombiana de Ciencias 24:205-218.

- Dezzeo, N. and N. Chacón. 2006. Nutrient fluxes in incident rainfall, throughfall, and stemflow in adjacent primary and secondary forests of the Gran Sabana, southern Venezuela. Forest Ecology and Management 234:218-226.

- Díaz, E. y L. Paz. 2002. Evaluación del régimen de humedad del suelo bajo diferentes usos en los Páramos Las Animas (Municipio de Silvia) y Piedra de León (Municipio de Sotará). Mg. Sc. Tesis. Universidad del Cauca. Popayán, Colombia. $119 \mathrm{p}$.

- Di Gregorio, A. and L. Jansen. 2000. Land Cover Classification System (LCCS): Classification Concepts and User Manual. Food and Agriculture Organization (FAO), Rome.

- van Dijk, A. I. J. M. and R. J. Keenan. 2007. Planted forests and water in perspective. Forest Ecology and Management 251:1-9.
- Ellison, D., C. E. Morris, B. Locatelli, D. Sheil, J. Cohen, D. Murdiyarso, V. Gutierrez, M. van Noordwijk, I. F. Creed, J. Pokorny, D. Gaveau, D. V. Spracklen, A. B. Tobella, U. Ilstedt, A. J. Teuling, S. G. Gebrehiwot, D. C. Sands, B. Muys, B. Verbist, E. Springgay, Y. Sugandi and C. A. Sullivan. 2017. Trees, forests and water: Cool insights for a hot world. Global Environmental Change 43:51-61.

- FAO. 2015. FRA 2015: Términos y definiciones. Documento de trabajo de la evaluación de los Recursos Forestales $N^{\circ}$ 180. Organización de las Naciones Unidas para la Agricultura y la Alimentación, Roma.

- Farley, K. A., E. F. Kelly and R. G. M. Hofstede. 2004. Soil Organic Carbon and Water Retention after Conversion of Grasslands to Pine Plantations in the Ecuadorian Andes. Ecosystems 7:729-739.

- Fleischbein, K., W. Wilcke, R. Goller, J. Boy, C. Valarezo, W. Zech and K. Knoblich. 2005. Rainfall interception in a lower montane forest in Ecuador: effects of canopy properties. Hydrological Processes 19:1355-1371.

- Fonseca, H. y M. Ataroff. 2005. Dinámica hídrica en la selva nublada de la cuenca alta del rio Cusiana y un pastizal de reemplazo. Cordillera oriental, Colombia. Venezuela. 6 p.

- $\quad$ Gaitán, L., I. Arnbrecht and S. Graefe. 2016. Throughfall and soil properties in shaded and unshaded coffee plantations and a secondary forest: a case study from Southern Colombia. Journal of Agriculture and Rural Development in the Tropics and Subtropics 117:321.

- García, C. 2007. Regulación hídrica bajo tres coberturas vegetales en la cuenc del Río San Cristóbal, Bogotá D.C. Revista Colombia Forestal 10:127-147. 
- Gayoso, J. y A. Iroumé. 1995. Impacto del manejo de plantaciones sobre el ambiente físico. Bosque 16(2): 3-12.

- Geroy, I. J., M. M. Gribb, H. P. Marshall, D. G. Chandler, S. G. Benner and J. P. McNamara. 2011. Aspect influences on soil water retention and storage. Hydrological Processes 25:3836-3842.

- Gilmour, D., M. Bonell and D.S. Cassells. 1987. The Effects of Forestation on Soil Hydraulic Properties in the Middle Hills of Nepal: A Preliminary Assessment. Mountain Research and Development Vol.7. 239 p.

- Gilmour, D. 2014. Forests and water: A synthesis of the contemporary science and its relevance for community forestry in the Asia-Pacific region. RECOFTC - The Center for People and Forests, Bangkok, Thailand. $40 \mathrm{p}$.

- Gomez-Peralta, D., S. F. Oberbauer, M. E. McClain and T. E. Philippi. 2008. Rainfall and cloud-water interception in tropical montane forests in the eastern Andes of Central Peru. Forest Ecology and Management 255:13151325.

- González, J. 2000. Monitoring cloud interception in a tropical montane cloud forest of the south-western Colombian Andes. Advances in Environmental Monitoring and Modelling 1: 97-117

- Gotsch, S.G., N. Nadkarni and A. Amici. 2016. The functional roles of epiphytes and arboreal soils in tropical montane cloud forests. Journal of Tropical Ecology 32:455-468

- Granda, M. y P. Yánez. 2017. Estudio sobre la percepción de los beneficios del programasocio bosque en la región amazónica ecuatoriana. La Granja: Revista de Ciencias de la Vida 26:28-37.
- Greenwood, K.L. and B.M. McKenzie. 2001. Grazing effects on soil physical properties and the consequences for pastures: a review. Australian Journal of Experimental Agriculture 41:1231-1250.

- Gyenge, J., M. Fernández and T. Schlichter. 2008. Tree-Grass Interactions and Water Use in Silvopastoral Systems in N.W. Patagonia. Ecological basis of agroforestry. CRC Press. p: 171-180.

- Hamilton, L. S and P.N. King. 1983. Tropical Forested Watersheds: Hydrologic and Soils Response to Major Uses or Conversions. Westview Press. 168 p.

- Hamilton, L. S. 2009. Los bosques y el agua: Estudio temático elaborado en el ámbito de la Evaluación de los recusos forestales mundiales 2005. Estudio FAO: Montes, Organización de las Naciones Unidas para la Agricultura y la Alimentación, Roma, Italia. $101 \mathrm{p}$.

- Harden, C. P., J. Hartsig, K. A. Farley, J. Lee and L. L. Bremer. 2013. Effects of Land-Use Change on Water in Andean Páramo Grassland Soils. Annals of the Association of American Geographers 103:375-384.

- Harmand, J., H. Ávila, E. Dambrine, U. Skiba, S. De Miguel, R.V. Renderos, R. Oliver, F. Jimenéz and J. Beer. 2007. Nitrogen dynamics and soil nitrate retention in a Coffea arabica-Eucalyptus deglupta agroforestry system in Southern Costa Rica. Biogeochemistry 85 (2): 125-139.

- Hartman, B. D., D. A. Cleveland and O. A. Chadwick. 2016. Linking changes in knowledge and attitudes with successful land restoration in indigenous communities: Local knowledge and land restoration. Restoration Ecology 24:749-760. 
- Herrera, A., R. Urich, E. Rengifo, C.

Ballestrini, A. González and W. León. 2012. Transpiration in a eucalypt plantation and a savanna in Venezuela. Trees 26:1759-1769.

- HIFM. 2008. Hydrologic Effects of a Changing Forest Landscape. National Academy of Science, Washington, USA. 4p.

- Hirsch, F., D. Clark and P. Viherva. 2011. Payments for Forest -related Ecosystem Services: What role for a Green Economy?. Workshop on Payments for Ecosystem Services. UNECE/FAO Forestry and Timber Section. Ginebra, Suiza. p: 1-46.

- Hölscher, D., L. Köhler, C. Leuschner and M. Kappelle. 2003. Nutrient fluxes in stemflow and throughfall in three successional stages of an upper montane rain forest in Costa Rica. Journal of Tropical Ecology 19:557-565.

- Hölscher, D. 2010. Hydrology of natural and anthropogenically altered tropical montane rainforests with special reference to rainfall interception. Tropical Mountain Forest: Patterns and Processes in a Biodiversity Hotspot. University of Akron Press. p: 129-136.

- Huber, A. y R. Trecaman. 2004. Respuesta del balance hídrico al raleo de una plantación joven de Pinus radiata (D. Don) en el secano Interior de Chile. Terra Latinoamericana 22(4): 417-424.

- Ilstedt, U., A. Malner, E. Verbeeten and D. Murdiyarso. 2007. The effect of afforestation on water infiltration in the tropics: A systematic review and meta-analysis. Forest Ecology and Management 251: 45-51.

- Ilstedt, U., A. Bargués, H. R. Bazié, J. Bayala, E. Verbeeten, G. Nyberg, J. Sanou, L. Benegas, D. Murdiyarso, H. Laudon, D. Sheil and A. Malmer. 2016. Intermediate tree cover can maximize groundwater recharge in the seasonally dry tropics. Scientific Reports 6. Article number: 21930 (2016)
- Janeau, J. L., S. Grellier and P. Podwojewski. 2015. Influence of rainfall interception by endemic plants versus short cycle crops on water infiltration in high altitude ecosystems of Ecuador. Hydrology Research 46 (6):10081018.

- Jaramillo-Robledo, Á. 2003. La lluvia y el transporte de nutrimentos dentro de ecosistemas de bosque y cafetales. Centro Nacional de Investigaciones de café "Cenicafé" 54:134-144.

- Jones, J., F. Cisneros, A. Iroumé, E. Jobbágy, A. Lara, W. Lima, C. Little, C. Llerena, L. Silveira and J.C. Villegas. 2017. Forests and water in South America. Hydrological Processes 31(5): 972-980.

- Kessler, A. 2006. Moving people: towards collective action in soil and water conservation. Experiences from the Bolivian mountain valleys, Wageningen.

- Knoke, T., J. Bendix, P. Pohle, U. Hamer, P. Hildebrandt, K. Roos, A. Gerique, M. L. Sandoval, L. Breuer, A. Tischer, B. Silva, B. Calvas, N. Aguirre, L. M. Castro, D. Windhorst, M. Weber, B. Stimm, S. Günter, X. Palomeque, J. Mora, R. Mosandl and E. Beck. 2014. Afforestation or intense pasturing improve the ecological and economic value of abandoned tropical farmlands. Nature Communications 5:5612.

- Lal, R. 1996. Deforestation and land-use effects on soil degradation and rehabilitation in western Nigeria. I. Soil physical and hydrological properties. Land Degradation \& Development 7:19-45.

- Lara, A., D. Soto, J. Armesto, J. Donoso y C. Wernli. 2003. Componentes científicos clave para una política nacional sobre usos, servicios y conservación de los bosques nativos chilenos. Universidad Austral de Chile. Universidad Austral de Chile. 134 p. 
- Lara, A., C. Little, R. Urrutia, J. McPhee, C. Álvarez-Garretón, C. Oyarzún, D. Soto, P. Donoso, L. Nahuelhual, M. Pino and I. Arismendi. 2009. Assessment of ecosystem services as an opportunity for the conservation and management of native forests in Chile. Forest Ecology and Management 258 (4): 415-424.

- León, L. M., P. G. Cueva, Z. Aguirre and L. Kvist. 2006. Floristic composition, structure, endemic and ethnobotany in the native forest "El Colorado", in Puyango, province of Loja. Lyonia. A journal of ecology and application 10:105-115.

- León, J. D., M. I. González y J. F. Gallardo. 2010. Distribución del agua lluvia en tres bosques altoandinos de la Cordillera Central de Antioquia, Colombia. Revista Facultad Nacional de Agronomía, Medellín 63:53195336.

- Llerena, C., R. Hermoza y L. M. Llerena. 2007. Plantaciones forestales, agua y gestión de cuencas. Debate agrario 42:79-110.

- Le Tellier, V., A. Carrasco and N. Asquith. 2009. Attempts to determine the effects of forest cover on stream flow by direct hydrological measurements in Los Negros, Bolivia. Forest Ecology and Management 258:1881-1888.

- Licata, J.A., T.G. Pypker, M. Weigandt, M. Unsworth, J.E. Gyenge, M. Fernández, T. Schlichter and B. Bond. 2011. Decreased rainfall interception balances increased transpiration in exotic ponderosa pine plantations compared with native cypress stands in Patagonia, Argentina. Ecohydrology 4(1): 83-93.

- Lindell, L., M. Åström and T. Öberg. 2010. Land-use change versus natural controls on stream water chemistry in the Subandean Amazon, Peru. Applied Geochemistry 25:485-495.
- Little, C., A. Lara, J. McPhee and R. Urrutia. 2009. Revealing the impact of forest exotic plantations on water yield in large scale watersheds in South-Central Chile. Journal of Hydrology 374: 162-170.

- Lundgren, B. O. and J. B. Raintree. 1983. Sustained agroforestry. Agricultural research for development: potentials and challenges in Asia. La Haya, Países Bajos, ISNAR.

- Mathez-Stiefel, S.-L. 2016. Opciones Agroforestales para la Adaptación al Cambio Climático: Comunidades de Ccerabamba, Andina y Pacchani (Distrito Pacobamba, Apurímac, Perú). Centro Internacional de Investigación Agroforestal (ICRAF), Lima, Perú. 24 p.

- Mathez-Stiefel, S.-L., S. Baéz y M. Peralvo. 2017. Hacía la conservación y la gobernanza sostenible de los paisajes de bosques Andinos: Una agenda de investigación. Page 32. Programa Bosques Andinos de la Agencia Suiza para el Desarrollo y la Cooperación - COSUDE, CONDESAN, Helvetas Swiss Intercooperation, CDE-University of Bern. Quito., Lima, Perú.

- Mena, H. D., C. C. Benavides y J. A. C. Franco. 2011. Evaluación de la susceptibilidad a la erosión hídrica de un Vitric haplustands, mediante el uso de un minisimulador de lluvia, en una zona de ladera en Colombia. Revista de Ciencias Agrícolas 28:70-80.

- Miller, G. 1990. Resource conservation and management. Wadsworth Publishing Company, USA.

- Misra, D., R. Daanen and A. Thompson. 2011. Base Flow/Groundwater Flow. Page 1253 Encyclopedia of Snow, Ice and Glaciers. Springer Netherlands. 
- Molina, J. 2001. Caracterización hidrológicoforestal de dos microcuencas con diferente cobertura vegetal en la cuenca del río San Alberto, Oxapampa, Perú. Mg. Sc. Tesis, Universidad Nacional Agraria La Molina, Lima, Perú.

- Molina, A., V. Vanacker, V. Balthazar, D. Mora and G. Govers. 2012. Complex land cover change, water and sediment yield in a degraded Andean environment. Journal of Hydrology 472-473:25-35.

- Molina, A., V. Vanacker, E. Brisson, D. Mora and V. Balthazar. 2015. Multidecadal change in streamflow associated with anthropogenic disturbances in the tropical Andes. Hydrology and Earth System Sciences 19:4201-4213.

- Moreno, C. A. 2012. Efectos de diferentes tipos de vegetación sobre la capacidad de infiltración de agua en suelos de páramos en la Reserva Privada Paluguillo (Ecuador). B.S. Tesis. Universidad San Francisco de Quito, Ecuador.

- Mulligan, M., A. Jarvis, J. Gonzáles and L.A. Bruijnzeel. 2011. Using "biosensors" to elucidate rates and mechanisms of cloud water interception by epiphytes, leaves, and branches in a sheltered Colombian cloud forest. Tropical Montane Cloud Forests: Science for Conservation and Management. Cambridge University Press.

- Muñoz-Villers, L., F. Holwerda, M. AlvaradoBarr, D. Geissert, B. Marín-Castro, A. Gómez-Tagle, J. McDonnell, H. Asbjornsen, T. Dawson y L. Adriaan. 2015. Efectos hidrológicos de la conversión del bosque de niebla en el centro de Veracruz, México. Bosque (Valdivia) 36:395-407.

- Nyberg, G., A. Bargués, J. Kinyangi and U. Ilstedt. 2012. Soil property changes over a 120-yr chronosequence from forest to agriculture in western Kenya. Hydrology and Earth System Sciences 16:2085-2094.
- Ochoa-Tocachi, B. F., W. Buytaert and B. De Bièvre. 2016a. Regionalization of land-use impacts on streamflow using a network of paired catchments: Regionalization using paired catchments. Water Resources Research 52:6710-6729.

- Ochoa-Tocachi, B. F., W. Buytaert, B. De Bièvre, R. Célleri, P. Crespo, M. Villacís, C. A. Llerena, L. Acosta, M. Villazón, M. Guallpa, J. Gil-Ríos, P. Fuentes, D. Olaya, P. Viñas, G. Rojas and S. Arias. 2016b. Impacts of land use on the hydrological response of tropical Andean catchments: Land Use Impacts on Tropical Andean Hydrology. Hydrological Processes 30:4074-4089.

- Oesker, M., J. Homeier, H. Dalitz and L. A. Bruijnzeel. 2011. Spatial heterogeneity of throughfall quantity and quality in tropical montane forests in southern Ecuador. Tropical Montane Cloud Forests: Science for Conservation and Management. Cambridge University Press.

- Oki, T. and S. Kanae. 2006. Global Hydrological Cycles and World Water Resources. Science 313:1068-1072.

- Olley, J., D. Ward, J. McMahom, N. Saxton, T. Pietsch, P. Laceby, F. Bengtsson, R. Calvin and F. Pantus. 2010. Phase 2c report: Rehabilitation priorities Lockyer focal area. Healthy Country Project. eWater Cooperative Research Centre Queensland, Australia. 61 p.

- OMM y UNESCO. 2012. Glosario Hidrológico Internacional. Organización Meteorológica Mundial y Organización de las Naciones Unidas para la Educación, la Ciencia y la Cultura, Ginebra, Suiza.

- Ortega, L. F. 2014. Evaluación comparativa del papel de diferentes coberturas vegetales sobre algunos servicios ecosistémicos en los Andes colombianos.Tesis. Universidad Nacional de Colombia-Sede Medellín, Medellín. 
- Oyarzún, C.E., P. Hervé-Fernandez and C. Frene. 2012. Effects of land use changes and management practices on water yield in native forests and exotic plantations in Southern Chile. Forest Management. p: 79-101.

- Plamondon, A., R. Ruiz, C. Morales and M. Gonzalez. 1991. Influence of protection forest on soil and water conservation (Oxapampa, Peru). Forest Ecology and Management 38:227-238.

- Ponette-González, A. G., E. Marín-Spiotta, K. A. Brauman, , K. A. Farley, K. C. Weathers and K. R. Young. 2014. Hydrologic Connectivity in the High-Elevation Tropics: Heterogeneous Responses to Land Change. BioScience 64:92-104.

- Ponette-González, A. G., K. A. Brauman, E. Marín-Spiotta, K. A. Farley, K. C. Weathers, K. R. Young and L. M. Curran. 2015. Managing water services in tropical regions: From land cover proxies to hydrologic fluxes. Ambio 44:367-375.

- Poulenard, J., J.C. Michel, F. Bartoli, J.M.Portal and P. Podowojew. 2004. Water repellency of volcanic ash soils from Ecuadorian paramo: effect of water content and characteristics of hydrophobic organic matter. European Journal of Soil Science 55: 487-496.

- Ramírez, B. H., A. J. Teuling, L. Ganzeveld, Z. Hegger and R. Leemans. 2017. Tropical Montane Cloud Forests: Hydrometeorological variability in three neighbouring catchments with different forest cover. Journal of Hydrology 552:151-167.

- Rangel, J. 2000. Colombia: Diversidad biótica III, la región de vida Paramuna. Universidad Nacional de Colombia e Instituto de investigación Alexander Von Humboldt, Bogotá, Colombia. 852 p.
- Rebollo, S. y A. Gómez. 2003.

Aprovechamiento sostenible de los pastizales. Revista Ecosistemas: 27.

- Reyes, R. 2014. Influencia de cuatro sistemas del uso de la tierra (Teca, citricos y café bajo sombra manejado y en abandono), en la sortividad en el IRD Selva Fundo La Génova, Chanchamayo, Junín. Tesis. Universidad Nacional Agraria La Molina, Lima, Perú. 127 p.

- Roa-García, M. C., S. Brown, H. Schreier and L. M. Lavkulich. 2011. The role of land use and soils in regulating water flow in small headwater catchments of the Andes. Water Resources Research 47:1-12.

- Robbins, P. 2004. Political Ecology. A Critical Introduction. Blackwell Publishing. Oxford.

- Rodríguez, J. A. y J. C. Camargo. 2009. Erosión y escorrentía: indicadores de respuesta temprana del suelo a distintas coberturas en la zona cafetera de Colombia. Recursos Naturales y Ambiente 58: 25-31.

- Roncal, W. 2006. Influencia de las plantaciones forestales sobre la escorrentía superficial y la erosión hídrica en Porcón, Cajamarca. Mg. Sc. Tesis, Universidad Nacional Agraria La Molina, Lima, Perú.

- Ruiz Suescún, O. A., J. J. Acosta Jaramillo and J. D. León Peláez. 2005. Surface runoff in natural montane forests and forest plantations in Antioquía, Colombia. Revista Facultad Nacional de Agronomía, Medellín 58:2635-2650.

- Salemi, L.F., J.D. Groppo, R. Trevisan, J. de Morales, S. de Barros, J.P. Villani, P. DuarteNeto and L.A. Martinelli. 2013. Land-use change in the Atlantic rainforest region: Consequences for the hydrology of small catchments. Journal of Hydrology 499: 100-109. 
- Suescún, D., J. C. Villegas, J. D. León, C. P. Flórez, V. García-Leoz and G. A. CorreaLondoño. 2017. Vegetation cover and rainfall seasonality impact nutrient loss via runoff and erosion in the Colombian Andes. Regional Environmental Change 17:827-839.

- Tobón, C. 2009. Los bosques andinos y el agua. Programa Regional ECOBONA INTERCOOPERATION, CONDESAN, Quito. $64 \mathrm{p}$.

- Trabucco, A., R. J. Zomer, D. A. Bossio, O. van Straaten and L. V. Verchot. 2008. Climate change mitigation through afforestation/ reforestation: A global analysis of hydrologic impacts with four case studies. Agriculture, Ecosystems \& Environment 126:81-97.

- Vanacker, V., A. Molina, G. Govers, J. Poesen, G. Dercon and S. Deckers. 2005. River channel response to short-term humaninduced change in landscape connectivity in Andean ecosystems. Geomorphology 72:340-353.

- Veneklaas, E. J. and R. Van Ek. 1990. Rainfall interception in two tropical montane rain forests, Colombia. Hydrological processes 4:311-326.

- Vis, M. 1986. Interception, drop size distributions and rainfall kinetic energy in four Colombian forest ecosystems. Earth Surface Processes and Landforms 11:591-603.

- Walker, J. and P. Reddell. 2006. Retrogressive Succession and Restoration on Old Landscapes. Linking Restoration and Ecological Succession. p: 69-89.

- Wilcke, W., S. Yasin, C. Valarezo and W. Zech. 2001. Change in water quality during the passage through a tropical montane rain forest in Ecuador. Biogeochemistry 55:45-72.
- Wilcke, W., S. Günter, F. Alt, C. Geißler, J. Boy, J. Knuth, Y. Oelmann, M. Weber, C. Valarezo and R. Mosandl. 2009. Response of water and nutrient fluxes to improvement fellings in a tropical montane forest in Ecuador. Forest Ecology and Management 257:1292-1304.

- WRI. s.f. What is degraded land?. Disponible en: www.wri.org/faq/what-degradedland:www.wri.org/faq/what-degraded-land.

- Wullaert, H., T. Pohlert, J. Boy, C. Valarezo and W. Wilcke. 2009. Spatial throughfall heterogeneity in a montane rain forest in Ecuador: Extent, temporal stability and drivers. Journal of Hydrology 377:71-79.

- Zhang, L., W.R. Dawes and G.R. Walner. 2001. Response of mean annual evapotranspiration to vegetation changes at catchment scale. Water resources research 37:701-708

- Zimmermann, B. and Elsenbeer. 2008. Spatial and temporal variability of soil saturated hydraulic conductivity in gradients of disturbance. Journal of Hydrology 361 : 78-95. 


\section{Anexos}

\section{Anexo 1. Fórmulas empleadas en cada motor de búsqueda}

\begin{tabular}{|c|c|c|}
\hline $\begin{array}{l}\text { Motor de } \\
\text { búsqueda }\end{array}$ & Características & Fórmula empleada \\
\hline \multirow[t]{3}{*}{ Scopus } & $\begin{array}{l}\text { C: Ubicación, vegetación y } \\
\text { ciclo hidrológico } \\
\text { I: Inglés } \\
\text { B: En título y resumen }\end{array}$ & 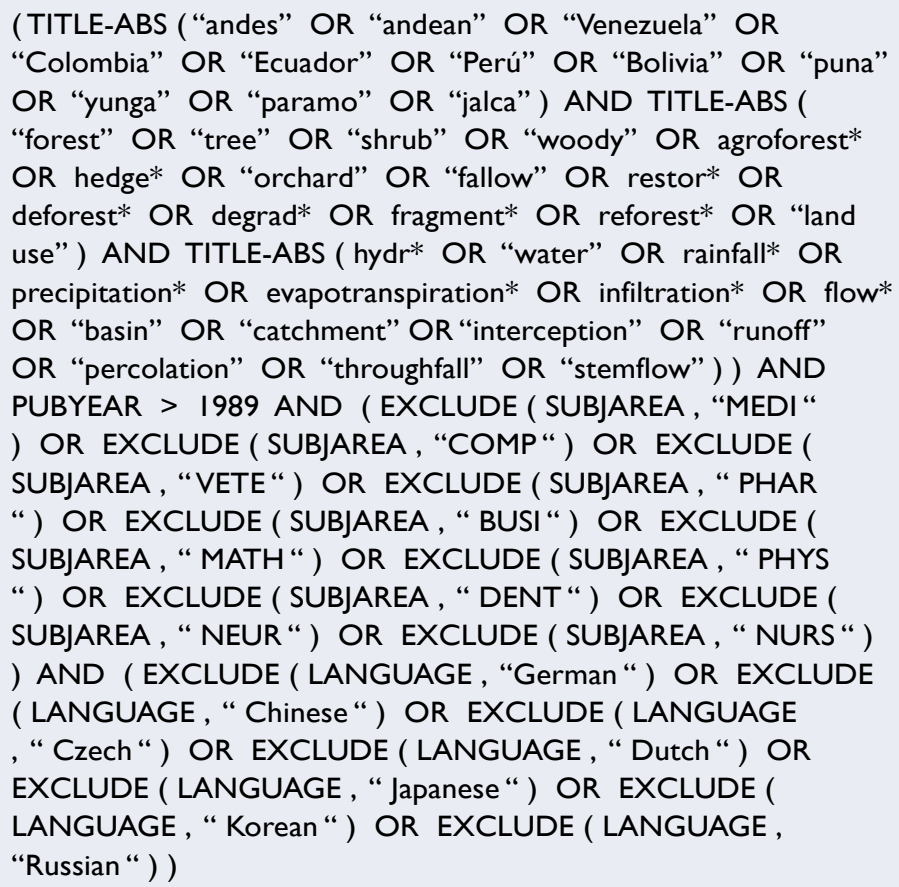 \\
\hline & $\begin{array}{l}\text { C: Ubicación, vegetación y } \\
\text { ciclo hidrológico } \\
\text { I: Español } \\
\text { B: En título y resumen }\end{array}$ & 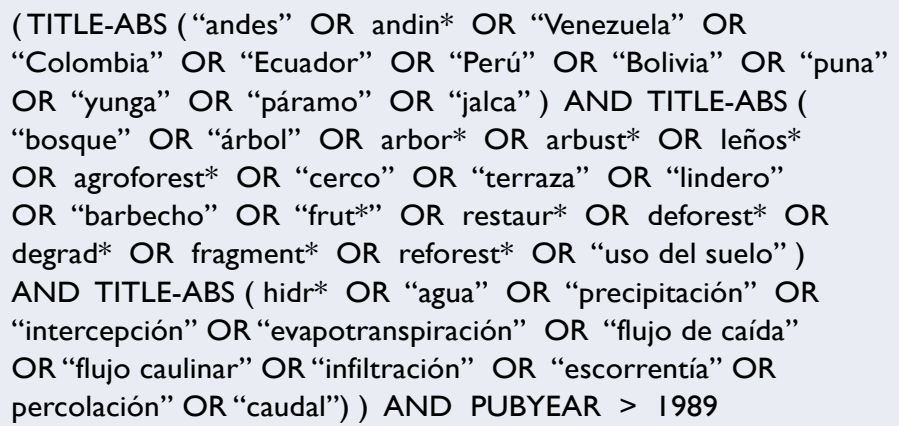 \\
\hline & $\begin{array}{l}\text { C: Ubicación, vegetación } \\
\text { y conocimiento ecológico } \\
\text { tradicional } \\
\text { I: Inglés } \\
\text { B: En título y resumen }\end{array}$ & 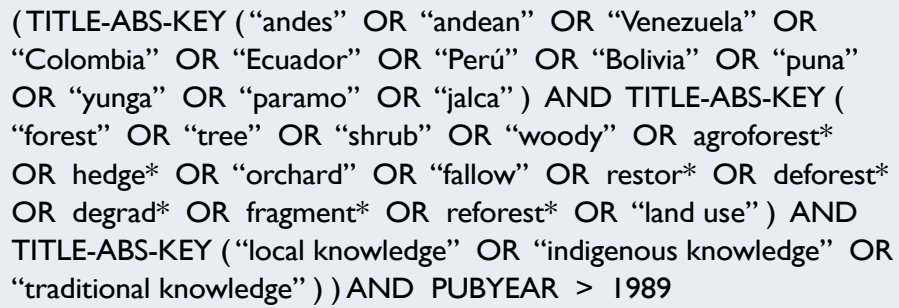 \\
\hline
\end{tabular}




\begin{tabular}{|c|c|c|}
\hline $\begin{array}{l}\text { Motor de } \\
\text { búsqueda }\end{array}$ & Características & Fórmula empleada \\
\hline \multirow{4}{*}{$\begin{array}{l}\text { Web of } \\
\text { Science }\end{array}$} & $\begin{array}{l}\text { C: Ubicación, vegetación y } \\
\text { ciclo hidrológico } \\
\text { I: Inglés } \\
\text { B: Título }\end{array}$ & $\begin{array}{l}\text { Título: (andes OR andean OR Venezuela OR Colombia OR } \\
\text { Ecuador OR Perú OR Bolivia OR puna OR yunga OR paramo } \\
\text { OR jalca) AND Título: (forest OR tree OR shrub OR woody OR } \\
\text { agroforest* OR hedge* OR orchard OR fallow OR restor* OR } \\
\text { deforest* OR degrad* OR fragment* OR reforest* OR land use) } \\
\text { AND Título: (hydr* OR water OR rainfall* OR precipitation* } \\
\text { OR evapotranspiration* OR infiltration* OR flow* OR basin } \\
\text { OR catchment OR interception OR runoff OR percolation OR } \\
\text { throughfall OR stemflow) }\end{array}$ \\
\hline & $\begin{array}{l}\text { C: Ubicación, vegetación y } \\
\text { ciclo hidrológico } \\
\text { I: Inglés } \\
\text { B: Tema }\end{array}$ & $\begin{array}{l}\text { Tema: (andes OR andean OR Venezuela OR Colombia OR Ecuador } \\
\text { OR Perú OR Bolivia OR puna OR yunga OR paramo OR jalca) } \\
\text { AND Tema: (forest OR tree OR shrub OR woody OR agroforest* } \\
\text { OR hedge* OR orchard OR fallow OR restor* OR deforest* OR } \\
\text { degrad* OR fragment* OR reforest* OR land use) AND Tema: (hydr* } \\
\text { OR water OR rainfall* OR precipitation* OR evapotranspiration* } \\
\text { OR infiltration* OR flow* OR basin OR catchment OR interception } \\
\text { OR runoff OR percolation OR throughfall OR stemflow) }\end{array}$ \\
\hline & $\begin{array}{l}\text { C: Ubicación, vegetación y } \\
\text { ciclo hidrológico } \\
\text { I: Español } \\
\text { B: Título }\end{array}$ & $\begin{array}{l}\text { Título: (andes OR andin* OR Venezuela OR Colombia OR Ecuador } \\
\text { OR Perú OR Bolivia OR puna OR yunga OR páramo OR jalca) AND } \\
\text { Título: (bosque OR árbol OR arbor* OR arbust* OR agroforest* } \\
\text { OR leños* OR cerco OR terraza OR lindero OR barbecho OR frut* } \\
\text { OR restaur* OR deforest* OR degrad* OR fragment* OR reforest* } \\
\text { OR uso del suelo) AND Título: (hidr* OR agua OR precipitación* } \\
\text { OR evapotranspiración* OR infiltración* OR caudal OR cuenca OR } \\
\text { intercepción OR flujo de caída OR flujo caulinar OR escorrentía OR } \\
\text { percolación) }\end{array}$ \\
\hline & $\begin{array}{l}\text { C: Ubicación, vegetación y } \\
\text { ciclo hidrológico } \\
\text { I: Español } \\
\text { B: Tema }\end{array}$ & $\begin{array}{l}\text { Tema: (andes OR andin* OR Venezuela OR Colombia OR Ecuador } \\
\text { OR Perú OR Bolivia OR puna OR yunga OR páramo OR jalca) AND } \\
\text { Tema: (bosque OR árbol OR arbor* OR arbust* OR agroforest* OR } \\
\text { leños* OR cerco OR terraza OR lindero OR barbecho OR frut* } \\
\text { OR restaur* OR deforest* OR degrad* OR fragment* OR reforest* } \\
\text { OR uso del suelo) AND Tema: (hidr* OR agua OR precipitación* } \\
\text { OR evapotranspiración* OR infiltración* OR caudal OR cuenca OR } \\
\text { intercepción OR flujo de caída OR flujo caulinar OR escorrentía OR } \\
\text { percolación) }\end{array}$ \\
\hline \multirow{2}{*}{$\begin{array}{l}\text { Web of } \\
\text { Science }\end{array}$} & $\begin{array}{l}\text { C: Ubicación, vegetación } \\
\text { y conocimiento ecológico } \\
\text { tradicional } \\
\text { I: Inglés } \\
\text { B: Título }\end{array}$ & $\begin{array}{l}\text { ((Título: }(((((((((\text { andes OR andean) OR Venezuela) OR Colombia) } \\
\text { OR Ecuador) OR Perú) OR Bolivia) OR puna) OR yungas) OR } \\
\text { paramo) OR jalna) AND Título: }((((((((()((\text { forest OR tree) OR } \\
\text { shrub) OR woody) OR agroforest*) OR hedge*) OR orchard) OR } \\
\text { fallow) OR restor*) OR deforest*) OR degrad*) OR fragment*) } \\
\text { OR reforest*) OR land use)) AND Título: ((local knowledge OR } \\
\text { indigenous knowledge) OR traditional knowledge)) }\end{array}$ \\
\hline & $\begin{array}{l}\text { C: Ubicación, vegetación } \\
\text { y conocimiento ecológico } \\
\text { tradicional } \\
\text { I: Inglés } \\
\text { B: Tema }\end{array}$ & $\begin{array}{l}\text { ((Tema: }(((((((((\text { andes OR andean) OR Venezuela) OR Colombia) } \\
\text { OR Ecuador) OR Perú) OR Bolivia) OR puna) OR yungas) OR } \\
\text { paramo) OR jalna) AND Tema: ((((((((((((forest OR tree) OR } \\
\text { shrub) OR woody) OR agroforest*) OR hedge*) OR orchard) OR } \\
\text { fallow) OR restor*) OR deforest*) OR degrad*) OR fragment*) } \\
\text { OR reforest*) OR land use)) AND Tema: ((local knowledge OR } \\
\text { indigenous knowledge) OR traditional knowledge)) }\end{array}$ \\
\hline
\end{tabular}




\begin{tabular}{|c|c|c|}
\hline $\begin{array}{l}\text { Motor de } \\
\text { búsqueda }\end{array}$ & Características & Fórmula empleada \\
\hline \multirow{5}{*}{ CAB Direct } & $\begin{array}{l}\text { C: Ubicación, vegetación y } \\
\text { ciclo hidrológico } \\
\text { I: Inglés } \\
\text { B: Título }\end{array}$ & 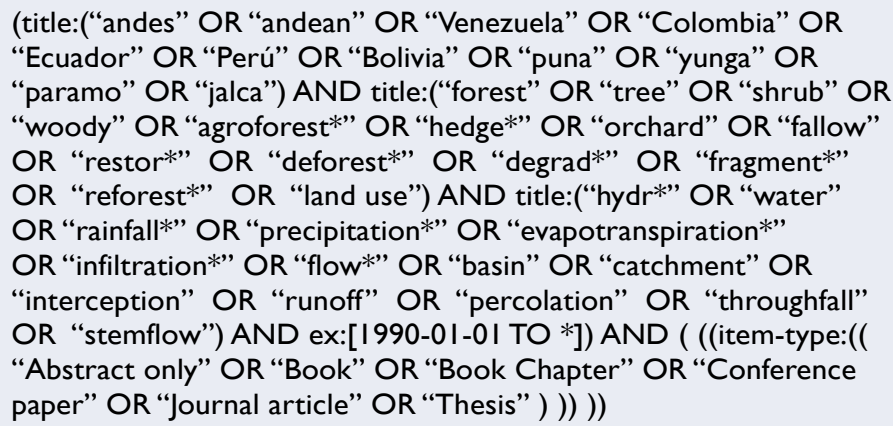 \\
\hline & $\begin{array}{l}\text { C: Ubicación, vegetación y } \\
\text { ciclo hidrológico } \\
\text { I: Inglés } \\
\text { B: Resumen }\end{array}$ & 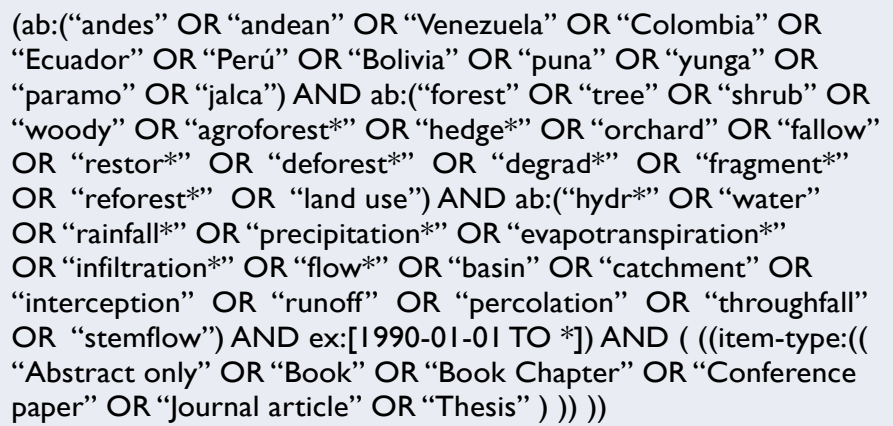 \\
\hline & $\begin{array}{l}\text { C: Ubicación, vegetación y } \\
\text { ciclo hidrológico } \\
\text { I: Español } \\
\text { B: Título }\end{array}$ & 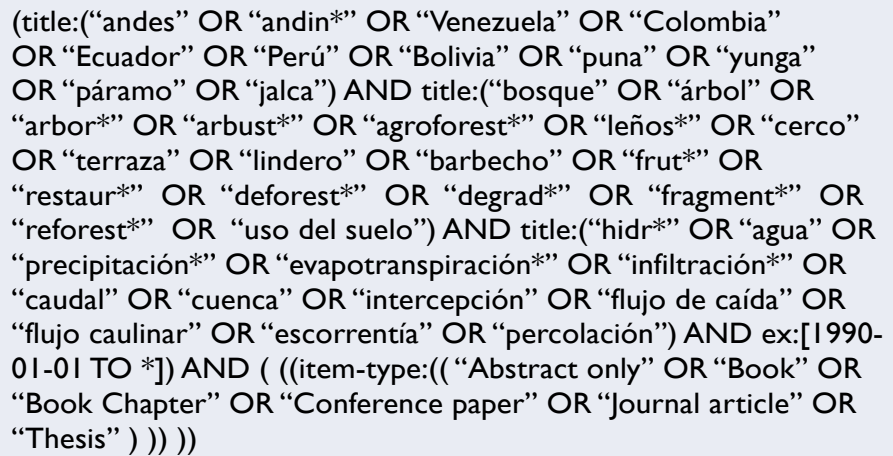 \\
\hline & $\begin{array}{l}\text { C: Ubicación, vegetación y } \\
\text { ciclo hidrológico } \\
\text { I: Español } \\
\text { B: Resumen }\end{array}$ & 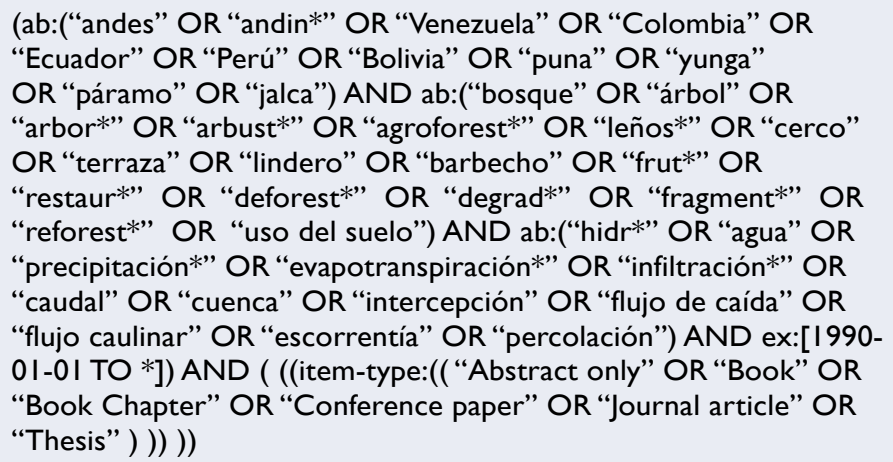 \\
\hline & $\begin{array}{l}\text { C: Ubicación, vegetación } \\
\text { y conocimiento ecológico } \\
\text { tradicional } \\
\text { I: Inglés } \\
\text { B: Todos }\end{array}$ & 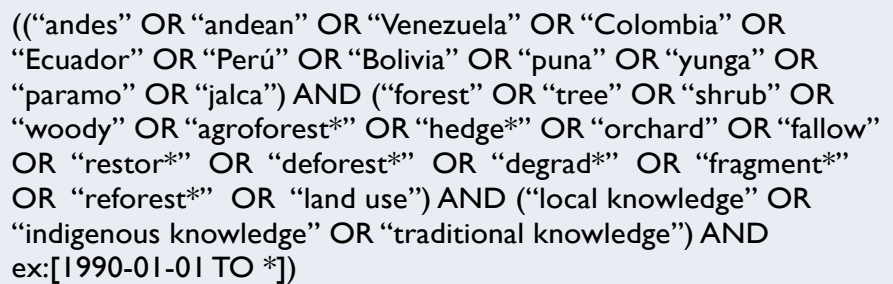 \\
\hline
\end{tabular}




\begin{tabular}{|c|c|c|}
\hline $\begin{array}{l}\text { Motor de } \\
\text { búsqueda }\end{array}$ & Características & Fórmula empleada \\
\hline \multirow{2}{*}{$\begin{array}{l}\text { Google } \\
\text { Scholar }\end{array}$} & \multirow{2}{*}{$\begin{array}{l}\text { C: Ubicación, vegetación y } \\
\text { ciclo hidrológico } \\
\text { I: Inglés } \\
\text { (Primeros } 100 \text { resultados en } \\
\text { cada búsqueda) }\end{array}$} & $\begin{array}{l}\text { andes OR Venezuela OR Colombia OR Ecuador OR Perú OR Bolivia } \\
\text { AND forest OR tree OR shrub OR agroforestry AND hydrological } \\
\text { OR water OR rainfall OR precipitation OR evapotranspiration OR } \\
\text { infiltration OR flow OR basin OR catchment }\end{array}$ \\
\hline & & $\begin{array}{l}\text { andes OR Venezuela OR Colombia OR Ecuador OR Perú OR } \\
\text { Bolivia AND restoration OR deforestation OR degradation OR } \\
\text { fragmentation OR land use AND hydrological OR water OR rainfall } \\
\text { OR precipitation OR evapotranspiration OR infiltration OR flow OR } \\
\text { basin OR catchment }\end{array}$ \\
\hline \multirow{7}{*}{$\begin{array}{l}\text { Google } \\
\text { Scholar }\end{array}$} & \multirow{2}{*}{$\begin{array}{l}\text { C: Ubicación, vegetación y } \\
\text { ciclo hidrológico } \\
\text { I: Inglés } \\
\text { (Primeros } 100 \text { resultados en } \\
\text { cada búsqueda) }\end{array}$} & $\begin{array}{l}\text { andes OR Venezuela OR Colombia OR Ecuador OR Perú OR Bolivia } \\
\text { AND forest OR tree OR shrub OR agroforestry AND interception } \\
\text { OR runoff OR percolation OR throughfall OR stemflow }\end{array}$ \\
\hline & & $\begin{array}{l}\text { andes OR Venezuela OR Colombia OR Ecuador OR Perú OR } \\
\text { Bolivia AND restoration OR deforestation OR degradation OR } \\
\text { fragmentation OR land use AND interception OR runoff OR } \\
\text { percolation OR throughfall OR stemflow }\end{array}$ \\
\hline & \multirow{4}{*}{$\begin{array}{l}\text { C: Ubicación, vegetación y } \\
\text { ciclo hidrológico } \\
\text { I: Español } \\
\text { (Primeros } 100 \text { resultados en } \\
\text { cada búsqueda) }\end{array}$} & $\begin{array}{l}\text { andes OR Venezuela OR Colombia OR Ecuador OR Perú OR Bolivia } \\
\text { AND bosque OR árbol OR arbusto OR leños OR agroforestería } \\
\text { AND Hídric OR agua OR precipitación OR evapotranspiración OR } \\
\text { infiltración OR caudal OR Cuenca OR intercepción OR escorrentía }\end{array}$ \\
\hline & & $\begin{array}{l}\text { andes OR Venezuela OR Colombia OR Ecuador OR Perú OR Bolivia } \\
\text { AND frutal OR restauración OR deforestación OR degradación } \\
\text { OR reforestación OR uso del suelo AND Hídric OR agua OR } \\
\text { precipitación OR evapotranspiración OR infiltración OR caudal OR } \\
\text { cuenca }\end{array}$ \\
\hline & & $\begin{array}{l}\text { andes OR Venezuela OR Colombia OR Ecuador OR Perú OR Bolivia } \\
\text { AND bosque OR árbol OR arbusto OR leños OR agroforestería } \\
\text { AND Hídrico OR percolación OR flujo }\end{array}$ \\
\hline & & $\begin{array}{l}\text { andes OR Venezuela OR Colombia OR Ecuador OR Perú OR Bolivia } \\
\text { AND frutal OR restauración OR deforestación OR degradación OR } \\
\text { reforestación OR uso del suelo AND Hídrico OR percolación OR flujo }\end{array}$ \\
\hline & $\begin{array}{l}\text { C: Ubicación, vegetación } \\
\text { y conocimiento ecológico } \\
\text { tradicional } \\
\text { I: Inglés } \\
\text { (Primeros } 100 \text { resultados) }\end{array}$ & $\begin{array}{l}\text { andes OR Venezuela OR Colombia OR Ecuador OR Perú OR } \\
\text { Bolivia AND forest OR tree OR shrub OR agroforestry restoration } \\
\text { OR deforestation OR degradation OR fragmentation OR land use } \\
\text { AND local knowledge OR indigenous knowledge OR traditional } \\
\text { knowledge }\end{array}$ \\
\hline \multirow{2}{*}{ SciELO } & $\begin{array}{l}\text { C: Ubicación, vegetación y } \\
\text { ciclo hidrológico } \\
\text { I: Español }\end{array}$ & $\begin{array}{l}\text { ((bosque OR árbol OR arbusto OR leñosa OR agroforestería } \\
\text { OR cerco OR terraza OR lindero OR barbecho OR frutal OR } \\
\text { restauración OR deforestación OR degradación OR reforestación } \\
\text { OR uso del suelo) AND (hídrico OR agua OR precipitación OR } \\
\text { evapotranspiración OR infiltración OR caudal OR cuenca OR } \\
\text { intercepción OR escorrentía OR percolación OR flujo)) AND (andes } \\
\text { OR Venezuela OR Colombia OR Ecuador OR Perú OR Bolivia) }\end{array}$ \\
\hline & $\begin{array}{l}\text { C: Ubicación, vegetación } \\
\text { y conocimiento ecológico } \\
\text { tradicional } \\
\text { I: Español }\end{array}$ & $\begin{array}{l}\text { ((bosque OR árbol OR arbusto OR leñosa OR agroforestería } \\
\text { OR cerco OR terraza OR lindero OR barbecho OR frutal OR } \\
\text { restauración OR deforestación OR degradación OR reforestación } \\
\text { OR uso del suelo) AND (conocimiento local OR conocimiento } \\
\text { indígena OR conocimiento tradicional)) AND (andes OR Venezuela } \\
\text { OR Colombia OR Ecuador OR Perú OR Bolivia ) }\end{array}$ \\
\hline
\end{tabular}




\begin{tabular}{|c|c|c|}
\hline $\begin{array}{l}\text { Motor de } \\
\text { búsqueda }\end{array}$ & Características & Fórmula empleada \\
\hline \multirow{5}{*}{ Redalyc } & \multirow{4}{*}{$\begin{array}{l}\text { C: Ubicación, vegetación y } \\
\text { ciclo hidrológico } \\
\text { I: Español } \\
\text { (Primeros } 100 \text { resultados en } \\
\text { cada búsqueda) }\end{array}$} & "árbol AND agua" \\
\hline & & "bosque AND agua" \\
\hline & & “plantación AND agua” \\
\hline & & “agroforestería AND agua” \\
\hline & $\begin{array}{l}\text { C: Ubicación, vegetación } \\
\text { y conocimiento ecológico } \\
\text { tradicional } \\
\text { I: Español } \\
\text { (Primeros } 100 \text { resultados) }\end{array}$ & $\begin{array}{l}\text { "agua AND árbol OR bosque OR plantación OR agroforestería } \\
\text { AND conocimiento local" }\end{array}$ \\
\hline \multirow{2}{*}{ Repositorios } & $\begin{array}{l}\text { C: Ubicación, vegetación y } \\
\text { ciclo hidrológico } \\
\text { I: Español }\end{array}$ & agroforest* OR árbol OR bosque OR plantación AND agua \\
\hline & $\begin{array}{l}\text { C: Ubicación, ciclo hidrológico } \\
\text { y conocimiento local } \\
\text { I: Español }\end{array}$ & $\begin{array}{l}\text { agroforest* OR arbol OR bosque OR plantacion AND agua AND } \\
\text { conocimiento local OR conocimiento tradicional OR conocimiento } \\
\text { indigena }\end{array}$ \\
\hline
\end{tabular}

Nota: C: Combinaciones de categorías de búsqueda (ubicación, vegetación, ciclo hidrológico, conocimiento ecológico tradicional); I: Idioma de búsqueda; B: Criterios de búsqueda (título, resumen, etc.)

\section{Anexo 2. Categorías de sistematización empleadas para Andes}

\begin{tabular}{|c|c|c|}
\hline \multicolumn{2}{|c|}{ Categorías de sistematización } & Descripción/Palabras claves \\
\hline \multirow{4}{*}{ Información general } & Titulo & \\
\hline & Autor (es) & \\
\hline & Año de publicación & \\
\hline & Tipo de publicación & Artículo, tesis, libro, sección de libro, reporte \\
\hline \multirow{6}{*}{$\begin{array}{l}\text { Características del área } \\
\text { de estudio }\end{array}$} & Escala & Cuenca, sub cuenca, parcela \\
\hline & Ubicación & $\begin{array}{l}\text { Ciudad, Región, o ciudad (cordillera occidental u oriental, } \\
\text { cabecera de la cuenca hidrográfica, ribera del río) }\end{array}$ \\
\hline & Coordenadas geográficas & Latitud, longitud \\
\hline & Clima & Temperatura, precipitación, humedad relativa \\
\hline & Altitud & Rango de altitud \\
\hline & Suelo & Tipo, textura, \%materia orgánica, pendiente, $\mathrm{pH}$ \\
\hline \multirow{4}{*}{ Metodología } & Objetivo (s) & \\
\hline & Tiempo & Duración/año (s)/época húmeda o seca \\
\hline & Métodos & Métodos de medición utilizados \\
\hline & Resumen de métodos & Palabras clave referentes al método utilizado \\
\hline
\end{tabular}




\section{Categorías de sistematización}

Especie (s)

Rasgos de la (s) especie (s)

Usos generales de la tierra

Usos específicos de la tierra

Procesos hidrológicos

Aspectos claves de la investigación

\section{Descripción/Palabras claves}

Nombre científico de especies nativas/exóticas de árboles $y$ arbustos

Tasa de transpiración, índice de área foliar, conductividad de estomas, flujo de savia, grosor de raíz, distribución de raíz, profundidad de enraizamiento (si influye)

Términos estándar de usos específicos de la tierra

Forestación, reforestación, agroforestería, bosque regeneración, pastoreo, cultivo, tierra degradada entre otros

Precipitación total, precipitación horizontal, precipitación neta, intercepción, flujo de caída, flujo caulinar, evapotranspiración, infiltración, escorrentía superficial, percolación, flujo de la corriente, rendimiento de agua

Densidad y edad de la plantación, manejo silvicultural, disposición espacial o prácticas agroforestales (cerco, cortinas rompeviento, terraza, vegetación en el cabezal de la cuenca entre otras)

Servicios hidrológicos (provisión y regulación), conservación, control de la erosión, mitigación de riesgos (movimiento de masas, inundaciones, sequía, incendios forestales), producción (productos forestales maderables y no maderables, productos agrícolas)

En particular: Relación entre plantas leñosas, usos de la tierra y procesos hidrológicos

Palabras específicas o frases que se refieren a los resultados claves

claves

Recomendaciones

Vacíos de conocimiento

\section{Anexo 3. Categorías de sistematización empleadas para otros ecosistemas de montaña}

\begin{tabular}{|l|l|l|}
\hline \multicolumn{2}{|c|}{ Categorías de sistematización } & \\
\hline & Titulo & \\
\hline & Autor (es) & \\
\hline Información general & Año de publicación & \\
\hline Tipo de publicación & Artículo, tesis, libro, sección de libro, reporte \\
\hline Características del área & Escala & Cuenca, sub cuenca, parcela \\
\hline de estudio & Ubicación & Ciudad, Región, o ciudad (cordillera occidental u oriental, \\
\hline & cabecera de la cuenca hidrográfica, ribera del río) \\
\hline
\end{tabular}




\section{Categorías de sistematización}

\begin{tabular}{|l|l|}
\hline Metodología & Objetivo (s) \\
\hline & Usos generales de la tierr \\
\hline Aspectos claves de la & Procesos hidrológicos \\
\hline investigación & \\
\hline Otros aspectos & Otros resultados claves \\
\hline Recomendaciones \\
\hline Vacíos de conocimiento
\end{tabular}

\section{Descripción/Palabras claves}

Términos estándar de usos específicos de la tierra

Resultados clasificados en 7 grupos:

Grupo 0: Precipitación total

Grupo I: Precipitación horizontal

Grupo 2: Intercepción y evapotranspiración

Grupo 3: Precipitación neta, flujo caulinar y de caída

Grupo 4: Escorrentía superficial, flujo sub-superficial

Grupo 5: Infiltración, retención hídrica y percolación

Grupo 6: Caudal y rendimiento hídrico

Grupo 7: Calidad del agua

En particular: Relación entre plantas leñosas, usos de la tierra y procesos hidrológicos

\section{Anexo 4. Especies leñosas y su influencia en diferentes procesos del ciclo hidrológico}

\begin{tabular}{|c|c|c|c|c|c|c|}
\hline Especie & Origen & $\begin{array}{c}\text { Proceso } \\
\text { hidrológico }\end{array}$ & $\begin{array}{c}\text { Comparado } \\
\text { con }\end{array}$ & Resultado principal & $\begin{array}{l}\text { Ubicación } \\
\text { y altitud }\end{array}$ & Fuente \\
\hline $\begin{array}{l}\text { Cordia } \\
\text { alliodora }\end{array}$ & Nativa & Intercepción & $\begin{array}{c}\text { Agroforestería, } \\
\text { bosque nativo } \\
\text { y cultivo }\end{array}$ & $\begin{array}{l}\text { SAF café con Cordia registró } \\
\text { una intercepción ligeramente } \\
\text { menor que el bosque y SAF } \\
\text { café con Inga; y mayor que } \\
\text { SAF café con pino, eucalipto } \\
\text { y monocultivo de café } \\
\text { Espaciamiento: I,5xI,5 m (café) } \\
\text { y } 6 \times 6 \text { m (árbol) }\end{array}$ & $\begin{array}{l}\text { Colombia, } \\
\text { Caldas y } \\
\text { Quindío } \\
1250-1300 \\
\text { m s.n.m. }\end{array}$ & $\begin{array}{c}\text { Jaramillo- } \\
\text { Robledo } \\
(2003)\end{array}$ \\
\hline $\begin{array}{l}\text { Cordia } \\
\text { alliodora }\end{array}$ & Nativa & $\begin{array}{l}\text { Escorrentía } \\
\text { superficial }\end{array}$ & $\begin{array}{c}\text { Agroforestería, } \\
\text { bosque nativo } \\
\text { y cultivo }\end{array}$ & $\begin{array}{l}\text { SAF café con Cordia registró } \\
\text { la mayor escorrentía en } \\
\text { comparación con el SAF } \\
\text { café con eucalipto, pino, Inga, } \\
\text { monocultivo de caféy el bosque } \\
\text { Espaciamiento: I,5xI,5 m (café) } \\
\text { y } 6 \times 6 \text { m (árbol) }\end{array}$ & $\begin{array}{l}\text { Colombia, } \\
\text { Caldas and } \\
\text { Quindío } \\
\text { I250- } 1300 \\
\text { m s.n.m. }\end{array}$ & $\begin{array}{c}\text { Jaramillo- } \\
\text { Robledo } \\
(2003)\end{array}$ \\
\hline $\begin{array}{l}\text { Cordia } \\
\text { alliodora }\end{array}$ & Nativa & Intercepción & $\begin{array}{c}\text { Agroforestería } \\
\text { y cultivo }\end{array}$ & $\begin{array}{l}\text { SAF café con Cordia registró } \\
\text { menor intercepción que el SAF } \\
\text { café con pino y eucalipto, y } \\
\text { mayor que el monocultivo de } \\
\text { café Espaciamiento: } 1,5 \times 1,5 \mathrm{~m} \\
\text { (café) y } 6 \times 6 \mathrm{~m} \text { (árbol) }\end{array}$ & $\begin{array}{l}\text { Colombia, } \\
\text { Quindío } \\
\text { I203 m } \\
\text { s.n.m. }\end{array}$ & $\begin{array}{c}\text { Arroyabe } \\
(2012)\end{array}$ \\
\hline
\end{tabular}




\begin{tabular}{|c|c|c|c|c|c|c|}
\hline Especie & Origen & $\begin{array}{c}\text { Proceso } \\
\text { hidrológico }\end{array}$ & $\begin{array}{c}\text { Comparado } \\
\text { con }\end{array}$ & Resultado principal & $\begin{array}{l}\text { Ubicación } \\
\text { y altitud }\end{array}$ & Fuente \\
\hline $\begin{array}{c}\text { Cordia } \\
\text { alliodora }\end{array}$ & Nativa & Evapotranspiración & $\begin{array}{c}\text { Agroforestería } \\
\text { y cultivo }\end{array}$ & $\begin{array}{l}\text { SAF café con Cordia registró } \\
\text { mayor evapotranspiración } \\
\text { que el SAF café con pino } \\
\text { y eucalipto, y menor que } \\
\text { el monocultivo de café } \\
\text { Espaciamiento: I,5xI,5 m (café) } \\
\text { y } 6 \times 6 \text { m (árbol) }\end{array}$ & $\begin{array}{l}\text { Colombia, } \\
\text { Quindío } \\
1203 \mathrm{~m} \\
\text { s.n.m. }\end{array}$ & $\begin{array}{c}\text { Arroyabe } \\
(2012)\end{array}$ \\
\hline $\begin{array}{l}\text { Cordia } \\
\text { alliodora }\end{array}$ & Nativa & $\begin{array}{l}\text { Escorrentía } \\
\text { superficial }\end{array}$ & $\begin{array}{c}\text { Agroforestería } \\
\text { y cultivo }\end{array}$ & $\begin{array}{l}\text { SAF café con Cordia registró } \\
\text { menor escorrentía que } \\
\text { el SAF café con pino y } \\
\text { eucalipto, y mayor que } \\
\text { el monocultivo de café } \\
\text { Espaciamiento: } 1,5 \times 1,5 \mathrm{~m} \text { (café) } \\
\text { y } 6 \times 6 \mathrm{~m} \text { (árbol) }\end{array}$ & $\begin{array}{l}\text { Colombia, } \\
\text { Quindío } \\
1203 \mathrm{~m} \\
\text { s.n.m. }\end{array}$ & $\begin{array}{c}\text { Arroyabe } \\
(2012)\end{array}$ \\
\hline $\begin{array}{l}\text { Cordia } \\
\text { alliodora }\end{array}$ & Nativa & Infiltración & $\begin{array}{c}\text { Agroforestería } \\
\text { y cultivo }\end{array}$ & $\begin{array}{l}\text { Las características de las hojas } \\
\text { de Cordia alliodora influenciaron } \\
\text { en la infiltración, debido a que } \\
\text { concentran mayor cantidad de } \\
\text { agua en la hojarasca }\end{array}$ & $\begin{array}{l}\text { Colombia, } \\
\text { Quindío } \\
\text { I203 m } \\
\text { s.n.m. }\end{array}$ & $\begin{array}{c}\text { Arroyabe } \\
(2012)\end{array}$ \\
\hline $\begin{array}{c}\text { Cordia } \\
\text { alliodora }\end{array}$ & Nativa & Caudal & $\begin{array}{c}\text { Agroforestería } \\
\text { y cultivo }\end{array}$ & $\begin{array}{l}\text { No hubieron diferencias } \\
\text { significativas Espaciamiento: } \\
1,5 \times 1,5 \mathrm{~m} \text { (café) y } 6 \times 6 \mathrm{~m} \\
\text { (árbol) }\end{array}$ & $\begin{array}{l}\text { Colombia, } \\
\text { Quindío } \\
\text { I } 203 \mathrm{~m} \\
\text { s.n.m. }\end{array}$ & $\begin{array}{l}\text { Arroyabe } \\
(20 \mid 2)\end{array}$ \\
\hline $\begin{array}{l}\text { Cordia } \\
\text { alliodora }\end{array}$ & Nativa & $\begin{array}{l}\text { Escorrentía } \\
\text { superficial }\end{array}$ & $\begin{array}{l}\text { Bosque nativo, } \\
\text { plantación } \\
\text { de bambú y } \\
\text { cultivo }\end{array}$ & $\begin{array}{l}\text { No hubieron diferencias } \\
\text { significativas Espaciamiento: } \\
\text { I,5xI,5 m (café) y } 6 \times 6 \mathrm{~m} \\
\text { (árbol) }\end{array}$ & $\begin{array}{l}\text { Colombia, } \\
\text { Quindío } \\
\text { Il00 m } \\
\text { s.n.m. }\end{array}$ & $\begin{array}{l}\text { Rodríguez } \\
\text { y Camargo } \\
(2009)\end{array}$ \\
\hline $\begin{array}{l}\text { Cuppressus } \\
\text { lusitanica }\end{array}$ & Exótica & Infiltración & $\begin{array}{l}\text { Bosque nativo } \\
\text { y plantación de } \\
\text { eucalipto }\end{array}$ & $\begin{array}{l}\text { Plantación de ciprés } \\
\text { registró mayor infiltración } \\
\text { en comparación con el } \\
\text { eucalipto y el bosque } \\
\text { Densidad de ciprés: } 2500 \text { árb/ha }\end{array}$ & $\begin{array}{l}\text { Colombia, } \\
\text { Bogotá } \\
3000-3600 \\
\text { m s.n.m. }\end{array}$ & $\begin{array}{l}\text { García } \\
(2007)\end{array}$ \\
\hline $\begin{array}{l}\text { Cuppressus } \\
\text { lusitanica }\end{array}$ & Exótica & $\begin{array}{l}\text { Escorrentía } \\
\text { superficial }\end{array}$ & $\begin{array}{c}\text { Bosque } \\
\text { de roble y } \\
\text { plantación de } \\
\text { pino }\end{array}$ & $\begin{array}{l}\text { Plantación de ciprés de } \\
39 \text { años registró mayor } \\
\text { escorrentía que la plantación } \\
\text { de pino y bosque de roble } \\
\text { Densidad de ciprés: } 615 \text { árb/ha }\end{array}$ & $\begin{array}{l}\text { Colombia, } \\
\text { Antioquia } \\
2400 \mathrm{~m} \\
\text { s.n.m. }\end{array}$ & $\begin{array}{l}\text { Ruíz et al. } \\
\text { (2005) }\end{array}$ \\
\hline $\begin{array}{l}\text { Cuppressus } \\
\text { lusitanica }\end{array}$ & Exótica & Flujo caulinar & $\begin{array}{l}\text { Bosque nativo } \\
\text { de roble y } \\
\text { plantación de } \\
\text { pino }\end{array}$ & $\begin{array}{l}\text { Plantación de ciprés registró } \\
\text { mayor flujo caulinar que los } \\
\text { otros usos, un resultado que } \\
\text { es probablemente influenciado } \\
\text { por la arquitectura del árbol } \\
\text { (grado de inclinación de las } \\
\text { ramas en su inserción con los } \\
\text { tallos y carácter monopódico) }\end{array}$ & $\begin{array}{l}\text { Colombia, } \\
\text { Antioquia } \\
2490 \text { m s.n. } \\
\text { m. }\end{array}$ & $\begin{array}{l}\text { León et al. } \\
\text { (2010) }\end{array}$ \\
\hline $\begin{array}{l}\text { Cuppressus } \\
\text { sp. }\end{array}$ & Exótica & $\begin{array}{c}\text { Intercepción/ } \\
\text { Evapotranspiración }\end{array}$ & $\begin{array}{l}\text { Bosque nativo } \\
\text { y plantación de } \\
\text { eucalipto }\end{array}$ & $\begin{array}{l}\text { Plantación de ciprés registró } \\
\text { mayor intercepción y menor } \\
\text { evapotranspiración que bosque } \\
\text { y plantación de eucalipto } \\
\text { Espaciamiento: } 3 \times 3 \mathrm{~m}\end{array}$ & $\begin{array}{l}\text { Colombia, } \\
\text { Cundinamarca } \\
\text { 3200-3600 m } \\
\text { s.n.m. }\end{array}$ & $\begin{array}{l}\text { De las } \\
\text { Salas y } \\
\text { García } \\
(2000)\end{array}$ \\
\hline
\end{tabular}




\begin{tabular}{|c|c|c|c|c|c|c|}
\hline Especie & Origen & $\begin{array}{l}\text { Proceso } \\
\text { hidrológico }\end{array}$ & $\begin{array}{l}\text { Comparado } \\
\text { con }\end{array}$ & Resultado principal & $\begin{array}{l}\text { Ubicación } \\
y \text { altitud }\end{array}$ & Fuente \\
\hline $\begin{array}{l}\text { Cuppressus } \\
\text { sp. }\end{array}$ & Exótica & $\begin{array}{l}\text { Precipitación neta/ } \\
\text { Flujo caulinar }\end{array}$ & $\begin{array}{l}\text { Bosque nativo } \\
\text { y plantación de } \\
\text { eucalipto }\end{array}$ & $\begin{array}{l}\text { Plantación de ciprés registró } \\
\text { menor precipitación neta y } \\
\text { flujo caulinar que bosque } \\
\text { y plantación de eucalipto } \\
\text { Espaciamiento: } 3 \times 3 \mathrm{~m}\end{array}$ & $\begin{array}{l}\text { Colombia, } \\
\text { Cundinamarca } \\
3200-3600 \mathrm{~m} \\
\text { s.n.m. }\end{array}$ & $\begin{array}{l}\text { De las } \\
\text { Salas y } \\
\text { García } \\
(2000)\end{array}$ \\
\hline $\begin{array}{l}\text { Eucalyptus } \\
\text { globulus }\end{array}$ & Exótica & Precipitación neta & $\begin{array}{l}\text { Bosque nativo } \\
\text { y plantación de } \\
\text { ciprés }\end{array}$ & $\begin{array}{l}\text { Plantación de eucalipto registró } \\
\text { mayor precipitación neta que el } \\
\text { bosque y plantación de ciprés }\end{array}$ & $\begin{array}{l}\text { Colombia, } \\
\text { Cundinamarca } \\
\text { 3200-3600 m } \\
\text { s.n.m. }\end{array}$ & $\begin{array}{l}\text { De las } \\
\text { Salas y } \\
\text { García } \\
(2000)\end{array}$ \\
\hline $\begin{array}{l}\text { Eucalyptus } \\
\text { globulus }\end{array}$ & Exótica & $\begin{array}{c}\text { Intercepción/ } \\
\text { Evapotranspiración }\end{array}$ & $\begin{array}{c}\text { Bosque nativo } \\
\text { y plantación de } \\
\text { ciprés }\end{array}$ & $\begin{array}{l}\text { Plantación de eucalipto registró } \\
\text { menor intercepción y mayor } \\
\text { evapotranspiración que el } \\
\text { bosque y plantación de ciprés }\end{array}$ & $\begin{array}{l}\text { Colombia, } \\
\text { Cundinamarca } \\
\text { 3200-3600 m } \\
\text { s.n.m. }\end{array}$ & $\begin{array}{l}\text { De las } \\
\text { Salas y } \\
\text { García } \\
(2000)\end{array}$ \\
\hline $\begin{array}{l}\text { Eucalyptus } \\
\text { globulus }\end{array}$ & Exótica & Intercepción & $\begin{array}{l}\text { Bosque nativo } \\
\text { y plantación de } \\
\text { ciprés }\end{array}$ & $\begin{array}{l}\text { Plantación de eucalipto registró } \\
\text { menor intercepción que el } \\
\text { bosque y plantación de ciprés } \\
\text { Densidad: } 1500 \text { árb/ha }\end{array}$ & $\begin{array}{l}\text { Colombia, } \\
\text { Bogotá } \\
3000-3600 \\
\text { m s.n.m. }\end{array}$ & $\begin{array}{l}\text { García } \\
(2007)\end{array}$ \\
\hline $\begin{array}{l}\text { Eucalyptus } \\
\text { globulus }\end{array}$ & Exótica & Caudal & $\begin{array}{l}\text { Bosque nativo } \\
\text { y plantación de } \\
\text { ciprés }\end{array}$ & $\begin{array}{l}\text { Plantación de eucalipto registró } \\
\text { menor regulación hídrica } \\
\text { Densidad : } 1500 \text { árb/ha }\end{array}$ & $\begin{array}{l}\text { Colombia, } \\
\text { Bogotá } \\
3000-3600 \\
\text { m s.n.m. }\end{array}$ & $\begin{array}{l}\text { García } \\
(2007)\end{array}$ \\
\hline $\begin{array}{l}\text { Eucalyptus } \\
\text { globulus }\end{array}$ & Exótica & Caudal & Bosque nativo & $\begin{array}{l}\text { La plantación de eucalipto } \\
\text { redujo los flujos pico }\end{array}$ & $\begin{array}{l}\text { Ecuador, } \\
\text { Cuenca }\end{array}$ & $\begin{array}{l}\text { Molina et } \\
\text { al. }(20 \mid 2)\end{array}$ \\
\hline $\begin{array}{l}\text { Eucalyptus } \\
\text { grandis }\end{array}$ & Exótica & Retención hídrica & $\begin{array}{c}\text { Agroforestería } \\
\text { y cultivo }\end{array}$ & $\begin{array}{l}\text { Las características de } \\
\text { las hojas de Eucalyptus } \\
\text { grandis influenciaron } \\
\text { en la concentración de } \\
\text { más agua en la hojarasca } \\
\text { Espaciamiento: I,5xI,5 m (café) } \\
\text { y } 6 \times 6 \text { m (árbol) }\end{array}$ & $\begin{array}{l}\text { Colombia, } \\
\text { Quindío } \\
\text { I } 203 \mathrm{~m} \\
\text { s.n.m. }\end{array}$ & $\begin{array}{l}\text { Arroyabe } \\
(2012)\end{array}$ \\
\hline $\begin{array}{l}\text { Eucalyptus } \\
\text { grandis }\end{array}$ & Exótica & $\begin{array}{l}\text { Escorrentía } \\
\text { superficial }\end{array}$ & $\begin{array}{l}\text { Agroforestería } \\
\text { y cultivo }\end{array}$ & $\begin{array}{l}\text { SAF café con eucalipto } \\
\text { registró mayor escorrentía } \\
\text { que SAF café con pino, } \\
\text { Inga y monocultivo de café } \\
\text { Espaciamiento: I,5xI,5 } \mathrm{m} \text { (café) } \\
\text { y } 6 \times 6 \mathrm{~m} \text { (árbol) }\end{array}$ & $\begin{array}{l}\text { Colombia, } \\
\text { Caldas y } \\
\text { Quindío } \\
\text { I250-I300 } \\
\text { m s.n.m. }\end{array}$ & $\begin{array}{l}\text { Jaramillo- } \\
\text { Robledo } \\
(2003)\end{array}$ \\
\hline $\begin{array}{l}\text { Eucalyptus } \\
\text { grandis }\end{array}$ & Exótica & Intercepción & $\begin{array}{l}\text { Agroforestería } \\
\text { y cultivo }\end{array}$ & $\begin{array}{l}\text { SAF café con eucalipto registró } \\
\text { menor intercepción que SAF } \\
\text { café con Inga, Cordia y pino y, } \\
\text { mayor al monocultivo de café } \\
\text { Espaciamiento: } 1,5 \times 1,5 \mathrm{~m} \\
\text { (café) y } 6 \times 6 \mathrm{~m} \text { (árbol) }\end{array}$ & $\begin{array}{l}\text { Colombia, } \\
\text { Caldas y } \\
\text { Quindío } \\
\text { I250-I300 } \\
\text { m s.n.m. }\end{array}$ & $\begin{array}{l}\text { Jaramillo- } \\
\text { Robledo } \\
\text { (2003) }\end{array}$ \\
\hline Inga sp. & Nativa & Intercepción & $\begin{array}{l}\text { Agroforestería, } \\
\text { bosque nativo } \\
\text { y cultivo }\end{array}$ & $\begin{array}{l}\text { SAF café con Inga registró } \\
\text { la mayor intercepción junto } \\
\text { al bosque y el SAF café con } \\
\text { Inga; y mayor que el SAF } \\
\text { café con pino, eucalipto } \\
\text { y monocultivo de café } \\
\text { Espaciamiento: } 2 \times 1 \text { m (café) y } \\
\text { I2x। } \mathrm{m} \text { (árbol) }\end{array}$ & $\begin{array}{l}\text { Colombia, } \\
\text { Caldas y } \\
\text { Quindío } \\
\text { I250-1300 } \\
\text { m s.n.m. }\end{array}$ & $\begin{array}{l}\text { Jaramillo- } \\
\text { Robledo } \\
(2003)\end{array}$ \\
\hline
\end{tabular}




\begin{tabular}{|c|c|c|c|c|c|c|}
\hline Especie & Origen & $\begin{array}{c}\text { Proceso } \\
\text { hidrológico }\end{array}$ & $\begin{array}{l}\text { Comparado } \\
\text { con }\end{array}$ & Resultado principal & $\begin{array}{l}\text { Ubicación } \\
\text { y altitud }\end{array}$ & Fuente \\
\hline Inga sp. & Nativa & $\begin{array}{l}\text { Escorrentía } \\
\text { superficial }\end{array}$ & $\begin{array}{c}\text { Agroforestería } \\
\text { y cultivo }\end{array}$ & $\begin{array}{l}\text { SAF café con Inga registró } \\
\text { mayor intercepción que el } \\
\text { monocultivo de café }\end{array}$ & $\begin{array}{l}\text { Venezuela, } \\
\text { Trujillo } \\
1200 \mathrm{~m} \\
\text { s.n.m. }\end{array}$ & $\begin{array}{l}\text { Arellano } \\
(2001)\end{array}$ \\
\hline $\begin{array}{l}\text { Mangifera } \\
\text { indica }\end{array}$ & Exótica & Flujo de caída & Agroforestería & $\begin{array}{l}\text { SAF café con Mangifera } \\
\text { registró mayor flujo de caída } \\
\text { en comparación con el SAF } \\
\text { café con Inga debido a las } \\
\text { características de la especie } \\
\text { (menor extensión de ramas } \\
\text { y superficie lisa de las hojas) } \\
\text { Espaciamiento: I,4xI,2 m (café) } \\
\text { y } 6 \times 6 \text { (árbol) }\end{array}$ & $\begin{array}{l}\text { Colombia, } \\
\text { Cauca } \\
\text { I340-I430 } \\
\text { m s.n.m. }\end{array}$ & $\begin{array}{l}\text { Gaitán et } \\
\text { al. (2016) }\end{array}$ \\
\hline $\begin{array}{l}\text { Pinus } \\
\text { oocarpa }\end{array}$ & Exótica & $\begin{array}{l}\text { Intercepción/ } \\
\text { Evapotranspiración }\end{array}$ & $\begin{array}{l}\text { Agroforestería } \\
\text { y cultivo }\end{array}$ & $\begin{array}{l}\text { SAF cafécon pino registró } \\
\text { mayor intercepción y menor } \\
\text { evapotranspiración que } \\
\text { el SAF café con eucalipto, } \\
\text { Cordia y monocultivo de café } \\
\text { Espaciamiento: I,5xI,5 m (café) } \\
\text { y } 6 \times 6 \text { m (árbol) }\end{array}$ & $\begin{array}{l}\text { Colombia, } \\
\text { Quindío } \\
1203 \mathrm{~m} \\
\text { s.n.m. }\end{array}$ & $\begin{array}{l}\text { Arroyabe } \\
(2012)\end{array}$ \\
\hline $\begin{array}{l}\text { Pinus } \\
\text { oocarpa }\end{array}$ & Exótica & Infiltración & $\begin{array}{l}\text { Agroforestería } \\
\text { y cultivo }\end{array}$ & $\begin{array}{l}\text { SAF café con pino registró baja } \\
\text { infiltración, que podría estar } \\
\text { relacionado con la estructura y } \\
\text { disposición de sus acículas que } \\
\text { favorecen la escorrentía y las } \\
\text { características de su cutícula } \\
\text { hidrófoba, que rechaza la } \\
\text { acumulación en la hojarasca }\end{array}$ & $\begin{array}{l}\text { Colombia, } \\
\text { Quindío } \\
1203 \mathrm{~m} \\
\text { s.n.m. }\end{array}$ & $\begin{array}{l}\text { Arroyabe } \\
(20 \mid 2)\end{array}$ \\
\hline $\begin{array}{l}\text { Pinus } \\
\text { patula }\end{array}$ & Exótica & Flujo caulinar & $\begin{array}{c}\text { Bosque } \\
\text { de roble y } \\
\text { plantación de } \\
\text { ciprés }\end{array}$ & $\begin{array}{l}\text { Plantación de pino registró } \\
\text { altos valores de flujo caulinar } \\
\text { al igual que el ciprés debido } \\
\text { a su mayor uniformidad } \\
\text { estructural en comparación } \\
\text { conl bosque }\end{array}$ & $\begin{array}{l}\text { Colombia, } \\
\text { Antioquia } \\
2490 \text { m s.n. } \\
\text { m. }\end{array}$ & $\begin{array}{l}\text { León et al. } \\
\qquad(2010)\end{array}$ \\
\hline $\begin{array}{l}\text { Pinus } \\
\text { patula }\end{array}$ & Exótica & Caudal & $\begin{array}{l}\text { Bosque nativo } \\
\text { y pajonal }\end{array}$ & $\begin{array}{l}\text { Plantación de pino registró } \\
\text { menor caudal y menor } \\
\text { capacidad de regulación }\end{array}$ & $\begin{array}{l}\text { Ecuador, } \\
\text { Azuay } \\
2900-3700 \\
\text { m s.n.m. }\end{array}$ & $\begin{array}{l}\text { Aichholzer } \\
\text { y Durán } \\
(2010)\end{array}$ \\
\hline $\begin{array}{l}\text { Pinus } \\
\text { patula }\end{array}$ & Exótica & Caudal & $\begin{array}{l}\text { Páramo y } \\
\text { cultivos }\end{array}$ & $\begin{array}{l}\text { Plantación de pino redujo el } \\
\text { caudal en casi la mitad, así } \\
\text { como los flujos base y flujo } \\
\text { pico }\end{array}$ & $\begin{array}{l}\text { Ecuador, } \\
\text { Cuenca } \\
2980-4100 \\
\text { m s.n.m. }\end{array}$ & $\begin{array}{l}\text { Buytaert et } \\
\text { al. (2007) }\end{array}$ \\
\hline $\begin{array}{l}\text { Pinus } \\
\text { patula }\end{array}$ & Exótica & Evapotranspiración & $\begin{array}{l}\text { Páramo y } \\
\text { cultivos }\end{array}$ & $\begin{array}{l}\text { Plantación de pino registró } \\
\text { mayor evapotranspiración }\end{array}$ & $\begin{array}{l}\text { Ecuador, } \\
\text { Cuenca } \\
2980-4100 \\
\text { m s.n.m. }\end{array}$ & $\begin{array}{l}\text { Buytaert et } \\
\text { al. (2007) }\end{array}$ \\
\hline $\begin{array}{l}\text { Pinus } \\
\text { patula }\end{array}$ & Exótica & Intercepción & $\begin{array}{l}\text { Bosques y } \\
\text { cultivos }\end{array}$ & $\begin{array}{l}\text { Plantación de pino registró } \\
\text { mayor interceptación, } \\
\text { reduciendo la escorrentía en } \\
\text { época seca }\end{array}$ & $\begin{array}{l}\text { Ecuador } \\
\text { I743-4I00 } \\
\text { m s.n.m. }\end{array}$ & $\begin{array}{l}\text { Crespo et } \\
\text { al. }(2011)\end{array}$ \\
\hline
\end{tabular}




\begin{tabular}{|c|c|c|c|c|c|c|}
\hline Especie & Origen & $\begin{array}{c}\text { Proceso } \\
\text { hidrológico }\end{array}$ & $\begin{array}{c}\text { Comparado } \\
\text { con }\end{array}$ & Resultado principal & $\begin{array}{l}\text { Ubicación } \\
\text { y altitud }\end{array}$ & Fuente \\
\hline $\begin{array}{l}\text { Pinus } \\
\text { patula }\end{array}$ & Exótica & Caudal & $\begin{array}{l}\text { Bosques y } \\
\text { cultivos }\end{array}$ & $\begin{array}{l}\text { No se reportaron diferencias } \\
\text { debido al bajo impacto de las } \\
\text { actividades antrópicas }\end{array}$ & $\begin{array}{l}\text { Ecuador } \\
1743-4100 \\
\text { m s.n.m. }\end{array}$ & $\begin{array}{l}\text { Crespo et } \\
\text { al. }(2011)\end{array}$ \\
\hline $\begin{array}{l}\text { Pinus } \\
\text { patula }\end{array}$ & Exótica & Evapotranspiración & $\begin{array}{c}\text { Pastizal y área } \\
\text { abandonada }\end{array}$ & $\begin{array}{l}\text { Plantación de pino de } 20 \text { años } \\
\text { tuvieron mayores valores } \\
\text { Densidad: IIII árb/ha }\end{array}$ & $\begin{array}{l}\text { Ecuador, } \\
\text { Oriental } \\
\text { I800-2100 } \\
\text { m s.n.m. }\end{array}$ & $\begin{array}{l}\text { Knoke et } \\
\text { al. (2014) }\end{array}$ \\
\hline $\begin{array}{l}\text { Pinus } \\
\text { patula }\end{array}$ & Exótica & Intercepción & $\begin{array}{c}\text { Pastizal y área } \\
\text { abandonada }\end{array}$ & $\begin{array}{l}\text { Plantación de pino y el área } \\
\text { abandonada registraron } \\
\text { mayores valores que pastizal }\end{array}$ & $\begin{array}{l}\text { Ecuador, } \\
\text { Oriental } \\
\text { I800-2100 } \\
\text { m s.n.m. }\end{array}$ & $\begin{array}{l}\text { Knoke et } \\
\text { al. }(2014)\end{array}$ \\
\hline $\begin{array}{l}\text { Pinus } \\
\text { patula }\end{array}$ & Exótica & $\begin{array}{l}\text { Escorrentía } \\
\text { superficial }\end{array}$ & $\begin{array}{c}\text { Bosque } \\
\text { de roble y } \\
\text { plantación de } \\
\text { ciprés }\end{array}$ & $\begin{array}{l}\text { Plantación de pino de } 39 \\
\text { años registró mayor valor } \\
\text { que el bosque y menor } \\
\text { que la plantación de ciprés } \\
\text { Densidad: } 439 \text { árb/ha }\end{array}$ & $\begin{array}{l}\text { Colombia, } \\
\text { Antioquia } \\
2400 \mathrm{~m} \\
\text { s.n.m. }\end{array}$ & $\begin{array}{c}\text { Ruíz et al. } \\
\text { (2005) }\end{array}$ \\
\hline $\begin{array}{l}\text { Pinus } \\
\text { patula }\end{array}$ & Exótica & Retención hídrica & Pastizal & $\begin{array}{l}\text { Plantación de pino de } 25 \text { años } \\
\text { facilitó el rápido movimiento } \\
\text { del agua a través del perfil del } \\
\text { suelo }\end{array}$ & $\begin{array}{l}\text { Ecuador, } \\
\text { Imbabura } \\
3299-3625 \\
\text { m s.n.m. }\end{array}$ & $\begin{array}{l}\text { Harden et } \\
\text { al. (20I3) }\end{array}$ \\
\hline $\begin{array}{l}\text { Pinus } \\
\text { patula }\end{array}$ & Exótica & Caudal & $\begin{array}{c}\text { Bosques } \\
\text { nativos }\end{array}$ & $\begin{array}{l}\text { No hubo una tendencia } \\
\text { con respecto a los bosques, } \\
\text { solo un incremento de la } \\
\text { evapotranspiración }\end{array}$ & $\begin{array}{l}\text { Ecuador, } \\
\text { Cuenca } \\
\text { I434-4333 } \\
\text { m s.n.m. }\end{array}$ & $\begin{array}{l}\text { Molina et } \\
\text { al. }(2015)\end{array}$ \\
\hline $\begin{array}{l}\text { Pinus } \\
\text { radiata }\end{array}$ & Exótica & Evapotranspiración & Bosque nativo & $\begin{array}{l}\text { Plantación de pino registró } \\
\text { una tendencia residual positiva } \\
\text { en la precipitación promedio } \\
\text { de la cuenca, lo que sugiere } \\
\text { un aumento en la pérdida por } \\
\text { evapotranspiración }\end{array}$ & $\begin{array}{l}\text { Ecuador, } \\
\text { Cuenca } \\
\text { I434-4333 } \\
\text { m s.n.m. }\end{array}$ & $\begin{array}{l}\text { Molina et } \\
\text { al. (20।5) }\end{array}$ \\
\hline $\begin{array}{l}\text { Pinus } \\
\text { radiata }\end{array}$ & Exótica & $\begin{array}{l}\text { Rendimiento } \\
\text { hídrico }\end{array}$ & $\begin{array}{l}\text { Pastizal y } \\
\text { cultivo }\end{array}$ & $\begin{array}{l}\text { Plantación de pino registró una } \\
\text { disminución del rendimiento } \\
\text { hídrico anual como } \\
\text { consecuencia del aumento } \\
\text { de la evapotranspiración en } \\
\text { comparación con el pastizal y } \\
\text { cultivo }\end{array}$ & $\begin{array}{l}\text { Ecuador, } \\
\text { Occidental } \\
2900-3960 \\
\text { m s.n.m. }\end{array}$ & $\begin{array}{l}\text { Crespo et } \\
\text { al. }(2010)\end{array}$ \\
\hline $\begin{array}{l}\text { Pinus } \\
\text { radiata }\end{array}$ & Exótica & Retención hídrica & Páramo & $\begin{array}{l}\text { Plantación de pino de mayor } \\
\text { edad ( } 20-25 \text { años) registró } \\
\text { una disminución de retención } \\
\text { hídrica, asociada probablemente } \\
\text { con la disminución de la } \\
\text { materia orgánica en el } \\
\text { suelo ( } C \text { en el horizonte } A) \\
\text { Las raíces de pino rompen } \\
\text { la estructura del suelo } \\
\text { contribuyendo a la pérdida de } \\
\text { capacidad de retención de agua } \\
\text { (Guo y Gifford } 2002 \text { ) }\end{array}$ & $\begin{array}{l}\text { Ecuador, } \\
\text { Cotopaxi } \\
3000-3800 \\
\text { m s.n.m. }\end{array}$ & $\begin{array}{l}\text { Farley et } \\
\text { al. (2004) }\end{array}$ \\
\hline
\end{tabular}




\begin{tabular}{|c|c|c|c|c|c|c|}
\hline Especie & Origen & $\begin{array}{c}\text { Proceso } \\
\text { hidrológico }\end{array}$ & $\begin{array}{c}\text { Comparado } \\
\text { con }\end{array}$ & Resultado principal & $\begin{array}{l}\text { Ubicación } \\
\text { y altitud }\end{array}$ & Fuente \\
\hline $\begin{array}{l}\text { Pinus } \\
\text { radiata }\end{array}$ & Exótica & Infiltración & Pastizal & $\begin{array}{l}\text { Plantación de pino de } 13 \text { años } \\
\text { generó condiciones adecuadas } \\
\text { para mayor infiltración de lluvia } \\
\text { y por tanto menor escorrentía. } \\
\text { Las raíces de pino mejoraron } \\
\text { la capacidad de infiltración, } \\
\text { especialmente en capas } \\
\text { profundas del suelo. } \\
\text { Espaciamiento: } 3 \times 3 \mathrm{~m}\end{array}$ & $\begin{array}{l}\text { Perú, } \\
\text { Cajamarca } \\
3435-3560 \\
\text { m s.n.m. }\end{array}$ & $\begin{array}{l}\text { Roncal } \\
(2006)\end{array}$ \\
\hline $\begin{array}{l}\text { Pinus } \\
\text { radiata }\end{array}$ & Exótica & Infiltración & Páramo & $\begin{array}{l}\text { Las raíces de los pinos son más } \\
\text { grandes, leñosas, espacialmente } \\
\text { no uniformes y se concentran } \\
\text { en el perfil superior del suelo } \\
\text { en comparación con los pastos } \\
\text { (páramo), por lo cual una raíz } \\
\text { de pino más profunda puede } \\
\text { facilitar el movimiento rápido } \\
\text { del agua a través del perfil del } \\
\text { suelo. Edad de la plantación: } \\
40 \text { años }\end{array}$ & $\begin{array}{l}\text { Ecuador, } \\
\text { Imbabura } \\
3299-3499 \\
\text { m s.n.m. }\end{array}$ & $\begin{array}{l}\text { Harden et } \\
\text { al. }(20 \mid 3)\end{array}$ \\
\hline $\begin{array}{l}\text { Polylepis } \\
\text { racemosa }\end{array}$ & Nativa & Retención hídrica & Pastizal & $\begin{array}{l}\text { Páramo con Polylepis registró } \\
\text { menor retención que los } \\
\text { pastizales. Espaciamiento: } 3 \times 3 \mathrm{~m}\end{array}$ & $\begin{array}{l}\text { Ecuador, } \\
\text { Imbabura } \\
3299-3625 \\
\text { m s.n.m. }\end{array}$ & $\begin{array}{l}\text { Harden et } \\
\text { al. (2013) }\end{array}$ \\
\hline $\begin{array}{l}\text { Polylepis } \\
\text { racemosa }\end{array}$ & Nativa & Infiltración & Pastizal & $\begin{array}{l}\text { Bosque con Polylepis de } 29 \\
\text { años }(5 \times 5 \mathrm{~m}) \text { registró mayor } \\
\text { infiltración que el de Polylepis } \\
\text { de } I I \text { años }(|\times| \mathrm{m}) \text {, y que el } \\
\text { pastizal }\end{array}$ & $\begin{array}{l}\text { Perú,Ancash } \\
3800-4460 \\
\text { m s.n.m. }\end{array}$ & $\begin{array}{l}\text { Alfaro } \\
(2015)\end{array}$ \\
\hline $\begin{array}{l}\text { Tectona } \\
\text { grandis }\end{array}$ & Exótica & Infiltración & $\begin{array}{c}\text { Agroforestería } \\
\text { y cultivo }\end{array}$ & $\begin{array}{l}\text { Plantación de teca de } 28 \\
\text { años registró altos valores } \\
\text { de infiltración debido a la } \\
\text { gran cantidad de hojarasca } \\
\text { Espaciamiento: } 2 \times 2,5 \mathrm{~m}\end{array}$ & $\begin{array}{l}\text { Perú, } \\
\text { Chanchamayo } \\
900-1500 \mathrm{~m} \\
\text { s.n.m. }\end{array}$ & $\begin{array}{l}\text { Reyes } \\
(2014)\end{array}$ \\
\hline
\end{tabular}




\section{Anexo 5. Publicaciones evaluadas en las categorías "Andes" y "Conocimiento Ecológico Tradicional"}

\begin{tabular}{|c|c|c|c|c|}
\hline $\mathbf{N}^{\circ}$ & Autor(es) & Año & Título & $\begin{array}{l}\text { Ámbito } \\
\text { de } \\
\text { estudio }\end{array}$ \\
\hline \multicolumn{5}{|c|}{ Documentos evaluados en la categoría “Andes" } \\
\hline 1 & Aichholzer, F.y W. Durán & 2010 & $\begin{array}{l}\text { Caracterización y comportamiento de un } \\
\text { ecosistema de páramo bajo la influencia de un } \\
\text { bosque de Pino (Pinus patula), bosque nativo y de } \\
\text { pajonal }\end{array}$ & Ecuador \\
\hline 2 & Alfaro, G. & 2015 & $\begin{array}{l}\text { Caracterización de la infiltración en bosques } \\
\text { plantados con Polylepis spp. de II y } 29 \text { años, Parque } \\
\text { Nacional Huascarán, Quebrada Quilcayhuanca, } \\
\text { Huaraz, Ancash }\end{array}$ & Perú \\
\hline 3 & Arellano, R. & 2001 & $\begin{array}{l}\text { Evaluación del escurrimiento y pérdida de suelo en } \\
\text { agroecosistemas de café }\end{array}$ & Venezuela \\
\hline 4 & Arroyabe, M. & 2012 & $\begin{array}{l}\text { Dinámica del agua y los nutrientes solubles en } \\
\text { agrosistemas cafeteros }\end{array}$ & Colombia \\
\hline 5 & Ataroff, M. y F. Rada & 2000 & $\begin{array}{l}\text { Deforestation impact on water dynamics in a } \\
\text { Venezuelan Andean cloud forest }\end{array}$ & Venezuela \\
\hline 6 & Ataroff, M. & 2002 & $\begin{array}{l}\text { Precipitación e intercepción en ecosistemas } \\
\text { boscosos de los Andes Venezolanos }\end{array}$ & Venezuela \\
\hline 7 & $\begin{array}{l}\text { Bellanger, B., S. Huon, F. } \\
\text { Velasquez, V.Valles, C. } \\
\text { Girardin y A. Mariotti }\end{array}$ & 2004 & $\begin{array}{l}\text { Monitoring soil organic carbon erosion with } \\
\delta I 3 C \text { and } \delta I 5 N \text { on experimental field plots in the } \\
\text { Venezuelan Andes }\end{array}$ & Venezuela \\
\hline 8 & $\begin{array}{l}\text { Bücker,A., P. Crespo, H. } \\
\text { Frede y L. Breuer }\end{array}$ & 2011 & $\begin{array}{l}\text { Solute behaviour and export rates in neotropical } \\
\text { montane catchments under different land-uses }\end{array}$ & Ecuador \\
\hline 9 & $\begin{array}{l}\text { Burbano-Garcés, ML., A. } \\
\text { Figueroa-Casas y M. Peña }\end{array}$ & 2014 & $\begin{array}{l}\text { Bulk precipitation, throughfall and stemflow } \\
\text { deposition of } \mathrm{N}-\mathrm{NH}_{4}, \mathrm{~N}-\mathrm{NH}_{3} \text { and } \mathrm{N}-\mathrm{NO}_{3} \text { in an } \\
\text { Andean forest }\end{array}$ & Colombia \\
\hline 10 & $\begin{array}{l}\text { Buytaert, W., V. Iñiguez y B. } \\
\text { De Bievre }\end{array}$ & 2007 & $\begin{array}{l}\text { The effects of afforestation and cultivation on water } \\
\text { yield in the Andean páramo }\end{array}$ & Ecuador \\
\hline 11 & Cavelier, J.y G. Goldstein & 1989 & $\begin{array}{l}\text { Mist and fog interception in elfin cloud forests in } \\
\text { Colombia and Venezuela }\end{array}$ & $\begin{array}{l}\text { Colombia, } \\
\text { Venezuela }\end{array}$ \\
\hline 12 & $\begin{array}{l}\text { Célleri, R., B. De Bievre y V. } \\
\text { Iñeguez }\end{array}$ & 2004 & $\begin{array}{l}\text { Efectos de la cobertura vegetal en la regulación } \\
\text { hidrológica de microcuencas de páramo }\end{array}$ & Venezuela \\
\hline 13 & $\begin{array}{l}\text { Crespo, P., A. Bücker, J. } \\
\text { Feyen, K.B.Vaché, H. Frede } \\
\text { y L. Breuer }\end{array}$ & 2011 & $\begin{array}{l}\text { Preliminary evaluation of the runoff processes in } \\
\text { a remote montane cloud forest basin using Mixing } \\
\text { Model Analysis and Mean Transit Time }\end{array}$ & Ecuador \\
\hline 14 & $\begin{array}{l}\text { Crespo, P., R. Célleri,W. } \\
\text { Buytaert, J. Feyen, V. Iñiguez, } \\
\text { P. Borja y B. De Bievre }\end{array}$ & 2010 & $\begin{array}{l}\text { Land use change impacts on the hydrology of wet } \\
\text { Andean páramo ecosystems }\end{array}$ & Ecuador \\
\hline
\end{tabular}




\begin{tabular}{|c|c|c|c|c|}
\hline 15 & $\begin{array}{l}\text { Crespo, P. J. Feyen, W. } \\
\text { Buytaert, A. Bücker, L. } \\
\text { Breuer, H. Frede y M. } \\
\text { Ramírez }\end{array}$ & 2011 & $\begin{array}{l}\text { Identifying controls of the rainfall-runoff response } \\
\text { of small catchments in the tropical Andes (Ecuador) }\end{array}$ & Ecuador \\
\hline 16 & De las Salas, G. y C. García & 2000 & $\begin{array}{l}\text { Water balance under three contrasting vegetation } \\
\text { covers in the basin of the Rio San Cristobal, Bogota }\end{array}$ & Colombia \\
\hline 17 & Dezzeo, N. y N. Chacón & 2006 & $\begin{array}{l}\text { Nutrient fluxes in incident rainfall, throughfall, and } \\
\text { stemflow in adjacent primary and secondary forests } \\
\text { of the Gran Sabana, southern Venezuela }\end{array}$ & Venezuela \\
\hline 18 & $\begin{array}{l}\text { Farley, K.A., E. Kelly y } \\
\text { R.Hofstede }\end{array}$ & 2004 & $\begin{array}{l}\text { Soil organic carbon and water retention after } \\
\text { conversion of grasslands to pine plantations in the } \\
\text { Ecuadorian Andes }\end{array}$ & Ecuador \\
\hline 19 & $\begin{array}{l}\text { Fleischbein, K.,W.Wilcke, } \\
\text { R. Goller, J. Boy, C.Valarezo, } \\
\text { W. Zech y K. Knoblich }\end{array}$ & 2005 & $\begin{array}{l}\text { Rainfall interception in a lower montane forest in } \\
\text { Ecuador: Effects of canopy properties }\end{array}$ & Ecuador \\
\hline 20 & Fonseca, H. y M.Ataroff & 2005 & $\begin{array}{l}\text { Dinámica hídrica en la selva nublada de la cuenca } \\
\text { alta del rio Cusiana y un pastizal de reemplazo. } \\
\text { Cordillera oriental, Colombia }\end{array}$ & Colombia \\
\hline 21 & $\begin{array}{l}\text { Gaitán, L., I.Arnbrecht y S. } \\
\text { Graefe }\end{array}$ & 2016 & $\begin{array}{l}\text { Throughfall and soil properties in shaded and } \\
\text { unshaded coffee plantations and a secondary forest: } \\
\text { a case study from Southern Colombia }\end{array}$ & Colombia \\
\hline 22 & García, C. & 2007 & $\begin{array}{l}\text { Regulación hídrica bajo tres coberturas vegetales en } \\
\text { la cuenc del Río San Cristóbal, Bogotá D.C. }\end{array}$ & Colombia \\
\hline 23 & $\begin{array}{l}\text { Gomez-Peralta, D., S. } \\
\text { Oberbauer, M. McClain y T. } \\
\text { Philippi }\end{array}$ & 2008 & $\begin{array}{l}\text { Rainfall and cloud-water interception in tropical } \\
\text { montane forests in the eastern Andes of Central } \\
\text { Peru }\end{array}$ & Perú \\
\hline 24 & Gonzaga, L. & 1993 & $\begin{array}{l}\text { Effect of vegetation cover of cypress, pine and } \\
\text { shrubs on soil moisture in two small catchments of } \\
\text { Piedras Blancas, Antioquia, Colombia }\end{array}$ & Colombia \\
\hline 25 & $\begin{array}{l}\text { Harden, C., J. Hartsig, K. } \\
\text { Farley, J. Lee y L. Bremer }\end{array}$ & 2013 & $\begin{array}{l}\text { Effects of land-use change on water in Andean } \\
\text { páramo grassland soils }\end{array}$ & Ecuador \\
\hline 26 & Hernández, E. & 2005 & $\begin{array}{l}\text { Estimation of runoff for a high slope planted with } \\
\text { Pinus tenuifolia using the curve number method }\end{array}$ & Venezuela \\
\hline 27 & $\begin{array}{l}\text { Herrera, A., R.Urich, E. } \\
\text { Rengifo, C. Ballestrini, A. } \\
\text { González y W. León }\end{array}$ & 2012 & $\begin{array}{l}\text { Transpiration in a eucalypt plantation and a savanna } \\
\text { in Venezuela }\end{array}$ & Venezuela \\
\hline 28 & $\begin{array}{l}\text { Janeau, J., S. Grellier y P. } \\
\text { Podwojewski }\end{array}$ & 2015 & $\begin{array}{l}\text { Influence of rainfall interception by endemic plants } \\
\text { versus short cycle crops on water infiltration in } \\
\text { high altitude ecosystems of Ecuador }\end{array}$ & Ecuador \\
\hline 29 & Jaramillo-Robledo,A. & 2003 & $\begin{array}{l}\text { La lluvia y el transporte de nutrimentos dentro de } \\
\text { ecosistemas de bosque y cafetales }\end{array}$ & Colombia \\
\hline 30 & Knee, K. y A. Encalada & 2014 & $\begin{array}{l}\text { Land use and water quality in a rural cloud forest } \\
\text { region (Intag, Ecuador) }\end{array}$ & Ecuador \\
\hline
\end{tabular}




\begin{tabular}{|c|c|c|c|c|}
\hline 31 & $\begin{array}{l}\text { Knoke, T., J. Bendix, } \\
\text { P. Pohle, U. Hamer, P. } \\
\text { Hildebrandt, K. Roos, A. } \\
\text { Gerique, M. Sandoval, L. } \\
\text { Breuer, A. Tischer, B. Silva, } \\
\text { B. Calvas, N. Aguirre, L. } \\
\text { Castro, D. Windhorst, M. } \\
\text { Weber, B. Stimm, S. Günter, } \\
\text { X. Palomeque, J. Mora, R. } \\
\text { Mosandl y E. Beck }\end{array}$ & 2014 & $\begin{array}{l}\text { Afforestation or intense pasturing improve the } \\
\text { ecological and economic value of abandoned } \\
\text { tropical farmlands }\end{array}$ & Ecuador \\
\hline 32 & $\begin{array}{l}\text { Le Tellier,V., A. Carrasco y } \\
\text { N.Asquith }\end{array}$ & 2009 & $\begin{array}{l}\text { Attempts to determine the effects of forest } \\
\text { cover on stream flow by direct hydrological } \\
\text { measurements in Los Negros, Bolivia }\end{array}$ & Bolivia \\
\hline 33 & $\begin{array}{l}\text { León, J., M. González y J. } \\
\text { Gallardo }\end{array}$ & 2010 & $\begin{array}{l}\text { Distribución del Agua Lluvia en Tres Bosques } \\
\text { Altoandinos de la Cordillera Central de Antioquia, } \\
\text { Colombia }\end{array}$ & Colombia \\
\hline 34 & $\begin{array}{l}\text { Lindell, L., M. Åström y T. } \\
\text { Öberg }\end{array}$ & 2010 & $\begin{array}{l}\text { Land-use change versus natural controls on stream } \\
\text { water chemistry in the Subandean Amazon, Peru }\end{array}$ & Perú \\
\hline 35 & $\begin{array}{l}\text { Mena, H., C. Benavides y J. } \\
\text { Castillo }\end{array}$ & 2011 & $\begin{array}{l}\text { Evaluación de la susceptibilidad a la erosión hídrica } \\
\text { de un Vitric haplustands, mediante el uso de un } \\
\text { minisimulador de lluvia, en una zona de ladera en } \\
\text { Colombia }\end{array}$ & Colombia \\
\hline 36 & Molina, J. & 2001 & $\begin{array}{l}\text { Caracterización hidrológico-forestal de dos } \\
\text { microcuencas con diferente cobertura vegetal en la } \\
\text { cuenca del río San Alberto, Oxapampa, Perú }\end{array}$ & Perú \\
\hline 37 & $\begin{array}{l}\text { Molina, A., G. Govers, A. } \\
\text { Van den Putte, J. Poesen y } \\
\text { V.Vanacker }\end{array}$ & 2009 & $\begin{array}{l}\text { Assessing the reduction of the hydrological } \\
\text { connectivity of gully systems through vegetation } \\
\text { restoration: field experiments and numerical } \\
\text { modelling }\end{array}$ & Ecuador \\
\hline 38 & $\begin{array}{l}\text { Molina, A.V.Vanacker,V. } \\
\text { Balthazar, D. Mora y G. } \\
\text { Govers }\end{array}$ & 2012 & $\begin{array}{l}\text { Complex land cover change, water and sediment } \\
\text { yield in a degraded Andean environment }\end{array}$ & Ecuador \\
\hline 39 & $\begin{array}{l}\text { Molina, A., V.Vanacker, } \\
\text { E. Brisson, D. Mora y V. } \\
\text { Balthazar }\end{array}$ & 2015 & $\begin{array}{l}\text { Multidecadal change in streamflow associated with } \\
\text { anthropogenic disturbances in the tropical Andes }\end{array}$ & Ecuador \\
\hline 40 & Moreno, C. & 2012 & $\begin{array}{l}\text { Effect of different vegetation types on infiltration } \\
\text { capacity of paramo soils in Paluguillo Private } \\
\text { Reserve (Ecuador) }\end{array}$ & Ecuador \\
\hline 41 & $\begin{array}{l}\text { Motzer,T., N. Munz, D. } \\
\text { Anhuf y M. Küppers }\end{array}$ & 2010 & $\begin{array}{l}\text { Transpiration and microclimate of a tropical } \\
\text { montane rain forest, southern Ecuador }\end{array}$ & Ecuador \\
\hline 42 & $\begin{array}{l}\text { Mulligan, M., A. Jarvis, J. } \\
\text { González y L.A. Bruijnzeel }\end{array}$ & 2010 & $\begin{array}{l}\text { Using "biosensors" to elucidate rates and } \\
\text { mechanisms of cloud water interception by } \\
\text { epiphytes, leaves, and branches in a sheltered } \\
\text { Colombian cloud forest }\end{array}$ & Colombia \\
\hline 43 & $\begin{array}{l}\text { Ochoa-Tocachi, B,W. } \\
\text { Buytaert y B. De Bievre }\end{array}$ & 2016 & $\begin{array}{l}\text { Regionalization of land-use impacts on streamflow } \\
\text { using a network of paired catchments }\end{array}$ & $\begin{array}{l}\text { Ecuador, } \\
\text { Perú, } \\
\text { Bolivia }\end{array}$ \\
\hline
\end{tabular}




\begin{tabular}{|c|c|c|c|c|}
\hline 44 & $\begin{array}{l}\text { Ochoa-Tocachi, B.,W., } \\
\text { Buytaert, B. De Bievre, } \\
\text { R. Célleri, P. Crespo, M. } \\
\text { Villacís, C. Llerena, L. } \\
\text { Acosta, M.Villazón, M. } \\
\text { Guallpa, J. Gil-Ríos, P. } \\
\text { Fuentes, D. Olaya, P.Viñas, } \\
\text { G. Rojas y S.Arias. }\end{array}$ & 2016 & $\begin{array}{l}\text { Impacts of land use on the hydrological response of } \\
\text { tropical Andean catchments }\end{array}$ & $\begin{array}{l}\text { Ecuador, } \\
\text { Perú, } \\
\text { Bolivia }\end{array}$ \\
\hline 45 & $\begin{array}{l}\text { Oesker, N., J. Homeier, H. } \\
\text { Dalitz y L.A. Bruijnzeel }\end{array}$ & 2010 & $\begin{array}{l}\text { Spatial heterogeneity of throughfall quantity and } \\
\text { quality in tropical montane forests in southern } \\
\text { Ecuador }\end{array}$ & Ecuador \\
\hline 46 & Ortega, L. & 2014 & $\begin{array}{l}\text { Evaluación comparativa del papel de diferentes } \\
\text { coberturas vegetales sobre algunos servicios } \\
\text { ecosistémicos en los Andes colombianos }\end{array}$ & Colombia \\
\hline 47 & $\begin{array}{l}\text { Plamodon, A., R. Ruiz, C. } \\
\text { Morales y M. Gonzalez }\end{array}$ & 1991 & $\begin{array}{l}\text { Influence of protection forest on soil and water } \\
\text { conservation (Oxapampa, Peru) }\end{array}$ & Perú \\
\hline 48 & $\begin{array}{l}\text { Ramírez, B., A. Teuling, L. } \\
\text { Ganzeveld, Z. Hegger y R. } \\
\text { Leemans }\end{array}$ & 2017 & $\begin{array}{l}\text { Tropical Montane Cloud Forests: } \\
\text { Hydrometeorological variability in three } \\
\text { neighbouring catchments with different forest cover }\end{array}$ & Colombia \\
\hline 49 & Reyes, R. & 2014 & $\begin{array}{l}\text { Influencia de cuatro sistemas del uso de la tierra } \\
\text { (Teca, citricos y café bajo sombra manejado y en } \\
\text { abandono), en la sortividad en el IRD Selva Fundo } \\
\text { La Génova, Chanchamayo, Junín }\end{array}$ & Perú \\
\hline 50 & $\begin{array}{l}\text { Roa-García, M., S. Brown, } \\
\text { H. Schreier y L. Lavkulich }\end{array}$ & 2011 & $\begin{array}{l}\text { The role of land use and soils in regulating water } \\
\text { flow in small headwater catchments of the Andes }\end{array}$ & Colombia \\
\hline 51 & Rodríguez, $\mathrm{O}$. & 1997 & $\begin{array}{l}\text { Hedgerows and mulch as soil conservation } \\
\text { measures evaluated under field simulated rainfall }\end{array}$ & Venezuela \\
\hline 52 & Rodríguez, J.y J. Camargo & 2009 & $\begin{array}{l}\text { Erosion and runoff: Indicators of soil early response } \\
\text { to different covers in the Colombian coffee region }\end{array}$ & Colombia \\
\hline 53 & Roncal,W. & 2006 & $\begin{array}{l}\text { Influencia de las plantaciones forestales sobre } \\
\text { la escorrentía superficial y la erosión hídrica en } \\
\text { Porcón, Cajamarca }\end{array}$ & Perú \\
\hline 54 & Ruiz, O., J.Acosta y J. León & 2005 & $\begin{array}{l}\text { Surface runoff in natural montane forests and forest } \\
\text { plantations in Antioquia, Colombia }\end{array}$ & Colombia \\
\hline 55 & $\begin{array}{l}\text { Suescún, D., J.Villegas, J. } \\
\text { León, C. Flórez,V. García- } \\
\text { Leoz y G. Correo-Londoño }\end{array}$ & 2016 & $\begin{array}{l}\text { Vegetation cover and rainfall seasonality impact } \\
\text { nutrient loss via runoff and erosion in the } \\
\text { Colombian Andes }\end{array}$ & Colombia \\
\hline 56 & $\begin{array}{l}\text { Timbe, E., J. Feyen, L. } \\
\text { Timbe, P. Crespo, R. Celleri, } \\
\text { D.Windhorst, H. Frede y L. } \\
\text { Breuer }\end{array}$ & 2017 & $\begin{array}{l}\text { Multicriteria assessment of water dynamics } \\
\text { reveals subcatchment variability in a seemingly } \\
\text { homogeneous tropical cloud forest catchment }\end{array}$ & Ecuador \\
\hline 57 & $\begin{array}{l}\text { Vanacker,V., A. Molina, } \\
\text { G. Govers, J. Poesen, G. } \\
\text { Dercon y S. Deckers }\end{array}$ & 2005 & $\begin{array}{l}\text { River channel response to short-term human- } \\
\text { induced change in landscape connectivity in Andean } \\
\text { ecosystems }\end{array}$ & Ecuador \\
\hline 58 & Veneklaas, E. y R.Van Ek & 1990 & $\begin{array}{l}\text { Rainfall interception in two tropical montane rain } \\
\text { forests, Colombia }\end{array}$ & Colombia \\
\hline
\end{tabular}




\begin{tabular}{|c|c|c|c|c|}
\hline 59 & Veneklaas, E. & 1990 & $\begin{array}{l}\text { Nutrient fluxes in bulk precipitation and throughfall } \\
\text { in two montane tropical rain forests, Colombia }\end{array}$ & Colombia \\
\hline 60 & Vis, M. & 1986 & $\begin{array}{l}\text { Interception, drop size distributions and rainfall } \\
\text { kinetic energy in four Colombian forest ecosystems }\end{array}$ & Colombia \\
\hline 61 & $\begin{array}{l}\text { Wilcke, W. S. Günter, F.Alt, } \\
\text { C. Geissler, J. Boy, J. Knuth, } \\
\text { Y. Oelmann, M. Weber, C. } \\
\text { Valarezo y R. Mosandl }\end{array}$ & 2009 & $\begin{array}{l}\text { Response of water and nutrient fluxes to } \\
\text { improvement fellings in a tropical montane forest in } \\
\text { Ecuador }\end{array}$ & Ecuador \\
\hline 62 & $\begin{array}{l}\text { Wilcke, W., S. Yasin, C. } \\
\text { Valarezo y W. Zech }\end{array}$ & 2001 & $\begin{array}{l}\text { Change in water quality during the passage through } \\
\text { a tropical montane rain forest in Ecuador }\end{array}$ & Ecuador \\
\hline 63 & $\begin{array}{l}\text { Wullaert, H.,T. Pohlert, } \\
\text { J. Boy, C.Valarezo y W. } \\
\text { Wilcke }\end{array}$ & 2009 & $\begin{array}{l}\text { Spatial throughfall heterogeneity in a montane rain } \\
\text { forest in Ecuador: Extent, temporal stability and } \\
\text { drivers }\end{array}$ & Ecuador \\
\hline 64 & $\begin{array}{l}\text { Zimmermann, A.,W. } \\
\text { Wilcke y H. Elsenbeer }\end{array}$ & 2007 & $\begin{array}{l}\text { Spatial and temporal patterns of throughfall quantity } \\
\text { and quality in a tropical montane forest in Ecuador }\end{array}$ & Ecuador \\
\hline \multicolumn{5}{|c|}{ Documentos evaluados en la categoría "Conocimiento Ecológico Tradicional” } \\
\hline 1 & Becker, D y K. Ghimire & 2003 & $\begin{array}{l}\text { Synergy Between Traditional Ecological Knowledge } \\
\text { and Conservation Science Supports Forest } \\
\text { Preservation in Ecuador }\end{array}$ & Ecuador \\
\hline 2 & $\begin{array}{l}\text { Brandt, R., H. } \\
\text { Zimmermann, I. Hensen, J. } \\
\text { Mariscal y S. Rist }\end{array}$ & 2012 & $\begin{array}{l}\text { Agroforestry species of the Bolivian Andes: an } \\
\text { integrated assessment of ecological, economic and } \\
\text { socio-cultural plant values }\end{array}$ & Bolivia \\
\hline 3 & Granda, M. and P.Yánez & 2017 & $\begin{array}{l}\text { Estudio sobre la percepción de los beneficios del } \\
\text { programa Socio Bosque en la región amazónica } \\
\text { ecuatoriana }\end{array}$ & Ecuador \\
\hline 4 & $\begin{array}{l}\text { Hartman, B., D. Cleveland } \\
\text { y O. Chadwick }\end{array}$ & 2016 & $\begin{array}{l}\text { Linking changes in knowledge and attitudes } \\
\text { with successful land restoration in indigenous } \\
\text { communities }\end{array}$ & Bolivia \\
\hline 5 & Kessler, A. & 2006 & $\begin{array}{l}\text { Moving people - towards collective action in soil } \\
\text { and water conservation }\end{array}$ & Bolivia \\
\hline 6 & $\begin{array}{l}\text { León, L., P. Cueva, Z. } \\
\text { Aguirre y L. Kvist }\end{array}$ & 2006 & $\begin{array}{l}\text { Floristic composition, structure, endemic and } \\
\text { ethnobotany in the native forest "El Colorado", in } \\
\text { Puyango, province of Loja }\end{array}$ & Ecuador \\
\hline 7 & Mathez-Stiefel, Sarah-Lan & 2016 & $\begin{array}{l}\text { Opciones Agroforestales para la Adaptación al } \\
\text { Cambio Climático: Informe de talleres participativos } \\
\text { realizados en diciembre del } 2015\end{array}$ & Perú \\
\hline 8 & Vela, E. y F. Jiménez & 2010 & $\begin{array}{l}\text { Agroforestry systems in water recharge areas for } \\
\text { human consumption in Bobo River, Colombia }\end{array}$ & Colombia \\
\hline
\end{tabular}




Centro Internacional de Investigación Agroforestal (ICRAF)

Avenida Naciones Unidas

PO Box 30677, GPO 00100, Nairobi, Kenya

Tel: $+254(0) 207224000$, via USA +16508336645

Fax: +254(0)20 7224001, via USA +1 6508336646

Email: icraf@cgiar.org

www.worldagroforestry.org

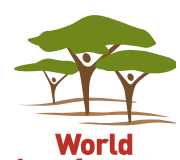

Agroforestry
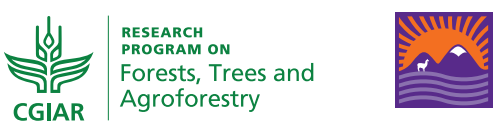

CONDESAN

CGIAR Agroforestry

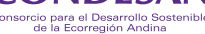

BOSQUES ANDINOS ES UN PROGRAMA DE:

Schweizerische Eidgenossenschaft
confédération suisse Confédération suisse
Confederazione Svizzera
Confederazizinn svizra Agencia Suiza para el Desarroll
y la Cooperación COSUDE 